Portland State University

PDXScholar

\title{
The Portland, Oregon ASAP : an evaluation of treatment effectiveness
}

\author{
Joan M. Wildebush Berry \\ Portland State University \\ Stefani K. Cuda \\ Portland State University \\ Judi L. Edwards \\ Portland State University \\ Mary E. Ericson \\ Portland State University \\ Emilie Ford Frisbee \\ Portland State University
}

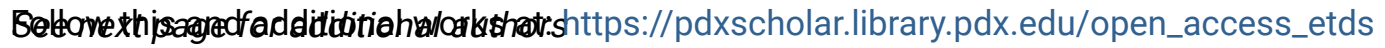

Part of the Social Work Commons, and the Substance Abuse and Addiction Commons Let us know how access to this document benefits you.

\section{Recommended Citation}

Wildebush Berry, Joan M.; Cuda, Stefani K.; Edwards, Judi L.; Ericson, Mary E.; Frisbee, Emilie Ford; Hand, Steve Ernest; Hannibal, Mary Anne; Myers, Laurel M.; Perry, Sharon Lee; Richards, Loree; Schmidtke, Barbara Burns; Voris, Stephen Walker; and Westby, Barbara M., "The Portland, Oregon ASAP : an evaluation of treatment effectiveness" (1981). Dissertations and Theses. Paper 3514.

https://doi.org/10.15760/etd.5398

This Thesis is brought to you for free and open access. It has been accepted for inclusion in Dissertations and Theses by an authorized administrator of PDXScholar. Please contact us if we can make this document more accessible: pdxscholar@pdx.edu. 


\section{Author}

Joan M. Wildebush Berry, Stefani K. Cuda, Judi L. Edwards, Mary E. Ericson, Emilie Ford Frisbee, Steve Ernest Hand, Mary Anne Hannibal, Laurel M. Myers, Sharon Lee Perry, Loree Richards, Barbara Burns Schmidtke, Stephen Walker Voris, and Barbara M. Westby 
THE PORTLAND, OREGON ASAP:

AN EVALUATION OF TREATMENT EFFECTIVENESS

by

JOAN M. WILDEBUSH BERRY

STEFANI K. CUDA

JUDI L. EDWARDS

MARY E. ERICSON

EMILIE FORD FRISBEE

STEVE ERNEST HAND

MARY ANNE HANNIBAL
LAUREL M. MYERS

SHARON LEE PERRY

LOREE RICHARDS

BARBARA BURNS SCHMIDTKE

STEPHEN WALKER VORIS

BARBARA M. WESTBY

A Practicum Submitted in Partial Fulfillment of the Requirements for the Degree of MASTER OF SOCIAL WORK

Portland State University 


\section{ACKNOWLEDGEMENTS}

We wish to acknowledge Barbara Grider, Executive Director of ASAP, and the ASAP staff for their willingness to undergo our scrutiny, and for their cooperation in all phases of this study. In addition, we are grateful to Ruth Green, ASAP Program Evaluator, who aided in the planning and implementation of this project.

We are indebted to the members of the Mental Health Division, Management Support Services Staff: to Earletta J. Bailey and Susan Rothberger, Consultants and Trainers, and Kathy A. Hempeck, Project Secretary and Trainer, for their time, expertise and practical assistance in training the interviewers to administer the OQLQ; to Linda stewart, and Madeline M. Olsen, Researchers, for their able guidance and technical assistance in the interpretation of the computer data.

We want to give special thanks to Mary Anne Hannibal, fellow student and Assistant Coordinator of our group research practicum, for her outstanding contribution and commitment throughout the duration of this project.

Finally, we especially want to acknowledge and thank Dr. Sandra C. Anderson, Portland State University, School of Social Work practicum advisor, whose guidance, expert 
advice, reactions, thoughtful criticisms, and perspective of the overall research goals contributed immeasurably to this project. 
TABLE OF CONTENTS

PAGE

ACKNOWLEDGEMENTS $\ldots \ldots \ldots \ldots \ldots \ldots \ldots \ldots \ldots \ldots \ldots \ldots \ldots \ldots \ldots \ldots$ i

INTRODUCTION $\ldots \ldots \ldots \ldots \ldots \ldots \ldots \ldots \ldots \ldots \ldots \ldots \ldots$

CHAPTER

I REVIEW OF RELEVANT LITERATURE $\ldots \ldots \ldots \ldots \ldots .2$

THE EVALUATION OF ALCOHOL TREATMENT:

METHODOLOGY .................. 2

FOLLOW-UP STUDIES OF ALCOHOLICS ....... 17

MANAGEMENT OF DRUNKEN DRIVING OFFENDERS • 34

II HISTORY AND DESCRIPTION OF THE PORTLAND, OREGON, ASAP $\ldots \ldots \ldots \ldots \ldots \ldots \ldots \ldots \ldots \ldots \ldots \ldots \ldots \ldots \ldots \ldots$

III METHODOLOGY ....................... 73

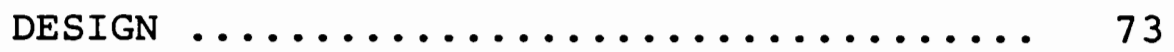

SAMPLING PLAN $\ldots \ldots \ldots \ldots \ldots \ldots \ldots \ldots \ldots \ldots \ldots$

DATA GATHERING METHODS $\ldots \ldots \ldots \ldots \ldots \ldots 76$

INSTRUMENTS $\ldots \ldots \ldots \ldots \ldots \ldots \ldots \ldots \ldots \ldots$

DATA ANALYSIS PLAN $\ldots \ldots \ldots \ldots \ldots \ldots \ldots . \ldots 3$

IV FINDINGS $\ldots \ldots \ldots \ldots \ldots \ldots \ldots \ldots \ldots \ldots \ldots \ldots \ldots$

OQLQ SCALE SCORES $\ldots \ldots \ldots \ldots \ldots \ldots \ldots \ldots$

DISCUSSION $\ldots \ldots \ldots \ldots \ldots \ldots \ldots \ldots \ldots \ldots \ldots \ldots \ldots \ldots \ldots$

CONCLUSION ........................ 101

CRITIQUE OF PRESENT STUDY ........... 104 
PAGE

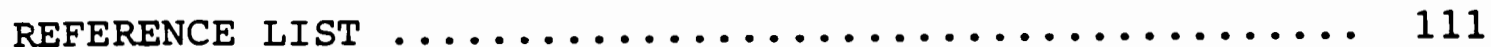

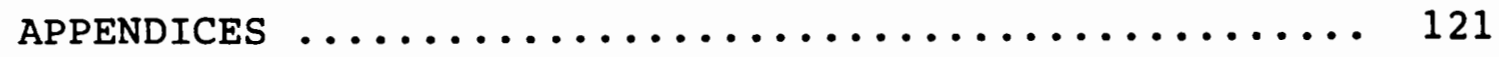

APPENDIX A: ASAP: RELATIONSHIP TO THE COMMUNITY - 122

APPENDIX B: ASAP: ADMINISTRATIVE ORGANIZATIONAL

CHART ............................ 123

APPENDIX C: PERCENTAGE DISTRIBUTION: COMPARISON

OF INTERVIEW SAMPLE, EXCLUDED CLIENTS

AND CLIENTS LOST AT FOLLOW-UP ...... 124

APPENDIX D: OREGON QUALITY OF LIFE QUESTIONNAIRE. 125

APPENDIX E: DEMOGRAPHIC DATA QUESTIONNAIRE ..... 143

APPENDIX F : REFERRAL TO P.I.M.S. STUDY ........ 146

APPENDIX G: APPOINTMENT FORM LETTER .......... 147

APPENDIX H: INTERVIEWER PROGRESS REPORT ........ 148

APPENDIX I: ASAP CONSENT FOR OQLQ FOLLOW-UP

INTERVIEW ........................ 149

APPENDIX J: CLINICIAN RATING OF SUCCESS ....... 150

APPENDIX K: OQLQ SCALES ................... 151

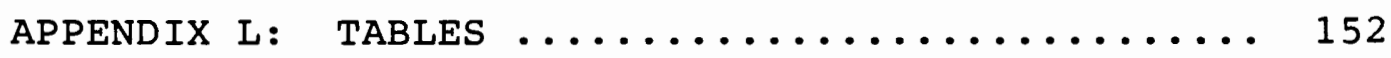


IIST OF TABLES

TABLE

PAGE

I DEMOGRAPHIC VARIABLES ................. 153

II DEMOGRAPHIC VARIABLES: ASAP AND OTHER

ALCOHOL PROGRAMS ..................... 154

II SCALE SCORES: ASAP INTAKE VS. STATEWIDE INTAKE

IV SCALE SCORES: ASAP FOLLOWUP VS. STATEWIDE FOLLOWUP ....................... 156

V SCALE SCORES : ASAP INTAKE VS. COMMUNTTY SAMPLE

VI SCALE SCORES: ASAP FOLLOWUP VS. COMMUNITY

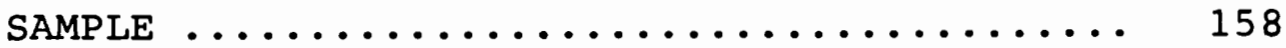

VII SCALE SCORES : ASAP INTAKE VS. FOLLOWUP .... 159

VIII SCALE SCORES: ASAP AND OTHER ALCOHOL PROGRAMS (INTAKE VS. FOLLOWUP) ........... 160

IX CLIENT OPINION: TREATMENT RELATED FACTORS .. 161

$X$ CLIENT OPINION: TREATMENT RELATED FACTORS (GRAPH)

XI ITEM RESPONSES: PERCENT CLIENT SATISFACTION

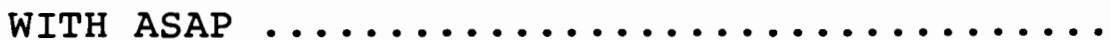

XII ASAP CLIENT OPINION OF PROGRAM IMPACT VS. ASAP COUNSELORS: CLINICIAN RATING OF SUCCESS 


\section{INTRODUCTION}

The Alcohol Safety Action Program (ASAP), in accordance with its goals and directives, determined, in 1980, the need for an evaluation of its services. In response to that need, the present study was conducted between April and October, 1980.

The initial step in this evaluation is a review of the relevant literature. The review includes literature in the areas of: treatment evaluation methodology, follow-up studies of alcohol treatment, and management of drunken drivers. In addition, the history and current organization of the Portland ASAP are discussed.

The study employs a one group pretest-posttest design and utilizes the Oregon Quality of Life Questionnaire. A comprehensive description of study methodology is followed by discussion of study findings and implications for practice. Finally, with the intent of providing direction for future study, the methodology of the present study is critiqued. 


\section{CHAPTER I}

THE EVALUATION OF ALCOHOL TREATMENT: METHODOLOGY

\section{Overview of Methodological Problem}

As part of this study, a review of the relevant literature on alcoholism treatment evaluation methodology was undertaken. A small number of excellent review articles delineate the limitations of the evaluation techniques used over the past 70 years in the field of alcoholism.

Voegtlin and Lemere (1942), examining 200 studies published between 1909 and 1940, are generally recognized as authors of the first major review in this area. They concluded that the almost complete absence of statistical outcome data made it impossible to form "any sort of opinion from an examination of the literature alone, as to the value of conventional psychotherapy in the treatment of alcoholism" (p. 795).

More than 20 years later, Hill and Blane (1967), reviewing 49 studies published between 1952 and 1963, came to essentially the same conclusion. They refused to summarize their findings about treatment outcomes, as Blane noted a decade later, "because the results might have been misleading given the ineptness of the evaluations" (Blane, 1977, p. 593). Hill and Blane therefore restricted 
themselves to a discussion of the basic requirements of scientific inquiry which would address the methodological inadequacies they found: lack of prior planning, lack of control groups, inadequate sampling procedures, illdefined criterion variables, use of unreliable measuring instruments, and insufficient follow-up techniques (Hill \& Blane, 1967).

By 1975, May and Kuller were reporting increased sophistication in the evaluative measurements utilized between 1965 and 1975, but stated, "concurrent improvements in study design have been almost nonexistent" (p. 148). They found most studies lacked control groups, randomization of subjects, and objective measures of behavioral change. Only $1 / 3$ of the studies collected baseline data, thereby seriously compromising any outcome. They discovered such a wide variety of study designs, sample selection methods, and measurement instruments as to make the findings incomparable. In addition, May and Kuller (1975) lamented the "lack of consensus as to what constitutes an effective measurement of that outcome for the alcoholic patient" (p. 475). Lowe and Thomas (1976) also emphasized that the evaluation of various treatment programs for alcoholics has been hampered by the lack of well-defined criteria for recovery or successful treatment. They called for standardization of evaluative measures with respect to success of treatment, length 
of time for follow-up studies, and concluded that assessment and evaluation procedures should be both standardized and broadened to reflect multidimensional behavioral changes.

In 1977, Crawford and Chalupsky indicated a general improvement in methodology used in evaluation of alcoholism programs when compared with those reviewed ten years earlier by Hill and Blane. However, they still concluded that the 40 studies published between 1968 and 1971 contained such methodological inadequacies as to put in question the integrity of the results. They noted critical methodological shortcomings: lack of control groups, inadequate sampling procedures, lack of concern with the reliability of measuring instruments, lack of pre-treatment baseline data, inaccurate or insufficient collection of data, the absence of specific descriptions of populations and treatments, failure to relate sample variations to outcome variations, collapse of data in coding which precluded inquiry into patient-treatment interactions, rudimentary level of statistical analysis, and poor reporting of and/or inadequate follow-up techniques (Crawford \& Chalupsky, 1977; see also Crawford \& Chalupsky, 1973).

While Blane (1977) was commenting on the "desirable advances in methodological sophistication, notably present in research design, measurement of outcomes and statistical 
analysis" (p. 593), Crawford and Chalupsky (1977) seemed considerably less optimistic in their assessment:

The problem is not that the field lacks an occasional investigation adequately coping with one or more aspects of evaluation problems, but rather that the median level of efforts remains at such a relatively unsophisticated level that most studies were both scientifically and practically unproductive. (p. 74)

Finally, in a recent review published by Maisto and Cooper (1980), there is nothing new in the list of major methodological problems in the evaluation of alcoholism treatment. Again, they include failures to assign subjects randomly to treatment conditions, use of retrospective as opposed to planned treatment outcome studies, use of insensitive measures for treatment outcome, failures to assess the reliability and validity of measures, and poor follow-up techniques. In the current proliferation of research, these authors see improvement in research design and measurement instruments but state, "the quality of this research has not matched its quantity" (p. 1).

The methodological problems revealed in this brief overview are clearly not idiosyncratic to the literature of alcoholism treatment evaluation. They are common throughout the evaluation literature of the behavioral and biological sciences. However, there are a few methodological issues, reflecting unique dynamics and challenges in the field of alcoholism treatment, which will be highlighted in this chapter: (a) the traditional reliance 
on abstinence as the sole criterion of treatment success, (b) the question of the reliability and validity of selfreports of alcoholics, and (c) the difficulty of locating alcoholics for follow-up.

Abstinence as a Criterion of Success

The adequacy of abstinence as a criterion of success in alcoholism treatment and the related hotly contested issue of using "controlled drinking" as a treatment goal appear as the most controversial topics in the literature. Most of the public comment, generated by the 1976 Rand Report (Armor, Polich, \& Stambul, 1976), focused on the abstinence question. This issue is so controversial, as Ron Roizen (1977) points out, not merely because the importance of abstinence is in question, but "at stake is the fate of a full paradigm or gestalt about alcoholrelated problems" (p. 172). This paradigm, primarily based on the work of Jellinek (1952), is often referred to in the literature as the "classical" or "traditional" model. In this model, alcoholics are considered "diseased" in that their drinking behavior is beyond their volitional control. As Roizen (1977) describes it, alcoholism treatment

is itself the inculcation of the disease conception of alcoholism, and in this domain, the disease concept means that a constitutional difference in alcoholics is at the root of troubles with arinking. If the constitutional basis theory is accepted, the alcoholic may be persuaded to give 
up drinking. Embracing abstinence is thus a sign that the model of alcoholism has been accepted by the patient. (p. 173)

Treatment is "designed to deal with the presumed entity of alcoholism, rather than with individuals who have alcohol problems" (Maisto \& McCollam, 1980, p. 18). Furthermore, abstinence is the only treatment outcome that can be considered successful, and it is assumed that improvement in other areas of life functioning are unlikely unless abstinence is maintained (Maisto \& McCollam, 1980).

Roizen (1977) hypothesized that the utility of the classical alcoholism theory not only provides a basis for treatment, but also provides the alcoholic with other benefits :

It gives an 'explanation' of alcoholismic behavior that avoids ladening the alcoholic with too much guilt for past drinking excesses; it wins his release from the morally bound criminal justice system of social management; it provides the rationale for abstinence; it opens a route for his reintegration into conventional roles and obligations; it provides the basis for medically oriented research on the etiology of the condition; it, when an alcoholic embraces it, arrests his condition. (pp. 174-5)

Pomerleau, Pertschuk, and Stinnett (1976) noted that the disease conception of alcoholism, found in the traditional paradigm, has produced major benefits, such as increasing medical services to alcoholics while shifting the society's response to alcoholism from moral condemnation and incarceration to treatment and rehabilitation. However, when they reviewed the research which challenges 
both the disease concept and the use of abstinence as a mandatory goal of treatment, they found "empirical support for these concepts is weak, and, in some cases absent" (p. 86) .

Other writers (Pattison, 1967; Reinert, 1968) have questioned the traditional paradigm and argued for a broader view. Indeed, an alternative paradigm has emerged, and the current trend in alcoholism treatment and evaluation research is to look at broader dimensions of outcome which include total life adjustment and adaptation (Belasco, 1971; Maisto \& Cooper, 1980). According to Maisto and Cooper (1980), this new "multivariate" conceptualization of alcoholism is based on multidimensional models that assume substance abuse is part of

complex behavioral patterns that, (1) have multiple causes, (2) can affect any individual, (3) can be treated by a variety of therapists in a variety of settings by a variety of techniques, and (4) treatment can be designed to affect multiple areas of life health. (p. 9)

This new conceptualization emphasizes the uniqueness of the individual, assumes different people will require different treatment programs or different elements within programs and, therefore, implies the requirement of individual and unique assessment prior to treatment (Pattison, 1973; Caddy, 1980). Cronkite and Moos (1978) studied the interrelationships among five major sets of variables: social background, intake symptoms, program type, treatment experiences, perceptions of the environment and their 
relationship to posttreatment functioning of alcoholics. They concluded that both the treatment experiences and the patients' perceptions of the treatment environment were strong predictors of outcome, and that a substantial proportion of the explained variance was shared between patient-related and program-related variables, suggesting important patient-program selection and congruence effects.

This perspective also has implications for treatment outcome evaluation. Besides the need to focus on multifaceted criteria, Caddy (1980) argues for data to be collected in a form which allows for assessment of individual subject change. This is in contrast to most studies which report outcomes only in terms of group data summaries. Smart (1978) proposed that more research evaluations be directed toward the processes of psychotherapy with alcoholics, rather than the traditional outcome evaluations. Noting that psychotherapy is beneficial for some alcoholics but not others, Smart emphasizes the need to identify and strengthen the crucial elements in alcoholism therapy. Maisto and Cooper (1980) contend that outcome evaluation "should be less directed toward simply looking at the effectiveness of a specific treatment or the differential effectiveness of two or more treatments" (p. 9). They would rather have studies with

outcomes produced by a specific treatment administered in a well-described setting to an individual who has been assessed on a variety of demographic, psychological, physical and related characteristics. 
This implies that early stages of research should focus on client-treatment-outcome interactions, rather than the main effects of treatment on an outcome. (p. 9)

Only after two or more treatments were found to be effective, with individuals who had particular characteristics matched with specific outcomes, would it be useful to evaluate the cost effectiveness of each treatment approach (Maisto et al., 1980).

To put this discussion into perspective, it may be helpful to consider a review by Maisto and McCollam (1980) of the 103 articles published between 1960 and 1977 which presented group data on multiple measures of alcoholism treatment outcome. Twenty-seven of these studies presented data on the correlation of multiple measures of alcohol treatment outcome. Analysis of these studies suggested that, "generally, drinking behavior is positively associated with other aspects of the alcoholic's rehabilitation" (p. 65). However, the authors, noting both exceptions to the findings (Pattison, 1966) and numerous methodological problems in the design of evaluation studies that have been conducted to date, concluded "no available data can be said to adequately address the issue of cause-effect relationship between drinking and other areas of treatment outcome" (p. 68).

Perhaps treatment outcome will eventually be defined by total Iife health as Maisto, Cooper, Caddy and others would prefer. In the meantime, the multivariate approach 
raises a whole new array of research questions. As Maisto and Cooper (1980) admit, the area of "Client x Treatment x Outcome interactions . . . is virtually unexplored" (p. 10)

The Validity and Reliability of Self-Reports by Alcoholics

As noted in the Rand Report, the problem of reliability and validity of self-reports is as old as the behavioral sciences. It is indeed common sense to regard information gathered from observation or official records as more dependable than that gained from personal interviews or questionnaires, since the former avoid "faulty memory, intentional lying, or an unconscious desire to please an interviewer" (Armor, Polich, \& Stambul, 1976, p. 141).

Alcohol treatment outcome literature relies heavily on the alcoholics' self-reports for information about drinking behaviors and life functioning following treatment. This may seem somewhat paradoxical, given that the alcoholic is supposedly notorious for denying negative events, especially drinking (Hill et al., 1967). However, there have been efforts to establish the reliability and validity of alcoholics' self-reports, with interesting results.

In 1970, summers concluded that self-reported drinking histories by chronic inpatient alcoholics were not valid and could not be relied on for evaluative 
purposes. Mark and Linda Sobell (1975), finding methodological problems in summer's study (not the least of which was the intoxication of some subjects) have questioned this conclusion. In 1974, the sobells, in association with F. H. Samuels, reported that a comparison of official records with self-reports of arrests for public drunkenness and driving while intoxicated indicated that these selfreports were reliable, particularly if the clients knew that answers would be used in decision making relative to their treatment programs. The following year, the Sobells found that voluntary outpatient alcoholics' selfreports of verifiable alcohol and non-alcohol related information (e.g. traffic accidents) were sufficiently valid for use in evaluation research (Sobell\& Sobell, 1975). In 1978, they examined whether population type (voluntary outpatient, voluntary inpatient, coerced outpatient) and question type (alcohol, non-alcohol, demographic) were significant variables in the validity of the alcoholics' self-reports. They not only found the validity of the self-reports consistent with previous findings, but also discovered that court-referred (coerced) subjects gave self-reports as valid as those who voluntarily entered treatment (Sobell \& Sobell, 1978). The following year, the Sobells published, with Maisto and Cooper, another report that indicated the reliability of alcoholics' self-reporting of drinking behavior. 
They concluded:

The results of this study parallel the findings of other recently published research showing the self-reports of alcohol abusers who are interviewed when abstinent are highly reliable and valid. These data, taken in concert, force reconsideration of the frequent clinical conjecture that alcoholics often lie or distort reports of their drinking behavior. (Sobell, Maisto, Sobell, \& Cooper, 1979, p. 160)

While the authors did not think these findings could be generalized to include chronic alcoholics who had been severely disabled by drinking, they did indicate that the setting and procedures they used to gather information probably influenced the accuracy of the results.

Along this same line of inquiry, Caddy (1980) suggested that the validity of the alcoholics' self-reports is a function of willingness and ability to recall. He argued that the context of the interview is an important motivator and cited research evidence (Sobells' and others) that given a context which is "conducive to the provision of valid self-report data, alcoholics can and do give valid self-reports" (p. 160). He speculated that problems with the validity of alcoholic self-reports might derive from the "climate" in certain programs which serves as a disincentive to factual reporting. He suggested that deception could be minimized if the collection of information were an integral part of therapy and follow-up, and if the patient saw the strategies used to collect information as relevant to his or her recovery. Caddy 
recommended several specific strategies to enhance the validity of self-reports. First, he would require routine gathering of information from collateral and official information sources, with any significant discrepancies discussed with the client. Second, he would have the therapeutic and follow-up relationship include a philosophy that assured clients would not experience negative consequences for reporting drinking behavior. In addition, he would promote positive consequences for factual reporting. Third, he suggested monitoring patients to assure they are not intoxicated when giving information. Caddy concluded that

the commitment to initiating procedures which maximize the validity of data gathered on a patient before and during his/her treatment would seem to be a prerequisite of any scientifically credible attempt to gather valid treatment outcome data. (p. 160)

The Difficulty of Locating Alcoholics for Follow-Up

Hill and Blane (1967) found that the majority of studies they reviewed had follow-up rates of less than 75\%. Vannicelli, Pfau, and Ryback (1976), reviewing the literature between 1967 and 1975, described the situation as "even gloomier" (p. 1325). They reported most studies with $30 \%$ to $50 \%$ nonresponders, and even larger percentages when follow-up employed interviews only. Vannicelli et al. also studied how these missing clients might be biasing the sample. They concluded that while nonresponders "are 
not necessarily treatment failures, they tend to be doing somewhat more poorly than responders" (Vannicelli et al., 1976, p. 1327). In 1978, Moos and Bliss found that patients who were difficult to follow up (non-cooperative or hard to locate) had poorer treatment outcomes than patients who were followed up more easily. Clearly, high rates of loss of clients at follow-up seriously bias the findings of research.

The loss of alcoholic clients at follow-up is usually accounted for in terms of client characteristics le.g. high mobility or the avoidance of disclosing failure to maintain abstinence) rather than procedural failures. However, most reviewers agree that low rates of success in follow-up are not attributable to client characteristics but are caused by faulty techniques, due to a lack of funds and personnel, or "the widely held conviction that alcoholics are harder than most to locate" (Hill et al., 1967, p. 94). Vanicelli et al. (1976) reported more successful follow-up with improvements in follow-up technology.

Caddy (1980) makes a number of suggestions to facilitate follow-up which he believes can virtually eliminate client loss: (a) integration of the evaluation component into the service delivery system should be made at the outset so that "both patients and staff come to realize 
that follow up is an integral part of the treatment system" (p. 160; see also Blum \& Blum, 1967, pp. 269-270), and (b) follow-up should be presented to both clients and staff as serving the dual role of outcome evaluation and continuity of care. Caddy would utilize staff who know clients to do follow-up since he feels the benefits of this approach "more than offset any disadvantages associated with the possibility of biasing the data" (p. 160), (c) use of collateral information sources (such as relatives and friends) is emphasized to facilitate tracking the client and cross-checking information, and finally (d) this approach would include frequent and continued contacts. Caddy thinks this procedure provides for easier tracking, maximizes opportunities for establishing rapport, and "offers an extremely low cost continuity of care after formal treatment has ended" (p. 160).

\section{Summary}

Most of the methodological problems revealed by our overview of alcohol treatment research are common throughout the literature of the behavioral and biological sciences. Many methodological dilemmas are inherent in struggling to conduct rigorous research within the context of the "real world." These difficulties are confounded in the field of alcoholism, where there is little agreement on the nature of the problem and no consensus on a theory of its etiology. 
Our review found no methodological issue more controversial than the adequacy of abstinence as a criterion of success. More important to our investigation, no controversy in this field has been more pivotal to the development of innovation in both treatment and research technology. The emergence of the "multivariate" conceptualization of alcoholism, with life adjustment as a criterion of success, has broadened the scope of research while stimulating interest in the application of increasingly complex and sophisticated techniques. The most recent literature written from this new perspective indicates the significant success of new approaches to enhance the reliability and validity of self-reports while facilitating follow-up. This would suggest that these perennial methodological problems do not necessarily reflect the symptomatology of a difficult class of cases but may be indicative of the "climate" in which treatment and research are conducted.

\section{FOLLOW-UP STUDIES OF ALCOHOLICS}

The literature review of follow-up studies of outpatient alcohol treatment will summarize the findings by modality of treatment: behavioral therapy, psychotherapy, drug therapy, and family therapy. The consideration of service delivery variables, group versus 
individual, and voluntary versus mandatory, will also be addressed.

While this review of findings will be restricted to outpatient treatment follow-up, it should be noted that inpatient therapy results are generally no more successful than outpatient therapy results (Baekeland, Ludwall, \& Kissin, 1975). The most significant difference between inpatient and outpatient treatment is the dropout rate, which is much higher for the latter.

Particular attention will be given to evaluations of the effectiveness of Alcohol Safety Action Projects (ASAP) in reducing alcohol related arrests/accidents and improving life functioning. The findings are grouped by the criteria used as measures of success.

The identification of possible predictors of treatment success, based on client characteristics, is an important secondary finding of alcohol treatment follow-up studies. A discussion of these treatment outcome predictors completes the literature review of follow-up studies of alcohol treatment.

\section{Treatment Modalities and Variables}

Behavioral Therapy

Classical aversive conditioning and systematic desensitization have been the predominant forms of behavioral therapy discussed in the literature. Classical 
aversion conditioning (electroshock, alcohol antagonist, etc.) has a corrected success rate of about $30 \%$ (Lemere \& Voegtlin, 1950). The more recent literature contains very few reports on aversion therapy, which may indicate its decline as a preferred treatment method.

At present, behavioral therapy is primarily used in controlled drinking programs (Watzel \& Olbrich, 1976). Its use is especially indicated for those alcoholics who are still in relative control of their drinking (Orford, 1973) .

\section{Psychotherapy}

A summarial review of 46 years of follow-up studies by Emrick (1974) found that $2 / 3$ of all clients receiving psychologically oriented alcoholism treatment improve. Their improvement is related to social, vocational, and psychological adaptation, but not necessarily to drinking behaviors.

Results of studies on the effects of group psychotherapy have been conflicting. Ends and Page (1957) and Hoff (1968) demonstrated positive effects on treatment outcome, while Hoy (1969) and Wolff (1967) demonstrated negative effects. Burton, Kaplan, and Hudd (1968) found that those clients who participated in group counseling had a significantly higher percentage of response at the time of follow-up. According to these researchers, this may be an indication that group treatment facilitates 
feelings of interest and concern for others in the group, the counselors, and the agency.

Controlled studies of group therapy have demonstrated success rates ranging from 158 to 478 , depending on the success criteria utilized (Baekeland et al., 1975). Matakas, Kaester, and Leidner (1978) state: "Currently group therapy is considered to be 'dogma' in the treatment of alcoholism, although there is a lack of adequately based clinical investigations regarding its effectiveness" (p. 5).

\section{Drug Therapy}

The successful use of disulfiram (Antabuse) to control alcohol consumption is a continuing point of controversy. Citing the results of three studies, Baekeland et al. (1975) reported that the use of Antabuse was ineffective. However, in a 1978 review of the literature, Matakas et al. state that Antabuse has a success rate which is generally no more unsuccessful than other alcohol therapies.

\section{Family Therapy}

There are few empirical studies of family-oriented therapy in the treatment of alcoholism. Most reports consist of case studies, and reliable success rates cannot be found (Matakas et al., 1978). 
Summary of Treatment Modalities

While proponents of each type of treatment modality propose the efficacy of their therapy as most successful in the treatment of alcoholism, research indicates that most therapies are about equally effective. Success rates are generally $40 \%$ and higher (Baekeland et al., 1975).

\section{Mandated Versus Voluntary Treatment}

In a 1979 literature review that critically analyzes methodology, ward states that there is no basis for believing that mandated treatment is effective. Individual study results, however, are less conclusive.

Dittman and Crawford (1966) report on the use of mandated treatment for alcoholics. As a condition of probation, 472 offenders were required to either attend A.A. or go to jail. of the 698 who attended A.A., $31 \%$ "flunked out" by not maintaining abstinence and/or attendance. They were then required to attend a more structured treatment program and $67 \%$ were successful. Overall, $88 \%$ of the original 698 who chose to go to treatment rather than jail were successful in A.A. or therapy.

The Boston ASAP (Rosenberg \& Liftek, 1976) referred a group of 49 clients to a hospital alcoholism clinic. The group consisted of mandated clients, threatened with the loss of their drivers' licenses, and voluntary clients. At the end of 6 months, $45 \%$ of the mandated clients remained in treatment, as compared to 58 of the voluntary. 
Two-thirds of those still in treatment were considered to be making progress. However, only $16 \%$ of the mandated clients continued in treatment after the first week following the expiration of their probation.

In another evaluative study of mandated treatment, 19 parolees who had committed alcohol related crimes were randomly assigned to two groups (Gallant, Faulkner, Stoy, Bishop, \& Langdon, 1968). The first group consisted of those who, as a condition of parole, participated in individual counseling for 6 months, with an option of an additional 6 months. The other group participated in one mandatory appointment with the option of 6 months of follow-up treatment. One year from the time of their first appointment, the results were as follows: five of the mandated clients were abstinent from alcohol compared to none of the voluntary, two mandated clients had been in new trouble with the law compared to seven voluntary clients, and seven mandated clients were working steadily compared to none of the voluntary clients.

Study results, overall, would indicate that mandating alcohol treatment increases the likelihood that an alcohol abuser will complete treatment, and thereby experience the benefits from the treatment in several areas of his life (employment, legal involvement, etc.). However, mandating treatment appears to have little impact on increasing motivation to attend and/or continue in treatment. 
ASAP Follow-UP Evaluations

Most of the studies of mandated outpatient treatment of alcoholism are evaluations of Alcohol Safety Action Projects. ASAPs were established in 35 communities around the United States to provide a comprehensive approach to reducing the incidence of alcohol traffic-related crashes and fatalities. Four areas were coordinated to address the problem:

(a) enforcement, (b) adjudication, (c) rehabilitation, and (d) public information and education. Persons who had been arrested for Driving while Intoxicated (DWI) or involved in alcohol related accidents were mandated by the courts to receive treatment at an ASAP. The evaluations of these programs will be discussed according to the criteria used by the researchers to measure success: (a) recidivism, or rearrest for alcohol related traffic offenses/accidents, (b) statistical analysis of the number of nighttime fatal crashes in ASAP communities, and (c) improvement for the client in both alcohol related and non-alcohol related functioning as measured by self-report. Some studies use both (a) and (c) as criteria. Special attention will be given to those studies with adequate controls and to studies that link client characteristics with treatment effectiveness.

The findings of the studies using arrest/accident recidivism as the criterion of success are inconclusive. Studies in Alberta, Canada and Nassau County, New York 
showed no reduction in the number of rearrests of persons who had received alcohol education/treatment (Zelhart, 1973; Nichols, Ellingstad, \& Struckman-Johnson, 1979). In contrast, studies in Phoenix, Arizona and Washtenaw County, Michigan, showed a reduction in rearrests for those who had received treatment (U.S. Dept. of Transportation, 1974; Stewart \& Malfetti, 1970; Filkins, 1974). However, only the Phoenix study showed a reduction in the number of crashes for those who had received treatment (Stewart et al., 1970).

An evaluative study of all the ASAPs, utilizing the criterion of arrest/accident recidivism, demonstrates more conclusive results (U.S. Dept. of Transportation, May 1979). This study attempts to link success to the treatment modality and to the level of alcohol involvement experienced by the client. Findings indicate that, overall, educational programs are effective in increasing the clients' knowledge of alcohol-related problems, but have little or no effect on reducing arrest/accident recidivism.

When the level of the alcohol involvement of the client is considered, the treatment modality utilized can be very important. For social drinkers, participation in any type of treatment results in a lower rate of rearrests when compared to those who have no treatment. However, their treatment involvement has no effect on 
accident rates. For social drinkers, the type of program attended does not influence outcome; they benefit equally from didactic (including home study courses) and interactive therapy.

Comparatively, the treatment outcome of the problem drinker is influenced by the treatment modality. Those attending large lecture-type educational programs have a poorer rearrest record than those attending small, interactive, intensive, interpersonal treatment sessions (U.S. Dept. of Transportation, May 1979). Problem drinkers have twice the recidivism rate of social drinkers (Nichols, 1979). The problem drinker is identified as having a high blood alcohol content at time of arrest, a large number of prior alcohol-related arrests, and a high score on the Mortimer Filkens Drinking Driver Questionnaire and Interview (a validated diagnostic test for measuring the extent of a person's problem with alcohol). The problem drinker is also more likely to be divorced or separated, to have less than a high school education, and to have a lower income than the non-problem drinkers. Problem drinkers are less likely to complete treatment; those who do complete treatment have a slightly better rearrest record than those who do not (U.S. Dept. of Transportation, May 1979).

Another criterion used in measuring the success of ASAP programs is the reduction of nighttime fatal 
crashes. This is a difficult measure to use because crashes are relatively rare events and are inconsistently reported. Three studies use the comparison over time of the number of nighttime fatal crashes in ASAP communities, or with the number of nighttime crashes in different but comparable communities. The rationale for using this measurement is that, since most alcohol related fatalities occur at night, a reduction in the expected number of nighttime fatalities indicates a positive effect of the ASAP program (U.S. Dept. of Transportation, April 1979). In 1972, 29 individual ASAP communities were studied using the comparison between nighttime fatal crashes in the ASAP community and daytime crashes. Eight projects showed a reduction in the projected number of fatal crashes by 94 . The crash data from the remaining 21 sites showed no reduction, while daytime crashes increased by 32 . The eight projects which showed positive results had been in operation 2 years in contrast to the remaining 21 , which had an operational period of 1 year (U.S. Dept. of Transportation, April 1979).

Paul Zador (1976) criticized the U.S. Dept. of Transportation study on the basis of lack of controls. In 1972, he designed and implemented a study comparing, on a year to year basis, nighttime fatal crashes at ASAP sites with those at comparable sites without ASAP. He found no statistically significant difference between the 
sites. He concludes that "ASAPs, as large scale social programs, have been ineffective" (p. 59).

Johnson, Levy, and Voas (1976) challenged Zador's findings on the basis that his interpretations go far beyond the data he presents. They assert that his study is incomplete, that he rearranged the borders of the comparison areas, and that he used statistical techniques too gross to measure the changes that the earlier U.S. Dept. of Transportation study reported.

The third evaluation of ASAPs was based on a reduction of nighttime fatal crashes in individual ASAP communities as compared to similar communities. There were statistically significant reductions in the number of crashes in 12 of the 35 projects. None of the comparison studies showed reductions. Two ASAP sites and three comparison sites showed increases (U.S. Dept. of Transportation, April 1979). In conjunction with this study, roadside surveys of blood alcohol content as measured by the breathalyzer were conducted on randomly selected drivers in 19 ASAP communities. The reduction in numbers of persons who had elevated BACs between the baseline data and operational data was statistically significant (U.S. Dept. of Transportation, April 1979). This finding reinforces the rationale for using reduction of nighttime crashes as a criterion of success. 
The third set of criteria used for evaluating the effectiveness of ASAPs is the self-report questionnaire on life changes, both alcohol and non-alcohol related. The Short Term Rehabilitation Study (STR), which used this criterion, was conducted at 11 ASAP sites during 1976. Involved were 3,666 clients: 1,113 in the control group and 2,087 in the treatment group (U.S. Dept. of Transportation, May 1979; Nichols et al., 1979). Clients were generally defined as "moderate drinkers." Selfreport questionnaires were given to the population at 6 month intervals beginning at intake. The 23 dependent variables were divided into three categories: drinking related, life status, and personality. At follow-up, two variables showed statistically significant differences. While both groups improved significantly in drinking behavior, the control group evidenced more improvement. The treatment group's improvement in "outgoingness" was greater than that of the control group (Nichols et al., 1979).

An evaluation of the Philadelphia, Pennsylvania, ASAP program used improvement in life functioning, as measured by self-report, as a criterion of success. A control group and a treatment group were assessed at intake and follow-up. Symptoms related to excessive alcohol use improved for both groups. Both groups also showed comparable decreases in psychopathology, but the treatment 
group showed a greater decrease in depression at followup than the control group (Fine, Steer, \& Scoles, 1979). In summary, the findings of studies to evaluate the success of mandated treatment at ASAPs are contradictory. Generally, studies found no effect on recidivism for alcohol related arrest/incidents. Social drinkers evidence a better response to treatment than problem drinkers, and problem drinkers react negatively to lecturetype treatment.

Two out of three studies using statistical analysis of nighttime crashes as criteria found a reduction of fatal crashes in ASAP communities. Well-controlled evaluations of treatment by ASAPs of drinking drivers (using self-report questionnaires over time) found similar improvement for both treatment and control groups.

There are significant methodological problems specific to measuring outcome of treatment of drinking drivers. Because treatment is mandated by the judicial system for most of the clients in these programs, a control group is not available. Carefully controlled evaluations of treatment generally show less positive results. In fact, "positive findings are indirectly proportional to the amount of experimental control exercised" (Nichols et al., 1979, p. 68).

Studies using rearrest and crash data are handicapped by the fact that rearrests and crashes are events that 
occur infrequently in relation to the population as a whole. Also, because reporting procedures are not uniform within and between communities, data collected on DWI arrests and blood alcohol content of drivers involved in alcohol-related crashes are not reliable.

\section{Prediction of Treatment Success}

One important outcome of follow-up studies has been the identification of possible predictors of treatment success. According to Weisner (1972), prognostic criteria are more important than the special techniques employed in treatment, with regard to the outcome of the treatment. The need to maximize treatment effectiveness by identifying stable predictors of success and relating client characteristics to a preferred treatment modality has implications for the direction of future follow-up studies.

General prognostic indicators of treatment success are identified by establishing a statistically significant relationship between client characteristics and outcome criteria. Although many prognostic criteria are disputed, there are some which may be good general predictors: long history of regular employment, late onset of drinking, high scores on the Arithmetic Scale of the Wechsler Adult Intelligence Scale (Gibbs \& Flanagan, 1977), marital stability, level of education, and number of treatment attempts (Goldfried, 1969). The identification of job stability as a criterion for predicting treatment success 
may account for the effectiveness of business/industry employee alcoholism programs, some of which claim recovery rates of $658-758$ (Lee, 1976).

The establishment of controlled drinking as a treatment goal has necessitated the identification of prognostic indicators for its success. Among the predictors identified to date are problem drinking rather than alcoholism, high socio-economic status, family and residential stability, and job stability (Thomas, Gliedman, Imber, Stone, \& Freund, 1959; Mayer \& Myerson, 1970; Miller \& Joyce, 1979).

According to some authors, another predictor of treatment outcome is the ability to locate and elicit cooperation from the client at the time of follow-up. Clients who are difficult to locate and engage in follow-up after treatment have poorer treatment outcomes than clients who are followed up more easily. The results of a study by Moos and Bliss (1978) suggest that there are three separate aspects of follow-up related to treatment outcome: initial ability to locate, relocation, and cooperation. The treatment outcome for clients hard to locate initially is considerably worse, but this is accounted for by sociodemographic characteristics and client functioning at intake. Clients who need to be relocated or are uncooperative also have poorer treatment outcome, but this is not accounted for by client characteristics at intake. 
Variables found to be useful for differentiating these clients at the time of intake are age, marital status, education, income, and residential stability.

Prognostic indicators for dropout rates from treatment have also been identified. Since the dropout rate for outpatient treatment is found to be between 508-75\% by the end of the fourth session, the prediction of client dropout could have greater implications than success predictors for intake procedures. Smart and Gray designed a study using a multivariant approach to identify the importance of client and treatment variables, and their reliability for predicting dropout. The important client variables at time of admission were found to be motivation for treatment, life experiences with alcohol, length of drinking problem, and problems experienced due to drinking. Treatment variables identified as dropout predictors were type of treatment, medication, treatment location, medical assessment, and the profession of the therapist. An important finding of the study was that clients who received a variety of out-patient medical interventions during treatment were more likely to remain in treatment. The growing trend to deprofessionalize alcohol treatment is contrary to the study indications that a medical approach leads to lower dropout rates (Smart \& Gray, 1978). 
Summary of Follow-Up Studies of Alcoholics

Some general conclusions can be drawn from the examination of alcohol treatment follow-up studies. Participation in alcohol treatment usually results in improvement in some areas of the clients' lives. In addition, there is generally a positive correlation between the reduction of alcohol consumption and these improvements (Emrick, 1974). When the success criteria are related to drinking behavior (abstinence, controlled drinking, and socially acceptable drinking), success rates are found to be between 40\%-50\% (Baekeland et al., 1975). However, there is also improvement, over time, in a percentage of people who experience no treatment. Approximately the same rate of success is demonstrated by all of the common treatment modalities. Different methods of service delivery (inpatient versus outpatient, individual versus group, voluntary versus mandated) do not produce significantly different results.

Follow-up studies attempting to identify predictors of success are inconclusive. There are no stable general predictors (Gibbs et al., 1977), and the failure of followup studies to identify general predictors and to provide evidence that any one treatment modality is superior to others may be the result of an interaction between the type of treatment and the personal characteristics of the client. Gibbs and Flanagan (1977) assert that a typology 
of alcoholics, based on the demonstrated association of characteristics with the outcome of treatment methods, must be established. The need to maximize treatment effectiveness by identifying stable predictors of treatment success may shape the direction of follow-up studies in the future.

\section{MANAGEMENT OF DRUNKEN DRIVING OFFENDERS}

The literature relevant to the management of the drunken driver encompasses a broad range of issues. Some of the points pertinent to the present study are the following: (a) the safety hazard caused by the drinking driver and monetary costs related to accidents, (b) the passage of legislation designed to increase public safety in relation to the drinking driver, (c) the descriptions of the driving while intoxicated (DWI) offender, (d) the inconsistency of enforcement practices by police, courts, and communities dealing with the drunken driver, (e) the treatment strategies utilized with the DWI offender, and (f) the development of predictive models to identify potential drunken drivers.

\section{Hazard to Public Safety}

In 1968, the Secretary of Transportation called attention to the hazard to public safety posed by the drinking driver. He reported that alcohol was involved 
in the deaths of 25,000 drivers and pedestrians each year, and was a factor in 800,000 traffic accidents (Hart, 1977). The drinking driver has continued to be a serious threat to highway safety. Of all highway fatalities, 408 to 558 are alcohol related (Program Level Evaluation of ASAP, 1976; Saunders, 1979; Zelhart \& Schurr, 1977). Drunk driving is a leading cause of death following heart disease and cancer (Chambers, Roberts, \& Voelker, 1975). The dollar cost of alcohol-related accidents in 1974 was estimated in the billions, "\$3.56 billion for fatal accidents, $\$ 2.38$ billion for injuries received from accidents, and $\$ .5$ billion for property damage" (Saunders, 1979, p. 86).

Legislation and the Drinking Driver

The threat to public safety caused by the drinking driver induced Congress to pass the National Alcohol Countermeasures Program of 1970. The act was designed to identify more fully the extent of alcohol abuse in traffic accidents and to provide funding sources for rehabilitation programs. This legislation was the product of a long-term investment by Congress in the problems of alcoholism. Legislative action in connection with the alcoholic began in the 1940's. Initial legislative efforts decriminalized the charge of public drunkenness. Emphasis then shifted to the development of treatment resources for the chronic alcoholic. Most recently, the emphasis is on the management of the drunk driving offender. 
An important legislative action related to the management of the drinking driver has been the adoption in each state of legal limits to indicate intoxication. This has been accomplished due to a number of available devices which detect the amount of alcohol present in the individual's blood stream. This measurement is called the blood alcohol content or the BAC. The BAC takes into account the amount of alcohol consumed, the length of time since the last drink, and body weight. The BAC of the individual drinker is affected by factors such as use of other drugs, the length of time since ingesting food and the individual's metabolism. Generally, for a 160-pound person to be legally drunk, he/she would need to consume five 1-ounce drinks in a 1-hour period (Saunders, 1979). The legal limit indicating intoxication in most states ranges from .08 to $.10 \mathrm{BAC}$. The use of the $\mathrm{BAC}$ to determine legal intoxication has provided an objective criterion to identify the drunk driver.

Descriptions of the DWI Offender

Attempts to develop a description of a "typical" DWI offender comprise a significant portion of the literature about the management of the drunk driver. The result of these efforts is the conclusion that the DWI is not easily categorized. Delellis (1975) describes the offender as a 35 to 40 year old, middle-class male who is married, 
has a family, and is a high school graduate. He began drinking at an early age, and drinks with others in predominantly social settings. He is involved in accidents and/or arrests at night and has been arrested three times in the last 10 years. Although his family members object to his drinking, he does not believe he has a problem. It is evident that this kind of driver is well represented in the DWI population.

Other studies, however, cite exceptions to this description. According to Zelhart and Schurr (1977), "the individual most likely to drink and drive, or to be a DWI, is a man, probably under the age of 30 , divorced or separated, and employed at a blue-collar job" (p. 206) . In another study, it was shown that men from disadvantaged ethnic groups were at least twice as vulnerable to arrest as other men in the study and, when age grouping was included, the chance for arrest among the youngest, minority sub-groups was further increased (Hyman, 1968b). In the same study, it was demonstrated that, in counties with low socio-economic status, arrest rates for DWI were higher among men aged 25-54 despite limited access to automobiles. The results of another study by Hyman (1968a) confirm that when alcohol was abused by persons in the 16-20 and 20-24 age groups, the probability of accident involvement increased significantly. What can be concluded 
is that the DWI offender is not easily identified except by sex.

Females are infrequently included in study samples of DWI offenders, possibly because in many areas women are arrested less often than men. An explanation offered by researchers about this discrepancy in arrest rates is that more men are licensed drivers, men drink more, and men drive more at night (Saunders, 1979). Even when stopped by a police officer, women are less likely to be arrested for DWI (Argeriou \& Paulino, 1976). Thus, it appears that arrest practices bias population samples, particularly in relation to women and other minority groups.

Although the DWI offender cannot easily be categorized, both social drinkers and problem drinkers are over-represented in the more serious and fatal accident statistics. However, research shows the accident rate to be much higher among the group identified as problem drinkers than among the group defined as social drinkers (Selzer, 1961, 1966). In addition, the likelihood of accident involvement correspondingly increases as the blood alcohol content (BAC) rises (Selzer, 1966). At .06 BAC, the driver is twice as likely as the non-drinking driver to be in an accident; at . 10 BAC the chance increases to six times that of a sober person, while at .15 BAC the driver is 25 times more accident vulnerable (Cramton, 1968). 
One conclusion about the value of the DWI descriptions can be reached. Although better descriptions of the DWI offender will not solve the problems of managing the drunk driver, these descriptions do provide data about target sub-groups requiring significant intervention.

\section{Enforcement Practices}

Another issue addressed by the literature in the management of the DWI is the enormous inconsistency surrounding enforcement practices throughout the country in relation to the drunk driver. The laws regarding drunk driving are similar in most areas. Their enforcement, however, is contingent upon community attitudes towards drinking and the community attitude about apprehension of drinking drivers. In most communities, it is acceptable to drink small amounts of alcohol and wait a reasonable length of time before driving. No societal consensus exists, however, on what is a reasonable amount to drink or a reasonable length of time to wait before driving. The general public believes the majority of those arrested are social drinkers. Since most of the public are social drinkers, they view efforts to curb drinking and driving as infringements on personal rights. Consequently, police are reluctant to enforce laws that are so controversial and unpopular (Saunders, 1979). In addition, as has already been pointed out, some sub-groups such as ethnic minorities are more frequently arrested while others such 
as women are seldom detained. These arrest practices reflect community attitudes toward the various subpopulations. Finally, penalties imposed for drinking and driving show similar discrepancies.

A recent trend toward more stringent penalties has emerged as the hazard to public safety has become more alarming. The widespread use of the breathalyzer test (a method for measuring the blood alcohol content) has provided objective evidence in convicting drunken drivers and has resulted in an increase in license suspensions and revocations. Many communities have levied severe fines and jail terms in an effort to curb drinking and driving. Such sanctions have proven largely ineffective with repeat offenders (Eddy, 1976), and local judges have become increasingly frustrated in their attempts to deal meaningfully with drunk drivers. As both judges and communities have become more aware of the diversity within the DWI population, the need for individual assessment and treatment of the offender has been recognized.

\section{Treatment Strategies}

The emphasis during the 1960's and 1970's on alcohol abuse and the drinking driver resulted in the appearance of treatment resources for those persons who had difficulty with drinking and driving. These treatment programs are another important area of focus in the literature on the management of the DWI offender. 
The first programs followed an educational model and were aimed at the social drinker. The objective of the educational method was to provide sufficient information to the drinker so that he/she could make better decisions about traffic safety after drinking. The rationale for this approach was the pervasive attitude that most accidents were caused by social drinkers. Providing education in DWI schools has proven an effective tool with the social drinker, particularly the first offender (Eddy, 1976; McGuire, 1978). However, in recent years it has been shown that accidents are most often attributed to the problem drinker (Selzer, Payne, Gifford, \& Kelly, 1963), and that the addiction of the habitual drinker remains impervious to the educational model. As it became apparent that the problem drinker was the client most in need of service, diagnosis of problem drinkers and referral to more intensive treatment situations became an important function of DWI schools (Kern, Schmelter, \& Paul, 1977).

In the early 1970's, the Department of Transportation provided funds for the development of another approach to the management of the DWI offender, the Alcohol Safety Action Projects (ASAP). Thirty-five pilot projects were funded directly with federal monies to focus on changing the drinking behavior of drivers (Charalampous \& Skinner, 1977). Based on the ASAP model, additional DWI programs 
have been developed on both local and state levels throughout the country. The DWI programs attempted to coordinate services and offer them to both social drinkers and problem drinkers and, therefore, employed a wide range of methods. Individual DWI programs differ in emphasis and approach depending on the resources and limitations of the communities in which they are located.

The specified objectives of ASAP have been and are "to identify problem drinking drivers, to develop procedures to ensure that they do not drink and drive, to reduce drinking problems, and to implement an action program to carry out these procedures" (Landstreet, 1977, p. 10). In order to carry out these objectives, local ASAPs have included components which address these five areas: enforcement of drunk driving laws, consistent disposition of drunk driving cases by local courts, development of comprehensive treatment and rehabilitation programs, public education programs about drinking and driving, and evaluation (Saunders, 1979). The coordination by some ASAPs of the various community systems which deal with the DWI offender (enforcement, judicial, licensing, diagnostic, referral, and rehabilitation) reduces the fragmentation of services to the offender (Program Level Evaluation of ASAP, 1976).

The intensive efforts of the ASAP projects have resulted in many law enforcement officers and courts 
viewing ASAP as a viable resource in the management of the drunk driver. A major service provided to the court by ASAP has been the pre-sentence evaluation. This report usually includes an assessment of the offender's alcohol problem and indicates treatment recommendations. Upon conviction, the judge may mandate the offender into an ASAP program (Hart, 1977). ASAP assists the mandated client either by acting as a referral agent to other community resources or by offering their own services depending on existing community options.

For these court and treatment processes to be effective, systematic arrest practices must occur. In communities where ASAP exists, offenders are now routinely charged and sent through the assessment and court phases where, in the past, the charges may have been dropped or reduced (Ennis, 1977; Little, 1975). The strengthening of the court and treatment components has encouraged enforcement and conviction policies to become more consistent. In addition to supporting consistent enforcement procedures, ASAP has made efforts to educate court officers about the problems of alcoholism. In some locales, this effort has been rewarded by the redefinition of court practices and the shortening of the judicial process in relation to DWI (Scrimgeour, 1975). The combination of treatment and the coercive element of mandated compliance is seen by many courts as especially effective 
with the DWI offender. This population traditionally avoids other methods of outreach (Charalampous et al., 1977; Landstreet, 1977; Scrimgeour, 1975; Zylman, 1971).

The ASAP approach to the management of drunk drivers offers a comprehensive range of rehabilitation and treatment programs to the variety of clients it serves. Defensive driving courses, alcohol education classes and individual, group, or family therapy are examples of possible treatment alternatives. The initial goal of treatment is the client's acceptance that he/she may have a drinking problem. Many ASAP programs reinforce the initial shock of arrest, jail, court procedures, and identification of a problem drinker by use of group diagnosis and group treatment. Peer confrontation used by these groups has been effective in influencing clients to accept their drinking behavior as problematic. Once the client accepts that he/she has a problem, he/she is usually more amenable to seeking and receiving help (Saunders, 1979).

As discussed previously, it has been difficult to evaluate the effectiveness of the ASAP model. The Department of Transportation, ASAP's principal funding source, chose the reduction of alcohol-related traffic accidents and fatalities as the major criterion in evaluating ASAPs (Charalampous et al., 1977). Based on this criterion, it would appear that these programs did not have a 
significant impact. On closer examination, the problem with the selection of this criterion becomes evident. Reduction of crashes does not validly determine whether the client benefited from the services of the ASAP program (Charalampous et al., 1977). Furthermore, methods of data collection by police and courts which identify the DWI and alcohol-related accidents are so varied that accurate recidivism rates are unlikely to be obtained. For this reason, recidivism rates are considered to be inadequate in assessing outcome (Zylman, 1971). In addition, only a small number of the drivers who drink are ever apprehended. Ennis (1977) indicates that over a year's time, about $25 \%$ of all those arrested will be repeat offenders while $75 \%$ are new arrestees. The chances of a drinking driver being arrested range from one driver in every 200 to one driver in every 2000 (Ennis, 1977; Zelhart et al., 1977). Despite differing figures, it is agreed by researchers that those involved in ASAP and similar programs account for only a small proportion of the at-risk population. These factors make it difficult to demonstrate success. Even if ASAP could demonstrate success with the clients it treats, there remains a significant problem with the drinking driver who is not reached by ASAP and other treatment agencies. 


\section{Predictive Instruments}

A final point pertinent to the present study is the current research effort in the management of drunk drivers. These efforts are directed toward development of predictive instruments that will identify the driver who drinks and is most likely to be involved in traffic accidents. Selzer $(1961,1968)$, an early researcher in this area, relates alcoholism to the symptomatology of mental illness. He hypothesizes that the suicidal ideation of the chronically depressed alcoholic is related to the incidence of traffic fatalities. Additional research relates the high risk of alcohol crashes to such variables as age, prior conviction for DWI, multiple traffic violations, recent divorce, and recent release from prison. The resulting statistical predictions for accidents show low to high degrees of correlation, particularly when more than one variable is involved (Lacy, Stewart, \& Council, 1979). Another research project is focused on the development of a predictive instrument that could be administered by a non-professional person. With such an instrument, it is conceivable that an employee of the Department of Motor Vehicles, lacking in clinical expertise, could identify potential alcohol abusers and deny such persons a driver's license pending further assessment (Jacobson, Niles, Moberg, Mandehr, \& Dusso, 1979). 
In summary, the need to manage drinking drivers grew out of increased awareness of the hazard drunk drivers pose to public safety. Initial efforts were aimed at the social drinker but subsequent efforts shifted to the problem drinker, who is more often involved in severe and fatal accidents, and is the repeat DWI offender. Effective management of the drinking driver has required a multifaceted approach which includes law enforcement, courts, public education, and comprehensive treatment programs. In localities where ASAP programs exist, they have been instrumental in coordinating services to the DWI offender. Evaluation of the effectiveness of these programs has been inadequate. Research has continued in the evaluation of present programs and in the development of predictive instruments to better identify the problem drinker. 


\section{CHAPTER II}

\section{HISTORY AND DESCRIPTION OF THE PORTLAND, OREGON, ASAP}

The Portland ASAP was founded in 1970 as part of a multi-state federal response to the drinking driver problem. Increasing concern in the late $1960^{\prime} \mathrm{s}$ about this problem resulted in the establishment of ASAP programs in 35 states, funded by the Federal Department of Transportation. The Portland and Lane County, Oregon, ASAPs were a part of this program. The primary goals of the original ASAPs were public safety and community education. To accomplish this, funds were made available for extra police patrols and judges, and for a mass media campaign. The emphasis of the original ASAP program was the early identification of the drinking driver, hopefully to prevent further arrests for driving under the influence of intoxicants (DUII). The ASAPs functioned as evaluation units for the court system, assessing the extent of an arrested individual's alcohol problem. Responsibility for an individual's treatment, if any, was deferred to the court's probation offices.

In 1972, the National Institute on Alcohol Abuse and Alcoholism (NIAAA) and the Department of 
Transportation collaborated to add a treatment component to the 35 ASAPs. This was accomplished by the formation of Services for Problem Drinking Drivers (SPDD). Individuals could now be mandated to treatment at ASAP as an alternative to imprisonment.

In 1973, there were two developments which greatly affected the Portland and Eugene ASAPs. The first of these was the addition of a medical-screening and monitoring service to screen and place clients on an Antabuse regime as part of the treatment plan. This was done largely in response to the need to have closer controls over the drinking of clients who were recommended for an occupational driver's license. At that time it was felt monitored Antabuse was the only sure method to guarantee that someone on a license recommendation was not drinking and driving. Secondly, the Oregon Legislature passed legislation pertaining to drivers' license penalties for repeated DUII, and to the securing of a special driver's license for occupational purposes following suspension because of repeated DUII's. Two convictions for DUII within a 5-year period resulted in a 1-year suspension of the driver's license; three convictions meant a 3-year suspension. As an incentive to induce multiple DUII offenders into treatment, ORS 482.477 made it possible for a person with a suspended license to secure an occupational license which allows driving to and from work, 
on-the-job driving, driving to school, medical appointments, and to treatment. This restricted license is granted only upon recommendation by ASAP (and now, by DWI/ DUII programs in all counties) and a concurring recommendation by the convicting judge. Occupational licensing has become an important service offered by the ASAP and all approved DUII programs in Oregon. Following referral by the court to ASAP after two DUII convictions, an evaluation of the client's alcohol problem is made and a treatment plan is developed. A recommendation for an occupational license is not made by ASAP until the client has been active in the program for a minimum of 6-8 weeks. The recommendation is usually, but not always, honored by the Department of Motor Vehicles.

In 1973, Senate Bill 448 was passed. Its purpose was to aid in the development of community mental health programs. This bill changed the role of the state Mental Health Division from that of a direct service provider to one of regulating standards for individual programs. It was in 1977 that the State Mental Health Division gave the directive to the Portland and Eugene ASAPs to transition themselves out of the state system. The Portland ASAP became a private nonprofit corporation in October of 1978, and contracts annually with Multnomah County Mental Health Services for state mental health funds. 
In addition to changes resulting from legislation, the Portland ASAP has instituted several program changes since 1978 with regard to treatment. First, a clinical supervisor (now Assistant Director) was hired to provide development of treatment services on a systematic basis and to train and supervise all the clinical staff. Second, there was a shift from the original case management system which utilized the original ASAP staff as evaluators/case managers and the original SPDD staff as counselors. UP to 1978 , only a small number of ASAP clients were ever in actual on-going counseling. The majority were seen sporadically as "follow-up," and were usually on Antabuse for a year. In 1978, the ASAP and SPDD staff were integrated in the sense that all were to assume evaluation as well as counseling duties, and all clients were to receive counseling to some degree, not just infrequent follow-up visits in a case management mode. Third, the use of Antabuse diminished greatly following the American Medical Association's findings that for most people, Antabuse is best used for short periods of time and only in conjunction with counseling.

In 1979, ASAP moved into new offices and the treatment program changes that began in 1978 were continued. In addition, the agency began to move away from individual and toward group treatment. This was due, in part, to some empirical support of the group treatment method, as 
well as to cost-effectiveness issues. In 1980, ASAP added evaluation and volunteer components to its program.

\section{Funding}

Funding of ASAP is and has been through the state Mental Health Division, with the County Mental Health being involved since the agency became a private non-profit agency. During the first 3 years of the program, $100 \%$ of ASAP's funds came from the Federal Department of Transportation. From 1974 to 1976, ASAP was funded jointly by the Oregon Traffic Safety Commission and the Oregon Department of Motor Vehicles. From 1977 until the present, ASAP has received $64 \%$ of its funds from the oregon Department of Motor Vehicles by virtue of their role in occupational licensing, $13 \%$ from NIAAA, and $23 \%$ from direct client fees, which are assessed by using a sliding scale. (See Appendix A.)

Early each spring ASAP completes its contract negotiations with Multnomah County Mental Health Services, after the County is notified by the State Mental Health Division of the level of funding the County will receive for the next fiscal year. The ASAP budget for 1979-80 was $\$ 410,304$, and for $1980-81, \$ 438,074$.

For 1981-83, the State Motor Vehicles Department and the State Mental Health Division have decided to reduce the funds to ASAP and use some of the Department of Motor Vehicles funds to support the DUII services provided by 
other counties statewide. At the federal level NIAAA funding is also seriously in jeopardy. If the NIAAA funds are withdrawn, coupled with the already stated intent of the State Department of Motor Vehicles and the State Mental Health Division to reduce the level of Department of Motor Vehicles money for the Portland ASAP, the future funding and future of ASAP is uncertain.

The Administration of ASAP

ASAP employs 21 staff under the general direction of an 11-member Board of Directors. The Board members are nominated by the Board's Personnel/Membership Committee, and are chosen from interested persons in the community. The background of the current Board is diverse: the Chair is a Certified Public Accountant, the Vice-Chair a pharmacist and the secretary-Treasurer is a deputy district attorney. The Board of Directors is responsible for setting general policy direction and providing direction and supervision to the Executive Director.

ASAP maintains four standing committees within the Board of Directors: Executive, Finance, Personnel/Membership, and Clinical Committees. The Chair of the Board of Directors is an ex-officio member of all standing committees.

All standing committees, with the exception of the Executive Committee, include a minimum of one non-voting staff member, other than the Executive Director. The 
Executive Director is required to be present at all standing committee meetings.

The Executive Committee consists of the three officers (Chair, Vice-Chair, Secretary-Treasurer) and the immediate past Chair. The Chair of the Board of Directors is also the Chair of the Executive Committee. The Executive committee meets on an "as needed" basis, and is responsible for the hiring and continual review of the Executive Director. This Committee is also responsible for any other specific projects that may be delegated by the Board of Directors.

The Personnel/Membership Committee (PMC) is chaired by the Vice-Chair of the Board. It also consists of three to four Board members appointed by the Chair of the Board. This Committee meets as needed to review and develop the personnel policies of ASAP. The PMC annually reviews the salaries and benefits of employees, in cooperation with the Finance Committee, and functions as a forum for dealing with staff grievances. The PMC is also responsible for the selection and initial interviews of potential members of the Board. The PMC meets with the potential Board member, outlines the functions of ASAP, assesses the candidate's qualifications in light of the current needs of ASAP, and presents the candidate to the Board of Directors for final approval. 
The Finance Committee is chaired by the SecretaryTreasurer of the Board of Directors, and consists of the Executive Director (an ex-officio member) and two or three Board members appointed by the Chairman of the Board. The Finance Committee is responsible for seeking the financial resources necessary to support ASAP and meets as needed to review the past year's budget in preparation for the upcoming year. The final budget must be submitted to, and approved by, the appropriate funding bodies. The Finance Comittee is also responsible for meeting with the Executive Director to prepare the budget for all grant proposals intended for the expansion of ASAP. These proposals must also be submitted to the Board for final approval.

The Clinical Committee consists of three or four Board members, appointed by the Chair of the Board, and the Executive Director, who is an ex-officio member. The Assistant Director is required to attend all Clinical Committee meetings. The Clinical Committee meets as needed with the Finance Committee to review ASAP's proposal of services. The proposal is then submitted to Multnomah County Mental Health Services. The Clinical Committee is also responsible for working with the Assistant Director to review proposals of service for inclusion in grant proposals written for program expansion. The clinical Committee is responsible for reviewing the ongoing 
treatment services provided by ASAP, as well as supporting adequate research methodology with which to evaluate treatment effectiveness.

ASAP is subdivided into five components under the overall supervision of the Executive Director. These components are: treatment, support services, medical, volunteer, and evaluation (see Appendix B).

The treatment component consists of nine counselors (8.3 F.T.E.) under the supervision of the Assistant Director. The educational background of the ten include one each of Master's of Psychology, Bachelor's of Psychology, Master's of Education, Master's of Vocational Rehabilitation, paraprofessional alcoholism counselor, and five Master's of Social Work.

The support services component includes three secretary-receptionists and one accountant. As of September, 1980, the volunteer component consisted of a volunteer coordinator and six volunteers. As of January, 1981, the volunteer coordinator position ended.

The medical component includes one Registered Nurse, now $20 \%$ time, to initiate the pre-Antabuse medical work-up, and two physicians (5 hours a week total) to complete the pre-Antabuse work-ups, prescribe, and do medical follow-up examinations. A psychiatrist works approximately 2-4 hours/month providing case consultation and staff training. 
The evaluation component currently consists of one full-time program evaluator, hired specifically for this evaluation. In addition, a group of 13 Master's candidates from the Portland State University School of Social Work were contracted for this evaluation.

\section{Client Characteristics}

Based on a total client population of 688 for the period of July, 1979, through June, 1980 (Oregon, 1980), the majority of the clients served by the Portland ASAP are white $(88 \%)$ and male $(898)$. Thirty-seven percent are single, with about an equal proportion of married and divorced clients ( $24 \%$ and 228 , respectively), with a smaller proportion of remarried, living as married, and widowed clients. Many have had at least some high school (278), or are high school graduates (33\%), or college/ vocational students $(24 \%)$. Sources of referral to ASAP are predominantly the court system (51\%) and self-referral (31\%). A small percentage of clients were arrested for the second DUII as much as two years prior to entering treatment at ASAP. Average treatment length at termination is 6 months or more $(2486$ months to 1 year, and $27 \% 1$ year and over). More than three times as many clients were terminated by the program as "improved" as opposed to "not improved" (402 to 123 cases). 
Treatment Philosophy

The Portland ASAP's philosophy of treatment is based on four major assumptions: (a) successful treatment depends on a good initial evaluation of the client and the role alcohol plays in his/her life, (b) successful treatment depends on the creation of flexible individual treatment plans, (c) people with alcohol problems are not necessarily alcoholic, and (d) alcohol cannot be dealt with as a singular problem, but it must be the first one addressed.

A comprehensive intake assessment gives the counselor a good idea of the role alcohol plays in the client's life, and facilitates the development of a treatment plan that provides effective intervention. Included in the evaluation is information concerning repeated problems in areas of the client's life related to alcohol, and family history of alcohol use or abuse. Also considered are an increase in physical tolerance or physical problems related to alcohol, and the social environment in which the client uses alcohol.

The development of individualized treatment plans recognizes that people with alcohol problems are an extremely heterogeneous group. Just as there is no single type of person susceptible to an alcohol problem, there can be no single treatment prescription. 
The recognition of the problem drinker as separate from the alcoholic is the third assumption of ASAP's treatment philosophy. This assumption stresses the difference in degree that exists between a person with alcohol problems and an alcoholic. The problems caused by drinking in the client's life, the amount of drinking done, and the patterns of drinking are central to this distinction. When, where, why, and with whom does the client drink? Has the client lost control of his/her drinking? Does the client evidence signs of physical addiction to alcohol such as blackouts, withdrawal, or "DT's"? These are questions that must be addressed with each individual to adequately assess the role of alcohol in his/her life (Echols, 1980).

The fourth assumption of ASAP's treatment philosophy is the identification of alcohol as the immediate problem. This assumption recognizes that, while some people can control the influence of alcohol on various areas of their life, frequently alcohol can become integrated with many other types of inter- and intra-personal problems. Some examples of this might be seen in alcohol related marital problems, loss of self-esteem, and poor employment performance. While marital satisfaction, self-esteem and job productivity are all significant issues to be dealt with in treatment, it would be much harder to resolve such difficulties if the client were persistent in the 
maladaptive use of alcohol. There is widespread conviction in the field of alcohol treatment that, once the problem with alcohol is resolved, other problem areas in the client's life seem to improve, if only because the client's judgement and problem solving skills are no longer impaired by alcohol. Thus, although several problem areas in a client's life may be treated concurrently by ASAP, primary attention is given to the resolution of the client's drinking problem (Echols, 1980).

\section{Intake Procedures}

A little over $1 / 2$ of ASAP clients are court referred after two DUII arrests for pre- or post-sentence evaluation and/or treatment. The pre-sentence evaluation takes approximately 30 days, and includes at least two to three visits to ASAP as well as follow-up collateral contacts. Written permission is obtained from the client to allow ASAP to contact three significant others as collateral sources of information about the client. These sources must be acceptable to the counselor as well as the client. The treatment plan is developed through a joint effort of the individual ASAP counselor and client, with the counselor having the right to terminate the client if the treatment plan is not adhered to by the client. The length of time in treatment is usually not specified. However, the average time is 9 to 10 months and the client 
may be monitored longer by ASAP if an occupational license is involved.

When the treatment plan is formulated, it may include group, couple, or individual counseling, and/or Antabuse. Detoxification may be arranged with local in-patient facilities. A requirement for abstinence for 3 to 6 months is not unusual. Additionally, all clients attend a 3-hour orientation prior to the first evaluation interview, to complete personal history forms, the Michigan Alcohol Screening Test, and to learn about the agency.

\section{Counseling}

Treatment at ASAP is moving away from individual counseling toward group counseling. As discussed earlier, this change is due both to research suggesting the efficacy of group treatment for alcohol problems and cost effectiveness issues. Group treatment seems to facilitate the resolution of denial more effectively than individual counseling. Within a properly functioning group, the person with an alcohol problem will be confronted, as well as supported, to a higher degree by other group members dealing with similar issues. The client, hopefully, will be able to gain a new perspective on his/her use of alcohol when seen in comparison to other clients' problems. The basic focus of treatment is to start where the client is initially in his/her drinking behavior. The processes of denial are worked through to bring the 
client to awareness of his/her alcohol usage patterns. Only then can the client be helped to develop alternatives to coping with problems by alcohol consumption.

Available group treatment options at ASAP include an ongoing 4-week alcohol education group which challenges the clients to think seriously about their alcohol use. Participation in this group is required of all ASAP clients. Other treatment groups include a couples' group, a young men's group, a gay group, a support/sobriety group for people who have decided they can no longer drink, a socialization group to promote ways of socializing without alcohol, and an 8-week, controlled drinking group for clients who wish to develop skills for controlling, without entirely relinquishing, their use of alcohol. A monthly group that monitors social or controlled drinkers with an occupational license is also provided. The majority of these groups were started in the fall of 1980 and in the early months of 1981 .

\section{Antabuse}

Although Antabuse is not being used as much as in the past, it is seen as a treatment option to aid those clients who physically need a break from their ongoing abuse of alcohol and who cannot stop drinking without the temporary assistance Antabuse provides. At the height of its use 2 to 3 years ago, $75 z-80 z$ of ASAP's clients were placed on Antabuse, and it was a mandatory condition 
for those who needed an occupational license recommendation (Grider, 1980). Due to research indicating possible harmful side effects from long-term use, the American Medical Association has cautioned against prolonged usage. Currently, the Portland ASAP has approximately 148 of its clients on Antabuse (Grider, 1980). ASAP offers the treatment option of Antabuse only to those clients who can physically tolerate it and can be trusted not to try to drink over it. The client is required to obtain a medical check-up performed by ASAP's medical staff, which includes a blood test and EKG. The check-up is required prior to beginning Antabuse treatment, and periodically during treatment. Also, medical check-ups are available, as needed, to any client who experiences unusual side effects. In addition, Antabuse is provided only in conjunction with some form of on-going counseling.

Services to the Chronically Mentally Ill

ASAP also provides some services to chronically mentally ill (CMI) clients who have alcohol problems. Although servicing the CMI population is not a key focus of ASAP, there is a shortage of services for them in Multnomah County. Treatment with this population primarily utilizes individual counseling and medication monitoring. 


\section{Future Developments}

Future plans for ASAP treatment focus on the development of more treatment groups and more coherent treatment plans. The volunteer component is developing more social/ recreational, educational, and support groups. Ongoing staff training in the assessment of clients and treatment in small groups is currently being emphasized. The objective is to develop a more systematic and effective treatment structure.

Relationship to Other Community Alcohol Treatment Agencies

ASAP is a member of the Local Alcohol Planning Committee which consists of all contracted alcohol treatment providers in Multnomah County. The Committee is legislatively mandated to assist the county in planning for adequate service delivery. It includes the administrators of the various community treatment agencies and an equal number plus one of non-social service community members.

ASAP is also a member of the Metropolitan Council on Alcoholism which consists primarily of community members, plus a smaller number of service providers. The Metropolitan Council would prefer to be an umbrella agency for Multnomah County alcohol treatment service providers, as it believes that it would be able to provide better access to various services and funding sources than is 
currently provided under the authority of the Department of Mental Health.

One of ASAP's current goals is to increase its use of other agencies in order to provide complementary or more beneficial treatment options. ASAP also functions as a resource for other treatment agencies that do not provide such services as occupational licensing or medical screening for Antabuse. The utilization of other agencies is dependent upon the individual case requirements, to be negotiated between counselor and client. Occasionally, an ASAP counselor and a counselor from another agency will consult with each other, on an as-needed basis, concerning a mutual client.

Previous Studies of the Portland ASAP

Since its inception, ASAP has been involved in several evaluations. The studies range from Federal Department of Transportation evaluations of the multi-state ASAP projects to evaluations of the local ASAP program. Recidivism with regard to re-arrest rates for DUII and the efficacy of Antabuse treatment have been the dominant foci of these evaluations. There has been no longitudinal study encompassing the changing functions and roles of the Portland ASAP.

In 1975, a study entitled Collections of Past ASAP Data and Preparation of Antabuse Studies for Oregon ASAP, Levels II-IV was prepared for the Department of 
Transportation by Noel Kaestner of the Oregon Traffic Safety Commission. The intent of the study was to determine the effect of Antabuse treatment on DUII recidivism and accident rates. In this study, the researchers examined the driving records of 104 clients who took Antabuse regularly. Records were chosen randomly from 1,146 clients who had been involved with the ASAP Antabuse program since April, 1971. Criteria for selection were that the client have: (a) supervised treatment with Antabuse for approximately 1 year, (b) received no other treatment from ASAP, (c) no 5 day intervals between dosages, and (d) generally evidenced a high level of cooperative behavior. An untreated control group of 58 clients was utilized. The clients in the control group experienced identical intake and evaluation procedures and were then referred back to court with a recommendation of "no involvement with ASAP." The results showed no overall difference in accident rates between the two groups.

In 1976, a study titled Description and Evaluation of the Portland ASAP Antabuse Program was conducted by Martha A. MCClay and Thomas S. Manaugh of the Alcohol Treatment and Training Center in Portland, Oregon. The study examined recidivism rates for arrests for DUII and accident rates for both a control and experimental group. Both groups consisted of a randomly selected sample of 30. The experimental group was selected on the basis 
of the following criteria: (a) client was evaluated by ASAP and determined to be a problem drinker, (b) client obtained an occupational driver's license through participation in the ASAP Antabuse program, and (c) client was terminated from the ASAP Antabuse program as "treatment complete." The control group consisted of clients who had been identified as problem drinkers by ASAP, but were not subsequently involved in treatment after their initial evaluation by ASAP. They were matched with the 30 experimental subjects on the variables of age, sex, race, marital status, and years of education. (The control group subjects were also part of a control group in a prior study by Inskeep, Keil, Vaught, \& Warmington in 1973.)

Driving records for both groups were examined for DUII arrests and alcohol-involved traffic accidents for 1 year prior to the arrest which brought the client to ASAP. During this period, both groups showed a total of two DUII arrests and two accidents. Thus, there were no significant differences between the two groups on this variable prior to the study. The number of accidents and DUII arrests for both groups was also examined during a "post-evaluation" period, defined as the time between the initial evaluation by ASAP and the date when the driving records were examined. The results showed no significant differences between treatment and control groups in either recidivism or accident rates. The 
difference in numbers of DUII arrests was significant $(p=.046)$, and the study concluded that the ASAP Antabuse program had a significant impact on lowering DUII arrests. An unpublished in-house study of the Portland ASAP was conducted in 1978 to evaluate changes in client characteristics in four areas: (a) drinking level, (b) employment, (c) living status, and (d) criminal status. Demographic statistics, occupational licensing, and length of treatment were also noted. The sample consisted of 50 randomly selected active cases. The findings indicate that in the first area, drinking level, 748 of the cases showed improvement or a decrease in drinking level after involvement with ASAP.

The second area of evaluation was employment. Results indicated that ASAP clients tended to have relatively stable work records. Of the 50 cases examined, $14 \%$ reflected a move toward more stable employment while $4 \%$ reflected a move toward less stable employment after involvement with ASAP.

In the third area, living arrangements also appeared to become more stable for some ASAP clients. The results indicated that $76 \%$ of the sample showed no change in living situation, 208 showed a change toward more stable living arrangements, and 48 showed a change toward less stable living arrangements. 
The final area of evaluation was criminal status, which indicated the average number of DUII arrests over the last 5 years to be 2.18. Of the total sample, three (68) incurred other arrests while involved with ASAP (that were known to the program); two of these involved driving with a suspended license, and one for DUII.

In summary, this study showed positive improvement in the study population. Involvement with ASAP reflected positive changes across the four areas of drinking level, employment stability, living situation stability, and criminal status.

One year later, in 1979, another in-house evaluation of the Portland ASAP was undertaken by the Executive Director, and resulted in an unpublished report to the Board of Directors. This study examined records of clients who had entered and terminated as "treatment complete" from the ASAP program during the 3-year period of July 1 , 1975 to June 30, 1978. Specifically, data was drawn from records on four separate occasions during this time period. The findings indicated that length of treatment for the 1975-76 and 1976-77 groups was 1 year and over in the majority of cases (778 and 648 , respectively). These results were interpreted as reflecting the common practice of placing the majority of persons involved with ASAP on Antabuse for 1 year. Length of time in treatment decreased in the subsequent 1977-78 group; the majority 
(70\%) of cases being treated for 6 months to 1 year. This finding was seen as reflecting ASAP's decreasing use of long-term Antabuse treatment.

This study also examined preferred modes of treatment. There were five primary modes of treatment examined in the study: (a) Antabuse only, (b) Antabuse plus followup, (c) Antabuse plus counseling, (d) follow-up only, and (e) counseling only. The results indicated that the preferred treatment modality during 1975-76 was fairly evenly distributed between the categories of "Antabuse only" (28\%), "Antabuse and follow-up" (30\%), and "Antabuse and counseling" (30\%). During the 1976-77 period, the combination of Antabuse and follow-up was the primary treatment modality $(708)$. During the $1977-78$ period, the Antabuse and follow-up method was utilized in $40 \%$ of the cases, and the follow-up only in 308. Thus, the majority of cases were involved in the Antabuse program with periodic follow-up.

This study also examined DUII arrest rates. With regard to DUII arrests before involvement with ASAP, the majority of cases had two or more DUII convictions across all three groups examined, with two convictions the most common occurrence. Of the total 117 cases for whom DMV records were obtained, ten cases (9\%) had a DUII conviction after termination from ASAP. Length of treatment with ASAP for those re-arrested showed 408 for 6 months to 
1 year, and 608 for 1 year and over for the 1975-76 group. The 1976-77 group and the 1977-78 group both showed a length of treatment by ASAP of 1 year or over for those rearrested.

The overall results of the study indicate that Antabuse or Antabuse combined with follow-up was the preferred treatment modality, while the most common length of treatment was 6 months to 1 year or over. Of the cases examined, the majority had two or more DUII convictions upon entering ASAP, while 98 incurred another DUII conviction after termination from ASAP.

These four studies indicate a trend toward more positive results from involvement with ASAP. The 1975 study showed no significant difference between treatment modalities. The 1976 study showed involvement with ASAP to have a significant impact on lowering DUII arrest rates. The 1978 study showed positive changes in drinking levels, employment and living situation stability, and DUII arrests. In addition, the 1979 study indicated improvement in DUII arrest rates.

\section{Summary}

The Portland ASAP originated in 1970 as part of a federal Department of Transportation project, and has the goals of promoting public safety and community education. ASAP serves a predominantly white, male, middleaged, court mandated clientele. Services at ASAP include 
evaluation and assessment, group and individual counseling, occupational licensing, and medical treatment (Antabuse). Past studies of ASAP are inconclusive as to treatment effectiveness. As noted in the previous chapter, most evaluative studies of alcohol programs have been fraught with methodological problems. The present study is more rigorous methodologically than any conducted of ASAP to date. 


\section{CHAPTER III}

\section{METHODOLOGY}

\section{Design}

This is a descriptive study of the Alcohol Safety Action Program (ASAP). The study is non-experimental, employing a successional one group pretest-posttest design. The independent variable is the provision of ASAP treatment. The dependent variables are: (a) improvement in the client's quality of life, and (b) client satisfaction with services provided by ASAP.

This particular design was chosen because: (a) ASAP was interested in an evaluation which was not narrowly focused on drinking behavior, but on the overall impact of ASAP treatment on the lives of its clients, (b) it was the methodology used by the Program Impact Monitoring System (PIMS), and (c) PIMS agreed to provide free technical assistance, monitoring, scoring, and analysis of data. PIMS is part of a comprehensive statewide program evaluation system developed by the Oregon Division of Mental Health (Bigelow, Brodsky, Howard, Olsen, Smith, \& Stewart, 1980). The 90-day evaluation reported in the present study will be followed by a 270-day evaluation bý ASAP. 
Sampling Plan

The sample for the present study consists of all ASAP clients who were seen for intake between April 15, 1980 and July 15, 1980. Those clients who came in no more than once after intake within the first 30 days were excluded from the sample. Twenty-nine clients were so excluded. Based on research done by Gerard and Sanger (1966), it is assumed that consecutive sampling yields a sample of representative clients. These researchers interviewed consecutive new admissions to out-patient alcoholism clinics and then compared that sample to all other patients. They found that the patients did not vary significantly on important variables such as age, marital status, education, occupation, and duration of alcohol problems.

The intake group in the present study consisted of 113 clients. The follow-up group (seen 90 days following intake) consisted of 89 clients. Thus, 798 of the original sample was interviewed at the time of followup with $21 \%$ being lost.

The 24 lost cases fell into five categories:

(a) cancelled and not rescheduled (7), (b) refused to do the interview (7), (c) left the program or area (4), (d) no contact as they were unreachable (4), and (e) other (2). Several trends which may explain client loss were noted within the above categories. In the "cancelled" 
category, many appointments were made and subsequently cancelled, with the window period ending prior to obtaining the interview. Two trends were noted within the "refused" category. First, several clients exhibited mixed feelings regarding the follow-up interview and finally did verbalize a refusal before the end of the window period. Second, several clients exhibited marked, hostile feelings about the follow-up interview, stemming from their feelings about ASAP in general, and refused to do the interview from the onset. In the "other" category, each client had a unique set of circumstances which did not allow for a common trend to be observed.

The follow-up sample of 89 is described in Appendix C. Eighty-five percent of the sample is male. The age range is between 18 and 67 , with a mean of 37 years. Eighty percent were mandated to ASAP for treatment while 208 came voluntarily. Ninety-two percent of the sample is white with $8 \%$ being minorities. In terms of social living situation, $17 \%$ live alone, $12 \%$ live with parents, 388 live with spouses, and 338 live with friends, relatives, or in a mandated living situation. The mean gross household income is $\$ 13,000$, with a range of $\$ 0$ to $\$ 84,999$.

In order to evaluate the representativeness of the sample, it was compared on demographic variables with both lost and excluded cases. As shown in Appendix $C$, there were more minorities in the lost cases than in the 
excluded cases or the sample. One other trend was that more people in the excluded cases were living alone or with parents.

The 89 follow-up subjects were seen at ASAP an average of five times; the number of visits ranged from one to ten. Ninety-six percent of the sample received individual counseling as their primary treatment with 38 receiving group counseling and 1 \& receiving couples counseling. In terms of secondary treatment, $4 \%$ received individual counseling, $35 \%$ group counseling, 28 couples counseling, $7 \%$ medication services, and $1 \frac{8}{6}$ brokerage services. Fifty-one percent did not receive secondary services.

Data Gathering Methods

Data for the present study was gathered by utilizing two instruments, the Demographic Data Questionnaire (DDQ) and the Oregon Quality of Life Questionnaire (OQLQ) (see Appendix $\mathrm{D}$ and $\mathrm{E}$ ). These instruments were administered 1 hour prior to the intake interview by ASAP's Evaluation Project Director, and at follow-up by eight selected interviewers of the research group. All interviewers were trained in the administration of the OQLQ by attending a $3 \frac{1}{2}$-day intensive session conducted by the research staff of Oregon's Mental Health Division. Training included small-group lecture, role-play, and videotape. Each 
interviewer was given a test at the end of training and passed by receiving at least a $95 \%$ reliability rating.

After the completion of their training, cases were assigned to the eight interviewers on a random basis. once assignments were made, a minimal number of cases were traded between interviewers due to scheduling problems.

For the 90-day follow-up, all clients were interviewed within a 17-day window period, between 82 and 94 days after intake. To insure that as many clients as possible were interviewed within the specified follow-up period, a number of procedures were followed. Each interviewer began locating the client 1 week prior to the 17day window period. The interviewer checked the client's referral form (see Appendix F) for information on how to contact the client. If a client's phone number was available, the interviewer attempted to call the client at least five times, at different times of the day and on different days of the week. If a client could not be reached by phone or at the address, a form letter (see Appendix G) was sent to the address, requesting the client to schedule an appointment for an interview. Prior to considering a client "unlocatable," the interviewer followed the above described procedures as well as: (a) checked the reference record for phone numbers, addresses, and other contacts, (b) called local public 
agencies, (c) checked local jails, and (d) visited places where the client was "known to frequent." If the interviewer had a question about locating or interviewing a particular client, he/she could check with the client's counselor. The counselor could advise against the interview if a client was thought to be in a clinically precarious state and might be disturbed by the interview. Each interviewer was responsible for reporting the progress of their cases to the coordinator on a weekly basis. If the interviewer were unable to complete the interview prior to the end of the window period, he/she prepared a written report explaining attempted client contacts (see Appendix H). The report was given to the Evaluation Project Director and Assistant Project Coordinator to alert them to begin trying to contact the client. As a result of intensive efforts of the coordinator over the remainder of the window period, the loss of several cases was prevented.

All interviews were conducted without a third party present, and every effort was made to conduct the interviews at ASAP. However, eight follow-up interviews were conducted elsewhere: five at the client's home, two at the client's place of employment, and one at the jail.

The interviewer first asked the questions contained in the DDQ and then obtained informed consent to administer the OQLQ. The client was given a copy of the consent 
form (see Appendix I), and was asked to read along while the interviewer explained the content of the form. If a client indicated a full understanding of the interview process and consented to proceed, a signature was obtained. The interviewer then gave the client a brief explanation of the OQLQ interview. The client was told that the questionnaire was designed to get his/her personal opinions and perceptions of what was going on and that there were no right or wrong answers. The response format of the OQLQ was explained by stating the following five points in the order shown:

(1) "The questionnaire is arranged in question and answer format."

(2) "The answers range from least to most with 'none of the time' being least and 'all of the time' being most."

(3) "The reason I am here is to answer any questions you may have about these questions."

(4) "I'll need you to choose the answer that most closely fits your situation."

(5) "Sometimes no answer will really fit. In that case, I'll still need you to choose the closest answer."

The OQLQ was then read and scored by the interviewer in the presence of the client, who was asked to follow along as questions and answer choices were read. Any 
additional comments made by the client during the program variable component of the questionnaire were written down by the interviewer.

\section{Instruments}

The DDQ, a three page questionnaire, was designed to obtain information on the client's age, sex, ethnic group, social and physical living situation, history of long-term hospitalization, reason for coming to ASAP, presenting problem, and annual gross household income. The follow-up DDQ included, in addition, data on treatment status, primary and secondary services received since intake, amount of services rendered, and a clinician rating of success. The clinician rating of success (see Appendix J) was filled out by the client's counselor on a separate form, and was coded on the DDQ after the follow-up interview was completed.

The OQLQ, an 18 page questionnaire, is composed of questions which have a structured set of alternative answers. Developed specifically for oregon in 1978, this instrument attempts to measure the impact of treatment by "assessing performance and satisfaction in the range of specific areas of individual-environmental interaction" (Bigelow et al., 1980, p. 19). It was designed to be used as an instrument of program evaluation, not as a psychological measure attempting the comparison and appraisal of individuals. 
The theoretical framework on which the OQLQ is based is the Quality of Life Theory, which provides a social adaptation perspective. According to this theory, the individual is viewed within the context of his/her environment, and the individual and environment are seen as interacting in a kind of exchange economy. The individual is perceived as having needs, while the environment provides the opportunities through which needs are met. Along with these opportunities, there are certain demands or performance requirements. Adjustment is defined as an individual's ability to satisfy his/her needs through environmental opportunities. Accordingly, "to the extent that adequate satisfaction and performance are achieved, the individual is adjusted to his environment and enjoys a good quality of life" (Bigelow et al., 1980, p. 12). This theoretical framework allows for a view of client problems as "deficient abilities, insufficient opportunities or excessive performance requirements" (Bigelow et al., 1980, p. 5).

Four groups of scales are used on the OQLQ to assess client variables: (a) personal adjustment, (b) interpersonal adjustment, (c) adjustment to productivity, and (d) civic adjustment. Personal adjustment includes psychological distress, tolerance of anxiety and depression, basic need satisfaction, and independence. Interpersonal adjustment includes interpersonal interactions, isolation, 
spouse role, and social support. Adjustment to productivity includes work at home, employability, performance, and other constructive activities. Civic adjustment includes legal, alcohol, drugs, and use of community resources.

The program variables included in the OQLQ are: (a) helpfulness of therapist's approach, (b) helpfulness of the Program, (c) client satisfaction, (d) perceived program impact on the above scales, and (e) non-program items such as helpfulness of friends, family, and religion. For specific items included in each category mentioned above, see Appendix $\mathrm{K}$.

The originators of the instrument state that the OQLQ has face validity. It is their opinion, based largely on common sense, that the instrument measures each scale according to its content name and that the items are easily understood by the intended population. A discriminant analysis was completed and the results indicate that affective status, psychological well-being, and psychological distress all have strong face validity; independence and meaningful use of time are satisfactory, and all remaining items are found to be weak. A survey of the opinion of other experts in the field has not been made regarding face validity. No clear standards of measurement exist for evaluating the OQLQ, so data on 
validity, based on experience with the instrument, is quite limited (Bigelow et al., 1980).

The OQLQ does appear to have high inter-raterreliability because of the standardized training of the interviewers. In addition, reliability testing of the interviewers had to be at least 958 before they could begin conducting actual interviews for this study.

\section{Data Analysis Plan}

This study utilized statistical analysis of grouped data. Comparisons were made between intake and follow-up data on scale scores and demographic variables. Comparisons were also made between ASAP, PIMS statewide sample, and PIMS community sample. The statewide sample is made up of clients from 18 western Oregon counties. These clients are involved with agencies because of mental and emotional disabilities, alcohol or drug problems, or because they are chronically mentally ill. The community sample is made up of 100 people from both rural and urban areas of western Oregon plus 60 more from recent research done in western Oregon (including Multnomah, Marion, Polk, Yamhill, Linn, and Benton counties). Finally, comparisons were made between ASAP and other alcohol programs within the clinical statewide sample with regard to demographic variables and scale scores at intake and follow-up.

Cross-tabulations were used to analyze the following: (a) demographic data, (b) client opinions about therapist, 
program, and other factors, and (c) client satisfaction with specific aspects of the program. One-way analysis of variance was utilized in the comparison of groups on scale scores, which controls for age. The level of significance used for all tests was .02 . Due to the large number of comparisons being made, chance alone at .05 would have shown many more significant differences where they really did not exist. 


\section{CHAPTER IV}

FINDINGS

\section{Introduction}

This chapter includes the statistical findings of the study, followed by discussion of possible interpretations and implications of the findings. To properly interpret the statistical tables provided, it is important to note that a high scale score represents better adjustment than does a low scale score. It should also be noted that probabilities are Iisted only for those categories on Tables I and IX (Appendix I) where a significant difference has been found. Significance levels are not included on Tables II and VIII (Appendix L) as the information is not available. Statistical comparisons are made between the ASAP sample and the statewide, Community, and Other Alcohol programs samples. The Statewide sample is composed of similar proportions of outpatient mental health, institutionalized, and other alcohol programs. The Community sample is composed of a random sample of 160 Oregon residents living in six different counties. The Other Alcohol Programs sample is composed of clients receiving treatment in oregon alcohol programs other than ASAP. In this text, the term alcoholic is used, for 
purposes of simplification, to describe individuals receiving treatment for possible alcohol problems. This includes social drinkers, problem drinkers, and alcoholics.

\section{OQLQ Scale Scores}

As shown on Table I (Appendix L), the ASAP loss is $21 \%$ of the sample at follow-up, whereas the statewide loss is 45\%. ASAP has proportionately fewer females in comparison with the statewide and Community samples. The ethnic distribution is similar among the three groups as all are greater than 908 white non-Hispanic. The data also indicates the Community sample is more likely to be living with spouse than the ASAP or Statewide samples. The Community sample is more likely to live in a single family dwelling while ASAP clients are more likely to reside in apartments. A substantial number of those in the Community sample are married or living as married in comparison to both the ASAP and statewide groups.

Table II (Appendix L) compares the demographic variables between ASAP and Other Alcohol Programs, the latter representing 398 of the Statewide sample. In the Other Alcohol Programs, $51 \%$ of the cases are lost at follow-up, which is much greater than the $21 \%$ loss experienced by ASAP. The mean age of both groups is similar; however, there are fewer females in the ASAP sample. It should also be noted that the ASAP sample is composed of 798 mandated clients at intake, which reflects a much 
larger percentage than the $55 \%$ mandated clients in other Alcohol Programs. At follow-up, the ASAP percentage of mandated clients remains greater than that of other Alcohol Programs. ASAP clients also receive more services (a mean of 5.3 contacts) than those in Other Alcohol Programs (a mean of 4.4 contacts).

On Table III (Appendix L), ASAP scores at intake are higher than statewide on 14 of the 15 scales. Of these 14, 11 are significantly higher. The 11 significantly higher scores are Personal Adjustment, Psychological Distress, Psychological Well-Being, Affective Status, Tolerance of Anxiety and Depression, Independence, Interpersonal Interactions, spouse Role, Adjustment to Work at Home, Employability, and Other Constructive Activity. On the Basic Need Satisfaction scale, the ASAP sample scores are lower than the statewide scores, but not significantly so.

As shown on Table IV (Appendix L), there are 20 follow-up scales. Follow-up ASAP scores are higher than statewide on 12 scales and lower on eight scales. Of the eight scales showing a significant difference, ASAP scores are significantly lower on Program Impact on Personal Adjustment, and significantly higher on Personal Adjustment, Psychological Distress, Psychological We11-Being, Affective Status, Tolerance of Anxiety and Depression, Interpersonal Interactions, and Spouse Role. The low N's on Table IV 
(Appendix L) are due to scoring decisions made by the statistician. Certain questions were dropped, primarily because of a less than 508 response rate.

As seen on Table $\mathrm{V}$ (Appendix L), ASAP intake scores are higher than the Community sample on six scales and lower on nine scales. Six of the 15 scales show significant differences. ASAP scores are significantly higher on Psychological Well-Being and Employability, and significantly lower on Tolerance of Anxiety and Depression, Total Basic Need Satisfaction, Social Support, and Negative Consequences of Alcohol Use.

On Table VI (Appendix L), ASAP follow-up scores are higher than the community sample on nine scales and lower on six scales. The Community sample scores are significantly higher on Total Basic Need Satisfaction, Social Support, and Negative Consequences of Alcohol Use, while ASAP scores are significantly higher on Psychological Distress.

As seen on Table VII (Appendix L), ASAP scores improve between intake and follow-up on nine scales and decline on six scales. Positive change is reflected on the following scales: Personal Adjustment, Psychological Distress, Affective Status, Tolerance of Anxiety and Depression, Total Basic Need Satisfaction, Interpersonal Interactions, Spouse Role, Negative Consequences of Alcohol Use, and Negative Consequences of Drug Use. The only 
scale showing a significant positive change is that of Negative Consequences of Alcohol Use. Negative change is seen in Psychological Well-Being, Independence, Social Support, Adjustment to Work at Home, Employability, and Other Constructive Activity.

On Table VIII (Appendix L), the ASAP sample size decreases by 218 at follow-up and the Other Alcohol Programs sample decreases by $51 \%$. When comparing intake and follow-up scores, ASAP clients improve on nine of 15 scales while clients of Other Alcohol Programs improve on all of the 15 scales. The comparison of scores at intake between ASAP and Other Alcohol Programs shows ASAP to be higher on 12 scales and lower on three scales: Tolerance of Anxiety and Depression, Total Basic Need Satisfaction, and Negative Consequences of Drug Use. At follow-up, five additional scales representing client opinion on program impact are included on the table. ASAP follow-up scores are higher on 12 scales and lower on eight scales. Five of the scales on which ASAP scores are lower reflect client report on program impact: Program Impact on Personal Adjustment, Program Impact on Interpersonal Adjustment, Program Impact on Adjustment to Productivity, Program Impact on Quality of Life, and Client Satisfaction. Between intake and follow-up the ASAP numerical increases are smaller than those for Other Alcohol Programs except on three scales: Tolerance of 
Anxiety and Depression, Spouse Role, and Negative Consequences of Drug Use.

Bar graphs (see Table X, Appendix L) are used to descriptively show the data on Table IX (Appendix L), which represents client opinion on Treatment Related Factors. Four percent of the ASAP and State sample responses on the summary graphs indicated Treatment Related Factors are "harmful." Thirty-eight percent of the ASAP sample indicate "no effect" while the figure for Statewide is $26 \%$. It is also noted that $58 \%$ of the ASAP sample and 708 of the statewide sample indicate items are "helpful." On the Therapist Related Items, the percentages are very close for all categories. "Harmful" responses are equal at $1 \%$ for both. The "no effect" responses are ASAP $17 \%$ and Statewide 15\%. The "helpful" responses are ASAP $82 \%$ and Statewide $84 \%$. On the graphs showing statistically Significant Items, the "harmful" category reveals 88 ASAP responses and $5 \%$ Statewide responses. The "no effect" ASAP response rate is 548 and the Statewide rate is $31 \%$. ASAP responses on the "helpful" category are 388 while the Statewide responses are $63 \%$.

Table XI (Appendix L) provides data regarding the percent of client satisfaction with ASAP for selected items of the OQLQ. The figures reflect an overall high degree of client satisfaction, ranging from 828 to 998 
in all areas except Medications (798), Access to ASAP (698), and Fee Assessment (788).

The graph shown on Table XII (Appendix L) illustrates client opinion on program impact as compared with clinician Rating of success. At follow-up, ASAP clients were asked their opinions of Program Impact on Personal Adjustment, Interpersonal Adjustment, and Adjustment to Productivity. "Improved" is the response given 258 of the time; "no effect," 738; and "worsened," 28. The Clinical Rating for success for the clients is as follows: "satisfactory," 398; "neither satisfactory nor unsatisfactory," 40\%; and "unsatisfactory," 218.

\section{Item Responses}

Six item responses (also included in scale scores) show significant differences between intake and follow-up and all six show improvement. They are responses to the questions: How much difficulty have you had handling feelings of depression? (Item \#22), In the last month, how much time did you miss from work? (Item \#124), Have you had anything alcoholic to drink in the last month? (Item \#161), In the last month have you had problems with your feelings (guilt, anger, depression) because of drinking? (Item \#164), In the last month have you had problems with your health because of drinking? (Item \#165), and, In the last month have you used counseling/guidance services (doctor, church, etc.)? (Item \#202). 


\section{Discussion}

On Table I (Appendix L), the higher percentage of males in the ASAP sample would appear to be explained in the literature review entitled Management of Drunken Driving offenders. The studies cited in that review show that more men than women are arrested for drunken driving. The high percentage of white non-Hispanic persons in all three samples would seem to be consistent with the low minority population of oregon. The greater percentage of those in the Community sample who are living in a single family dwelling and married and living as married may indicate lower mobility in the Community sample in comparison to the ASAP and Statewide samples. It is also noted, however, that the ASAP clients are drawn from a metropolitan area where there are more apartments than in predominantly rural counties from which the Community sample is derived.

As seen on Table II (Appendix L), the ASAP sample at intake has approximately $1 / 3$ more mandated clients than the Other Alcohol Programs, which may indicate different motivations for entering treatment. A higher percentage of Other Alcohol Program clients entered treatment voluntarily, which could be due to recognition of personal problems. The smaller proportion of lost cases in the ASAP group may be partially explained by the larger 
percentage of mandated clients in the ASAP sample and the rigorous follow-up procedures.

The data on Table III (Appendix L) could yield several interpretations. The higher ASAP than statewide intake scores might indicate a better adjusted group, perhaps entering treatment at an earlier phase in the alcoholic process. However, one could argue that the higher scores result from denial and resistance to treatment which could be expected from clients whose treatment is mandated. Scores on the Total Basic Need Satisfaction scale, which measure external problems, are low, perhaps indicating a tendency to project difficulties onto the environment. Although no significant difference was found on the Total Basic Need Satisfaction scale on this table, a lower ASAP score on that scale is a trend which is revealed throughout the tables. The significantly higher ASAP Employability score at intake could be expected, as a majority of the ASAP clients work.

On Table IV (Appendix L), ASAP follow-up continues to show higher scores than the statewide sample; however, the Statewide sample consistently shows greater improvement between intake and follow-up scores than does ASAP. Although no significant difference is noted, the ASAP score on Total Basic Need Satisfaction is again low in comparison to the statewide sample. Both of these findings would appear to support the contention noted about 
Table III (Appendix L) regarding denial of alcohol related problems and resistance to mandated treatment. The high ASAP scores may reflect the client's desire to represent him/herself as well adjusted. The fact that ASAP scores are significantly lower on Program Impact on Personal Adjustment and significantly higher on Personal Adjustment, Psychological Distress, Psychological Well-Being, Affective Status, Tolerance of Anxiety and Depression, Interpersonal Interactions, and spouse Role could again reflect overall superior functioning of ASAP clients, hence, less need for program impact. This might be expected if ASAP clients are at an earlier phase in the alcoholic process. It may also indicate a lack of recognition pertaining to personal difficulties; therefore, they perceive no need to improve.

On Table V (Appendix L), ASAP scores are higher on some scales at intake than the Community sample, but the ratio has decreased from 14 high scores out of 15 scales on Table III to six higher scores out of 15 scales on Table V. In contrast to what might be expected for individuals receiving treatment, it is interesting that ASAP clients continue to score higher on some scales at intake even in comparison with the random Community sample. An exception to this trend is that ASAP scores significantly lower on Total Basic Need Satisfaction, which would appear to support the possibility that ASAP clients deny 
problems of internal feelings and perceive difficulties as resulting from the environment. ASAP also scores significantly lower than the Community sample on Negative Consequences of Alcohol Use, which could be the result of alcohol-related legal difficulties or may indicate recognition of some problems with alcohol. However, the high numerical value of that score could also substantiate the denial of problems with alcohol.

As reflected on Table VI (Appendix L), ASAP clients at follow-up continue to show higher psychological functioning in comparison with the community sample on the following scales: Psychological Distress, Psychological Well-Being, Affective Status, and Tolerance of Anxiety and Depression. The Psychological Distress scale score is significantly higher than that of the community. However, the Total Basic Need Satisfaction scale shows a highly significant ASAP score. This relationship again reinforces the possibility that ASAP clients tend to perceive problems as caused by external or environmental phenomena. The ASAP group in comparison to the Community sample also shows significantly lower scores on the Social Support scale which might indicate that the alcoholic group has fewer close relationships. As noted on Table V (Appendix L), the Negative Consequences of Alcohol Use scale is significantly lower for the ASAP sample than for the random Community sample. 
The overall ASAP changes between intake and followup on Table VII (Appendix L), do not seem to indicate major improvement, since only one significantly higher ASAP score is found: Negative Consequences of Alcohol Use. This significant change could represent valid improvement or could be related to legal pressures and a desire by ASAP clients to obtain an occupational license. Even though the differences were not significant, increases are shown on the instrument's most valid scales (Psychological Distress, Psychological Well-Being, and Affective Status), which could be valid indicators of improvement. Table VIII (Appendix L) shows ASAP lost approximately $1 / 5$ of the sample at follow-up and Other Alcohol Programs lost approximately $1 / 2$. This may be due to the quality of treatment at ASAP, more aggressive followup methodology, the tendency of mandated clients to remain in treatment, or some combination of these factors. Clients who are lost at follow-up generally have been found to exhibit less improvement. Since other Alcohol Programs lost more clients at follow-up than ASAP, the Other Alcohol Programs' clients may appear to be doing better because of the large number of lost cases. On the Tolerance of Anxiety and Depression scale, ASAP scores are lower than Other Alcohol Programs at intake and higher at follow-up, which may indicate either an increase in their ability to tolerate stress or a decrease 
in stress resulting from a lessening of legal or other pressures. On the Total Basic Need Satisfaction scale, ASAP client scores are lower at both intake and follow-up than the intake score shown for Other Alcohol Programs. Both groups show improvement. ASAP intake scores are also higher than Other Alcohol Program follow-up scores on the scales which are indicators of internal distress: Psychological Distress, Psychological Well-Being, and Affective Status. Again, this could indicate that ASAP clients reach treatment at an earlier phase in the alcoholic process than do clients in other alcohol programs. On the other hand, the supposition that ASAP clients deny internal distress and place the blame on external factors would appear to be supported. Due to the more voluntary nature of Other Alcohol Programs, those individuals may be more likely to acknowledge the existence of personal problems in comparison to the ASAP clients, a majority of whom are in treatment as a result of court action. The graphs depicting Table IX (see Table $\mathrm{X}$, Appendix L) visually show the percentage of ASAP and Statewide client opinion on certain Treatment Related Factors. The notable differences on the summary graphs are found in the "no effect" and "helpful" categories. Perhaps a larger percentage of the ASAP clients than the statewide clients fall within the "no effect" category because, as mandated clients, they do not perceive a need for treatment and, 
therefore, would be less likely to acknowledge program impact. This may also explain the lower ASAP percentage in the "helpful" category. One must consider, however, the possibility that ASAP clients are accurately assessing the Treatment Related Factors. On the two graphs showing the percentage of response to Therapist Related Items, both samples exhibit similar results. Both reveal very high response rates in the "helpful" category which, for ASAP clients, is not consistent with their predominant trend of indicating "no effect." This could reflect positive feeling for the therapist, while not necessarily perceiving the need for ongoing treatment. The graphs displaying Statistically Significant Items show notable differences between the ASAP and Statewide samples. The large percentage of ASAP clients in the "no effect" category could confirm the denial of a need for change.

Table XI (Appendix L) reflects a high degree of client satisfaction with the agency, as the majority of scores are greater than $81 \%$. The lowest percentage, $64 \%$, is not unusually low, hence, high client satisfaction would appear to be a valid interpretation. Lesser satisfaction on the three items with percentages below 82 could be expected due to the nature of the applicable OQLQ questions. The 798 satisfaction with Medications is computed from a small sample $(\mathrm{N}=14)$, as medications are prescribed for few clients. A lower percentage of 
satisfaction, $64 \%$ with Access to ASAP is understandable because the agency is located in a congested city center. Seventy-eight percent satisfaction with Fee Assessment would actually appear quite high, particularly when considering that the greater percentage of clients are mandated.

The graphs, shown on Table XII (Appendix L), depict Client Opinion of Program Impact and the Clinician Rating of success. At least two of these findings are noteworthy. First, the large number of responses by ASAP clients in the "no effect" category (73\%) could support the notion that clients who were resistive to treatment are now denying the effects of treatment. Secondly, the clinicians' evaluations are not consistent with those of the clients. Clinicians rate $21 \%$ of the clients as "unsatisfactory," while only $2 \%$ of the clients view themselves as "worsened." This finding may reflect client denial as compared to a more realistic professional view. In addition, there is a possibility that this finding is indicative of higher clinician expectations and, thus, a tendency to rate the client more critically. Finally, a third explanation is that these two scales do not measure equivalent dimensions of improvement.

As mentioned previously, when scale items were individually analyzed, a number of significant differences were found between ASAP responses at intake and follow-up. 
At follow-up, there is a significant positive change in the area of handing feelings of depression. The percentage of clients indicating they have some difficulty in this area decreased significantly. This could reflect notable improvement in coping ability, fewer feelings of depression due to a decrease in legal problems, or a decrease in alcohol consumption.

Significant improvement between intake and follow-up is also seen in the amount of time missed from work. The increase from 498 at intake to 698 at follow-up who did not miss any work days in the past month could imply a reduction in alcohol consumption.

Three items relating specifically to alcohol use show significantly positive changes. Twice as many clients at follow-up than at intake reported being abstinent in the past month. In spite of this change, however, $2 / 3$ of the sample at follow-up reported drinking in the past month. Since abstinence is not the goal for all ASAP clients, some improvement in drinking patterns can still be inferred. In support of this interpretation, there was significant improvement shown on the item assessing problems with feelings (guilt, anger, depression) because of drinking. There was significant improvement shown on the item assessing problems with health because of drinking. The follow-up responses on these items reflect 
improvement in alcohol related functioning that would seem to be related to reduced drinking.

Finally, there is a significant increase in the number of clients receiving treatment in addition to that provided by ASAP, at follow-up. At intake, $17 \%$ were receiving additional treatment, while the rate is $32 \%$ at follow-up.

\section{Conclusion}

One could conclude from the statistically significant data that ASAP clients are psychologically healthier than the Statewide sample. While ASAP scores were also higher than the Other Alcohol Programs sample, these scores were not compared for statistical significance, thus only a trend can be noted. It is possible that ASAP clients have entered treatment at an earlier phase of the problem drinking process. In addition, however, ASAP clients appear to be healthier than the Community sample on the most valid psychological scales. Thus, it seems more likely that ASAP clients tend to deny personal difficulties and perceive problems as resulting from external factors which are beyond their control. The consistently low ASAP scores on Total Basic Need Satisfaction would appear to corroborate this interpretation.

The data also indicates that the majority of ASAP clients believe that they have not benefited from treatment. It is possible that they are at an earlier phase in the 
problem drinking process, or view the court order as unfair and, therefore, resist treatment. It is also possible that they deny or fail to recognize the existence of problems and, hence, feel they have little need for improvement. The fact that both the Statewide and Other Alcohol Programs samples scored higher than the ASAP sample on the scales measuring client opinion of program impact could reflect less successful intervention or denial and resistance in the ASAP sample. It is also possible that ASAP clients who receive treatment improve in functioning, but refuse to admit this because of denial and/or resistance to treatment due to their mandated status. The findings of this study have some useful implications for future treatment of clients mandated to alcohol programs. The present findings suggest the importance of confronting the issues of resistance and denial in the early phases of treatment. The denial of alcohol problems and resistance to mandated treatment appear to be the core issues to address. It has long been recognized that denial is the main defense mechanism of the alcoholic. It would seem to be beneficial for the in-service education program to give high priority to this issue. In addition, 968 of this ASAP sample is receiving individual counseling as their primary treatment. An increase in the use of group treatment, based on sound principles of differential diagnosis and group composition, 
would seem to be indicated. The literature review indicates that resistance is dealt with more effectively in a group context.

The findings of this study and the experience of the research group also provide some useful implications for future evaluation of treatment effectiveness. There is no doubt that follow-up of alcohol treatment clients is time-consuming and difficult, requiring a great deal of planning and persistence. The respectable follow-up rate of this study is, at least in part, the result of the utilization of rigorous follow-up procedures by a team of interviewers. This follow-up effort would be difficult and costly to replicate without the use of graduate students.

Fortunately, recent innovations in evaluation technology such as the incorporation of research into ongoing therapeutic activities seem to promise highly successful, cost-efficient follow-up with valid and reliable selfreports. Further research is needed to substantiate these claims, however. Progress in this field would be hastened by investigations of these new approaches. 


\section{CRITIQUE OF THE PRESENT STUDY}

Design

As discussed earlier, this study utilizes a successional one group pretest-posttest design in which the independent variable is the provision of ASAP treatment and the dependent variables are (a) improvement in the client's quality of life and (b) client satisfaction with services provided by ASAP. Because all clients received on intake during the study period between April 15, 1980 and July 15, 1980 were offered treatment services by ASAP, the study does not employ the use of a control group.

The absence of a control group for this study poses several problems with validity. First, the internal validity of the study is jeopardized because the dependent variables are subject to the influence of confounding variables; in particular, the intervening history and test-retest effects. Secondly, the generalizability of the findings is hampered by the design. An ASAP agency with similar treatment methods and a similar population might find these results relevant. However, in general, the study findings can be considered pertinent only to this particular study population.

Sampling Plan

The present study sample is solely representative of the clients who came to treatment at ASAP during this 
period of time. It cannot be considered representative of clients in other alcohol treatment agencies nor can it be considered representative of the alcoholic population not involved in treatment. This sample has been subjected to a number of biasing effects. The subjects included may be affected by arrest and enforcement practices in this area and, therefore, may represent only those who do get arrested in the Portland area. In addition, although many of those referred to this agency were mandated to treatment by the court for drunk driving offenses, a number of clients were self-referred. It is possible that differences exist in motivation between mandated and voluntary clients. If differences are significant, it could bias findings about the sample group.

A possible additional source of bias involves cases lost and excluded from the study. Although this does not comprise a large number, it is important to take into consideration significant differences between these groups and the larger sample. (See Appendix C.) While differences exist between the interviewed sample and lost and excluded samples in ethnicity and social living situation, these differences are not considered significant enough to bias the findings.

\section{Data Gathering Method}

The standardization provided by the interviewer training and the structure in the administration of the 
instruments support the reliability of the data collection process. The interviewers related one limitation which might have influenced the sample population. Interviewers were instructed during their training to begin contacting clients 1 week prior to the 17-day window period for the 90-day follow-up interview. Some interviewers did not start contacting clients early in this week. When the clients of these interviewers had moved, in some cases sufficient time did not remain in the window period to locate them. This factor, in combination with others, may have influenced the loss of approximately three cases.

\section{Instruments}

The study utilized two instruments for data collection--the DDQ and the OQLQ. The DDQ is limited by several factors. Although the demographic data collected is useful in characterizing the study population, it does not include information about the duration of the presenting alcohol problem or the educational level of the client. In addition, rather than identify the marital status of individuals, the data only relates to the clients' social living situation. Thus, a married person who is living with someone other than his/her spouse is not accurately described in the demographic data. These deficits become important when comparing the present study sample with other samples to determine similarity between study populations. 
The scale in the follow-up version of the DDQ which rates client success (see Appendix J) contains two problem areas: (a) the choice of evaluator and (b) the design of the scale. An element of bias is introduced by having the clinician as rater of client performance. It can be argued that clinicians have a subjective perspective of their counseling relationships and may be biased, positively or negatively, toward individual clients. This possibility is exacerbated by the second problem area, the lack of objective criteria in the rating scale. Anchoring criteria are defined in only general terms. For example, regular attendance is cited as a criterion for a "satisfactory" or "very satisfactory" rating. However, what constitutes regular attendance is not specified. Likewise, distinctions are not made between investment in treatment (satisfactory level) and a high degree of investment in treatment (very satisfactory level); similarly, working toward most treatment goals (satisfactory level) and working hard toward treatment goals (very satisfactory level) are undefined. These problem areas cause the rating scale to be an unreliable and possibly invalid instrument for assessing outcome. This is especially unfortunate because it is the only variable in the study designated to correlate treatment outcome as seen by the client with treatment outcome as seen by the agency. 
In the OQLQ, the second of the instruments used in the study, it is questionable whether validity and reliability are adequate. The originators (Bigelow et al., 1980) state that the instrument has face validity. This assertion is based on their assessment that the scales measure those factors related to a person's life functioning and that items within each scale are consistent evaluators of that particular factor.

In order to validate their assumption, a discriminant analysis of the test variables was performed. In this analysis, clinic samples tested both at intake and at follow-up were compared with a sample from the community at large. On the basis of the testing it was concluded that scales measuring Psychological Distress, Psychological Well-Being, and Affective Status strongly correlated with the factors identified within these scales. They are believed, therefore, to have strong face validity. The scales measuring Independence and Meaningful Use of Time are judged to be adequate while those scales related to Social Support, Friend Role, Close Friend Role, Spouse Role, Parent Role, Work at Home, Employability, Work on the Job, and Work at School are assessed as having low degrees of correlation.

The designers of the questionnaire recognize its limitations in terms of validity and have recommended a number of methods to improve its deficiencies. In 
The Oregon Program Impact Monitoring System (Bigelow et al., 1980), the authors point out that the OQLQ requires a survey by professionals, other than those involved in its development, to validate their assertion of face validity. In addition, the summary statement outlines a number of areas where revision of the instrument is desirable. In particular, the OQLQ would be more useful for program evaluation if versions of the questionnaire were developed for those under age 16, for those over age 65, and for those of Spanish speaking backgrounds. The authors (Bigelow et al., 1980) conclude their critique by saying:

There is a need for further validation studies involving the OQLQ. The relationships of the OQLQ, as a measure of mental health, should be established with other measures of social adaptation, "level of functioning," psychiatric assessment (DSM-III), observations of significant others, behavioral assessment, and archival measures. Basic methodological assumptions and issues in the OQLQ should be investigated--e.g. the validity of self-report performance. (pp. 144-5)

Thus, the present assumption of validity in the OQLQ can only be partially substantiated.

In terms of reliability, the instrument profits from the interviewer training and the standardized manner in which the questionnaire is administered. These factors give the instrument its high inter-rater-reliability. 
Data Analysis Plan

The primary limitation of the data analysis plan is the use of aggregate data in the findings. The data identifies the overall satisfaction of the sample group with the agency and indicates clients' perceptions of changes in life functioning. The use of group data, however, precludes identification of particular counselors or counseling methods which are highly successful. Likewise, ineffective treatments and therapists cannot be identified, nor can subgroups within the sample, which are more or less amenable to treatment, be distinguished. 
Argeriou, M. \& Paulino, D. Women arrested for drunken driving in Boston: Social characteristics and circumstances of arrest. Journal of Studies on Alcohol, $1976, \underline{37}(5), 648-658$.

Armor, D. J., Polich, J. M., \& Stambul, H. B. Alcoholism and treatment. Santa Monica, California: Rand Corporation, 1976 .

Baekeland, F. L., Lundwall, L., \& Kissin, B. Methods for the treatment of chronic alcoholism: A critical appraisal. In R. J. Gibbins, J. Irael, H. Kalant, R. E. Popham, W. Schmidt, \& R. G. Smart (Eds.), Research advances in alcohol and drug problems (Vol. 2). New York: Wiley, 1975 .

Belasco, J.A. The criterion question revisited. British Journal of Addictions, $1971,66,39-44$.

Bigelow, D., Brodsky, G., Howard, B., Olson, M., Smith, J., \& Stewart, $L$. The oregon program impact monitoring system. Unpublished manuscript, 1980. (Available from State of Oregon, Department of Human Resources).

Blane, H. T. Issues in the evaluation of alcoholism treatment. Professional Psychologist, $1977, \underline{8}, 593-608$.

Blum, E. M., \& Blum, R. H. Alcoholism: Modern psychological approaches to treatment. San Francisco: Jossey-Bass, 1967 .

Burton, G., Kaplan, H., \& Hudd, E. Marriage counseling with alcoholics and their spouses: A critique of the methodology of a follow-up study. British Journal of Addiction, 1968, 63, 151-160.

Caddy, G. R. Problems in conducting alcohol treatment outcome studies: A review. In L. C. Sobell, M. B. Sobell, \& E. Ward (Eds.), Evaluating alcohol and drug abuse treatment effectiveness: Recent advances. New York: Pergamom Press, 1980. 
Chambers, L. W., Roberts, R. S., \& Voelker, C. C. The epidemiology of traffic accidents and the effect of the 1969 breathalyzer law in Canada. In S. Israelstam \& F. Lambert (Eds.), Alcohol, drugs and traffic safety. Toronto: Alcoholism and Drug Addiction Research Foundation of Ontario, 1975.

Charalampous, K. D., \& Skinner, T. J. Alcoholism and the courts: Experience with a traffic safety project. Hospital \& Community Psychiatry, 1977, $\underline{28}(1), 33-35$.

Cramton, R. C. The problem of the drinking driver. American Bar Association Journal, 1968, 54, 995-999.

Crawford, J. J., \& Chalupsky, A. B. Evaluation strategies used in current alcoholism rehabilitation programs: Problems and specifications for improvement. Proceedings of the American Psychological Association, 1973, 81, 791-792.

Crawford, J. J., \& Chalupsky, A. B. The reported evaluation of alcoholism treatments, 1968-1971: A methodological review. Addictive Behaviors, 1977, 2. 63-72.

Cronkite, R. C., \& Moos, R. H. Evaluating alcoholism treatment programs: An integrated approach. Journal of Consulting and Clinical Psychology, 1978, $\underline{46(5),}$ 1105-1119.

Delellis, J. D. Changing DWI behavior: Strategies for the DWI instructor. Traffic Safety, 1975, 75(5), 6-8.

Dittman, K. S., \& Crawford, G. The use of court probation in the management of the alcohol addict. American Journal of Psychiatry, 1966, 122, 757-762.

Echols, B. Personal communication, November 5, 1980.

Eddy, J. A DWI educational program. Journal of Drug Education, 1976, $6(2), 137-140$.

Emrick, C. D. A review of psychologically oriented treatment of alcoholism: The use and interrelationship of outcome criteria and drinking behavior following treatment. Quarterly Journal of Studies on Alcohol, $1974, \underline{35}, 52 \frac{23-549}{}$ 
Ends, E. J., \& Page, C. W. A study of three types of group psychotherapy with hospitalized male inebriates. Quarterly Journal of Studies on Alcohol, $1957,18,263-277$.

Ennis, P. K. General deterrence and police enforcement: Effective countermeasures against drinking and driving? Journal of Safety Research, 1977, 9(1), 15-25.

Filkins, L. D. Washtenaw County Alcohol Safety Action Program evaluation summary, final report. Prepared for Washtenaw County Alcohol Safety Action Program (Report No. UM-HSRI-AL-73-17). Ann Arbor: University of Michigan, Highway safety Research Institute, 1974 .

Fine, E. W., Steer, R. A., \& Scoles, P. E. Evaluation of a treatment program for drunk driving offender. In M. Galanter (Ed.), Currents in alcoholism (Vol. 6). New York: Grune \& Stratton, 1979.

Gallant, D. M., Faulkner, M., Stoy, B., Bishop, M. P., \& Langdon, D. Enforced treatment of paroled criminal alcoholics: A pilot evaluation. Quarterly Journal of Studies on Alcohol, 1968, 29, 77-83.

Gerard, D. I., \& Sanger, G. Outpatient treatment of alcoholics (Brookside Momograph No. 4). Toronto: University of Toronto Press, 1966.

Gibbs, J., \& Flanagan, J. Prognostic indicators of alcoholism treatment outcome. International Journal of the Addictions, $1977,12(8), 1097-1141$.

Goldfried, M. R. Prediction of improvement in an alcoholism outpatient clinic. Quarterly Journal of Studies on Alcohol, 1969, 30, 129-139.

Grider, B. Personal communication, October 11, 1980.

Hart, L. A review of treatment and rehabilitation legislation regarding alcohol abusers and alcoholics in the United States: 1920-1971. International Journal of Addiction, 1977, 12, 667-678.

Hi11, M. J., \& Blane, H. T. Evaluation of psychotherapy with alcoholics: A critical review. Quarterly Journal of Studies on Alcohol, 1967, 28, 76-104. 
Hoff, E. C. Group therapy with alcoholics. Psychiatric Research Report, 1968, 24, 61-70.

Hoy, R. M. The personality of inpatient alcoholics in relation to group psychotherapy, as measured by the 16-P.F. The Quarterly Journal of Studies on Alcohol, 1969, 30, 401-407.

Hyman, M. M. Accident vulnerability and blood alcohol concentrations of drivers by demographic characteristics. Quarterly Journal of Studies on Alcohol, 1968, Supplement No. 4, 34-57.

Hyman, M. M. The social characteristics of persons arrested for driving while intoxicated. Quarterly Journal of Studies on Alcohol, 1968, Supplement No. $4,138-177$.

Inskeep, N. R., Vaught, R. S., Warmington, S. K., \& Kiel, S. R. An analysis of problem drinker diagnosis and referral activity: Final analytic study 5 . Prepared for Office of Alcohol Countermeasures, National Highway Traffic Safety Association, Dept. of Transportation, 1973.

Jacobson, G. R., Niles, D. H., Moberg, D. P., Mandehr, E., \& Dusso, L. N. Identifying alcoholic and problemdrinking drivers: Wisconsin's field test of a modified NCA criteria for the diagnosis of alcoholism. In M. Galanter (Ed.), Currents in Alcoholism: Treatment and Rehabilitation and Epidemiology (Vol. 6). New York: Grune \& Stratton, 1979.

Jellinek, E. M. Current notes: Phases of alcohol addiction. Quarterly Journal of Studies on Alcohol, $1952,13,673-684$.

Johnson, P., Levy, P., \& Voas, R. A critique of the statistical evaluation of the effectiveness of Alcohol Safety Action Projects. Accident Analys is and Prevention, 1976, ㅇ, 67-77.

Kern, J. C., Schmelter, W. R., \& Paul, S. R. Drinking drivers who complete and drop out of an alcohol education program. Journal of Studies on Alcohol, 1977, 38(1), 89-95. 
Lacey, J. H., Stewart, J. R., \& Council, F. M. Development of predictive models to identify persons at high risk of alcohol related crash involvement. In I. R. Johnston (Ed.), Proceedings of the 7 th International Conference on Alcohol, Drugs and Traffic Safety, Melbourne, 23-28 January 1977. Canberra: Australian Government Publishing Service.

Landstreet, B. F. The drinking driver: The alcohol safety action programs. Springfield, Ill.: Charles C. Thomas, 1977 .

Lee, A. Personal communication, July 12, 1976.

Lemere, F., \& Voegtlin, W. L. An evaluation of the aversion treatment of alcoholism. Quarterly Journal of Studies on Alcohol, 1950, 11, 199-204.

Little, J. Administration of justice in drunk driving cases. Gainesville, Fla.: University Presses of Florida, 1975.

Lowe, W. C., \& Thomas, S. D. Assessing alcoholism treatment effectiveness: A comparison of three evaluative measures. Journal of Studies on Alcohol, 1976, 37, 883-889.

Maisto, S. A., \& Cooper, A. M. A historical perspective on alcohol and drug treatment outcome research. In L. C. Sobell, M. B. Sobell \& E. Ward (Eds.), Evaluating alcohol and drug abuse treatment effectiveness: Recent advances. New York: Pergamon Press, 1980 .

Maisto, S. A., \& McCollam, J. B. The use of multiple measures of life health to assess alcohol treatment outcome: A review and critique. In L. C. Sobell, M. B. Sobell \& E. Ward (Eds.), Evaluating alcohol and drug abuse treatment effectiveness: Recent advances. New York: Pergamom Press, 1980.

Matakas, F., Kaester, H., \& Leidner, B. Which treatment for which alcoholic?: A review. Psychiatirschep Praxis, 1978, ㄷ․ 143-152.

May, S. J., \& Kuller, L. H. Methodological approaches in the evaluation of alcoholism treatment: A critical review. Preventive Medicine, 1975, ㄴ, 593-608. 
Mayer, J., \& Myerson, D. J. Characteristics of outpatient alcoholics in relation to change in drinking, work and marital status during treatment. Quarterly Journal of Studies on Alcohol, 1970, 31, 889-897.

McGuire, F. L. The effectiveness of a treatment program for the alcohol involved driver. American Journal of Drug and Alcohol Abuse, 1978, 5 (4), 517-525.

Miller, W. R., \& Joyce, M. A. Prediction of abstinence, controlled drinking, and heavy drinking outcomes following behavioral self-control training. Journal of Consulting \& Clinical Psychology, 1979, 47, 773-775.

Moos, R., \& Bliss, F. Difficulty of follow-up and outcome of alcoholism treatment. Journal of Studies on Alcohol, 1978, 39(1), 473-490.

Nichols, J. I. The effectiveness of ASAP education and rehabilitation programs. In I. R. Johnston (Ed.), Proceedings of the 7 th International Conference on Alcohol, Drugs and Traffic Safety, Melbourne, 23-28 January 1977. Canberra: Australian Government Publishing Service, 1979.

Nichols, J. L., Ellingstad, V. S., \& Struckman-Johnson, D. I. An experimental evaluation of the effectiveness of short term education and rehabilitation programs for convicted drinking drivers. In $\mathrm{M}$. Galanter (Ed.), Currents in alcoholism (Vol. 6). New York: Grune \& Stratton, 1979.

Oregon. Dept. of Mental Health. Annual report on alcohol programs. June 1980. (Report MOLIO41P)

Orford, J. A comparison of alcoholics whose drinking is totally uncontrolled and those whose drinking is mainly controlled. Behavior Research and Therapy, $1973,11,565-576$.

Pattison, E. M. Abstinence criteria in alcoholism treatment. Addictions, 1967, 14(3), 1-19.

Pattison, E. M. Discussion of session B: Criteria in treatment evaluation. Proceedings of the 2nd Annual Conference of the National Institute on Alcoholism and Alcohol Abuse, 1973, 2, 211-221. 
Pomerleau, O., Pertschuk, M., \& Stinnett, J. A critical examination of some current assumptions in the treatment of alcoholism. Journal of Studies on Alcohol, 1976, 37, 849-867.

Program level evaluation of ASAP diagnosis, referral and rehabilitation efforts: Description of ASAP diagnosis, referral and rehabilitation functions. Final report (Vol. 1). Prepared for U.S. Department of Transportation, Washington, D.C. September 1976. (Contract \# DOT-HS-191-3-759)

Reinert, R. E. The concept of alcoholism as a disease. Bulletin of the Menninger Clinic, 1968, 32, 21-35.

Roizen, R. Comments. Journal of Studies on Alcohol, 1977, 38, 170-178.

Rosenberg, C. M., \& Liftek, J. Use of coercion in the outpatient treatment of alcoholism. Journal of Studies on Alcohol, 1976, 37, 58-62.

Saunders, D. N. Prevention and control of 'drunk driving': Lessons for social work. Health and Social Work, $1979, \underline{4}(4), 84-106$.

Scrimgeour, G. J. ASAP and the courts: Learning from experience the problems of system interface. Journal of Drug Issues, $1975, \underline{5}(3), 248-254$.

Selzer, M. I. Personality versus intoxication as critical factor in accidents caused by alcoholic drivers. The Journal of Nervous and Mental Disease, 1961, $132(4), 298-303$.

Selzer, M. L. Alcohol impairment, alcoholism, and traffic accidents. The University of Michigan Medical Center Journal, $1966, \underline{32}(5), 238-241$.

Selzer, M. L. Fatal traffic accidents: Deterrents to an emergency approach. The University of Michigan Medical Center Journal, 1968, 34(2), 102-105.

Selzer, M. L., Payne, C. E., Gifford, J. D., \& Kelly, W. L. Alcoholism, mental illness and the "drunk driver." American Journal of Psychiatry, 1963, 120(4), 326-331. 
Smart, R. G. The evaluation of alcoholism treatment evaluation. In G. A. Marlatt \& P. E. Nathan (Eds.), Behavioral approaches to alcoholism (NIAAA-RUCAS Alcoholism Treatment Series No. 2). New Brunswick: N. J.: Rutgers Center of Alcohol Studies, 1978.

Smart, R. G., \& Gray, G. Multiple predictors of dropout from alcoholism treatment. Archives of General Psychiatry, 1978, 35(3), 363-367.

Sobell, L. C., Maisto, S. A., Sobell, M. B., \& Cooper, A. M. Reliability of alcohol abusers self-reports of drinking behavior. Behavior Research and Therapy, $1979,17,157-160$.

Sobell, L. C., \& Sobell, M. B. Outpatient alcoholics give valid self-reports. Journal of Nervous and Mental Disease, $1975, \underline{161}, \frac{12-42}{32}$

Sobell, L. C., \& Sobell, M. B. Validity of self-reports in three populations of alcoholics. Journal of Consulting and Clinical Psychology, 1978, 48(5), 901-907.

Sobell, M. B., Sobell, L. C., \& Samuels, F. H. Validity of self-reports of alcohol related arrests by alcoholics. Quarterly Journal of Studies on Alcohol, $1974,35, \frac{\text { Quarter }}{276-280}$.

Stewart, E. I., \& Malfetti, J. Rehabilitation of the drunken driver: A corrective course in Phoenix, Arizona, for persons convicted of driving under the influence of alcohol. New York: Teachers College Press, Columbia University, 1970.

Summers, T. Validity of alcoholics' self-reported drinking history. Quarterly Journal of Studies on Alcohol, $1970, \underline{31}, 972-974$.

Thomas, R. E., Gliedman, L. H., Imber, S. D., Stone, A. R., \& Freund, J. Evaluation of the Maryland alcoholic rehabilitation clinics. Quarterly Journal of Studies on Alcohol, $1959, \underline{20}, 65-76$.

U.S. Dept. of Transportation. National Highway Traffic Safety Administration. Alcohol Safety Action Projects. Evaluation of operations - 1972 (Vol. 2, Chapter 6). Department of Transportation, Washington, D.C. 1974. (Report No. DOT-HS-800-874) 
U.S. Dept. of Transportation. National Highway Traffic Safety Administration. Alcohol Safety Action Projects. Evaluation, methodology, and overall program impact (Vol. 3). Department of Transportation, Washington, D.C. April 1979. (Report No. DOT-HS803-896)

U.S. Dept. of Transportation. National Highway Traffic Safety Administration. Alcohol Safety Action Projects. Results. Department of Transportation, Washington, D.C. May 1979. (Report No. DOT-HS804-033)

Vannicelli, M., Pfau, B., \& Ryback, R. S. Data attrition in follow-up studies of alcoholics. Journal of Studies on Alcohol, $1976,37,1325-1350$.

Voegtlin, W. L., \& Lemere, F. Treatment of alcohol addiction: A review of the literature. Quarterly Journal of Studies on Alcohol, 1942, 2, 717-803.

Ward, D. A. The use of legal coercion on the treatment of alcoholism: A methodological review. Journal of Drug Issues, 1979, 9, 387-397.

Watzl, H., \& Olbrick, R. Controlled drinking in the treatment of alcoholism. Psychiatrische Praxis, $1976, \underline{3}, 204-213$.

Wieser, S. Psychotherapy and social therapy of the alcoholic. In K. P. Kisker, J. E. Meyer, M. Miller, \& E. Strömgen (Eds.), Modern Psychiatry (Vol. 2). Berlin: Springer Verlag, 1972 .

Wolff, K. Group therapy for alcoholics. Mental Hygiene, 1967, 51, 549-551.

Zador, P. Statistical evaluation of the effectiveness of alcohol safety action projects. Accident Analysis \& Prevention, $1976, \underline{8}, 51-66$.

Zelhart, P. F. The Alberta impaired drivers program: A final report. Edmonton, Canada: University of Alberta Press.

Zelhart, P. F., \& Schurr, B. C. People who drive while impaired: Issues in treating the drinking driver. In N. J. Estes \& M. E. Heinemann (Eds.), Alcoholism: Development, consequences, and intervention. Saint Louis: C. V. Mosby Company, 1977. 
Zylman, R. The alcohol highway safety countermeasures program: A panacea or Pandora's box. Traffic Digest and Review, 1971, 19(4), 16-24. 
APPENDICES 


\section{APPENDIX A}

\section{ASAP: RELATIONSHIP TO THE COMMUNITY}

\section{Clients}

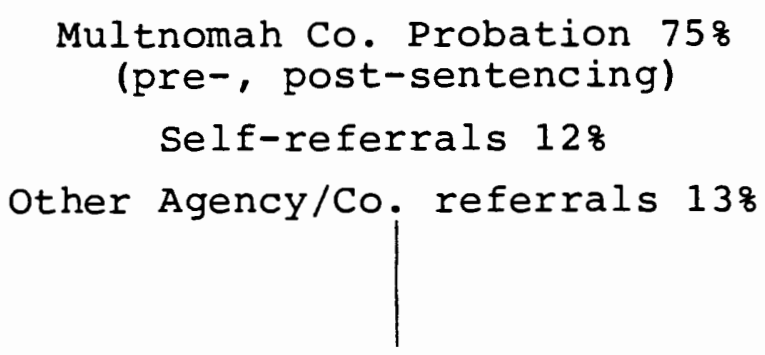

$\underline{\text { ASAP }}$

State/County

Corrections

clients

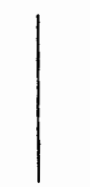

Multnomah County Mental Health

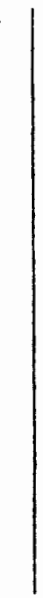

\section{State Dept. of \\ Motor Vehicles}

Iicensing

Clients

State Mental Health Division

Funding

Standards 


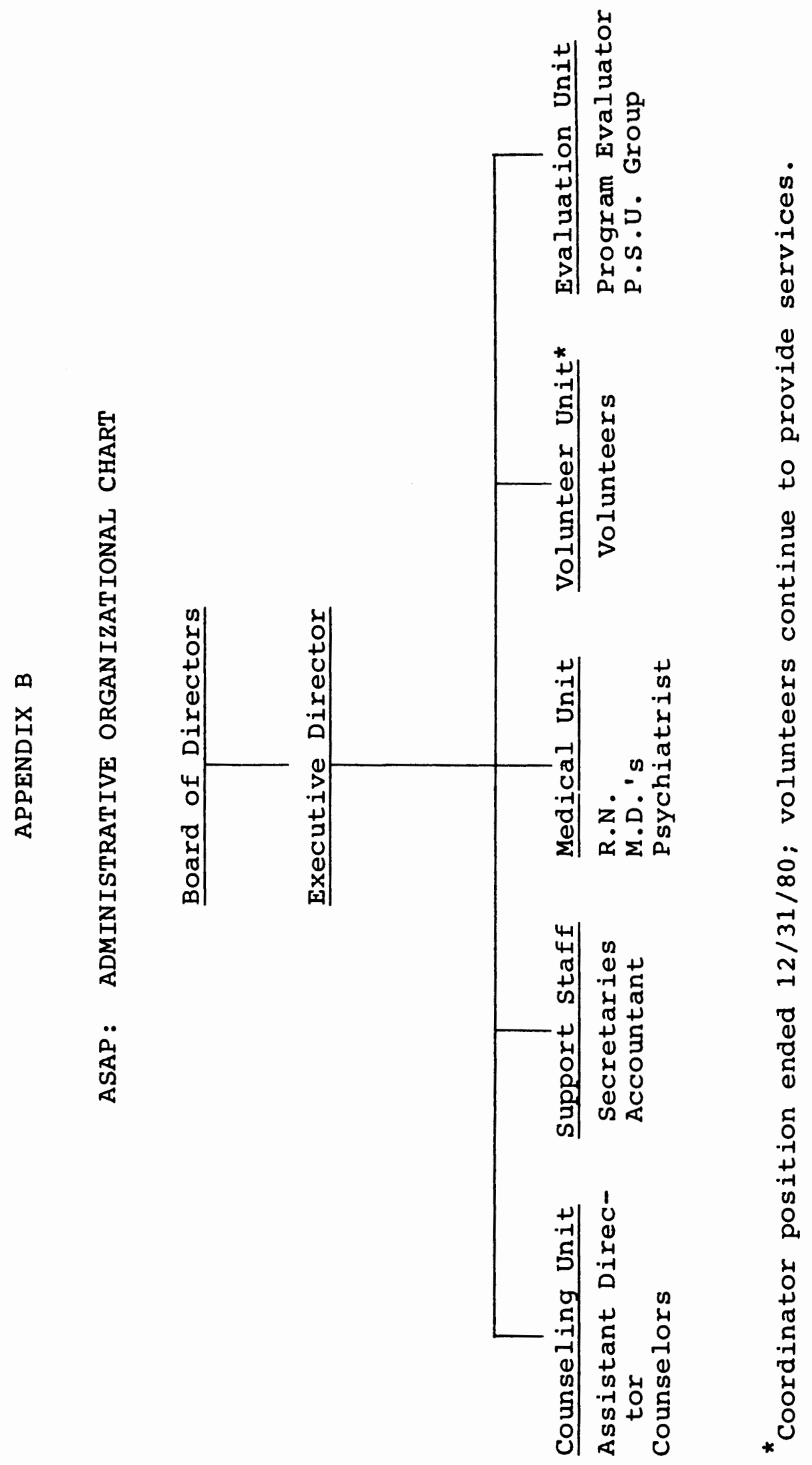


APPENDIX C

PERCENT DISTRIBUTION : COMPARISON OF INTERVIEW

SAMPLE, EXCLUDED CLIENTS, AND

CLIENTS LOST AT FOLLOW-UP

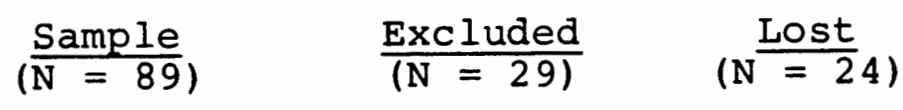

$\underline{\text { Sex }}$

Male

Female

Age

Mean

Range

Race

White

Other

Reason for Treatment
$85 \quad(76)$

15 (13)
$83 \quad(24)$

17 (15)
$92 \quad(22)$

8 (2)
Mandated
Voluntary

Social Living

Situation

Alone

with Parents

with Spouse

Other
$92 \quad(82)$

8 (7)

$80 \quad(71)$

$20 \quad(18)$
35
$21-54$

35

$21-67$ $\begin{array}{rr} & 21-54 \\ 90 & (26) \\ 10 & (3)\end{array}$

$\begin{array}{rr} & 21-54 \\ 90 & (26) \\ 10 & (3)\end{array}$

$86 \quad(25)$

14 (4)

83 (20)

17 (4)

$83 \quad(20)$

17 (4) 
se questions ask about how you have been feeling in the past week. Pleasant cond leasant feelings of several different kinds are covered.

$n$ the past week, how often have you elt very restless, unable to sit t111, or fidgety?

in the past week, how often have you injoyed your leisure hours (evenings, lays off, etc.):

[n the past week, how often have you felt preoccupied with your problems (can't think of anything else)?

In the past week, how often have you been pleased with something you did?

In the past week, how often have you felt unpleasantly different from everyone and everything around you?

In the past week, how of ten have you

felt proud because you were complimented?

In the past week, how often have you felt fearful or afraid?

In the past week, how of ten have you

felt that things were "going your way"?

In the past week, how of ten have you

felt sad or depressed?

In the past week, how of ten have you

felt excited or interested in something?
4 all the time.

3 often

Iseveral times

Inone of the time

yall the time

$01-02$

30 ten

2 several times

Inone of the time

yall the time

01-03

sosten

2 several times

Inone of the time

sall the time

01-04

3 often

Iseveral times

Inone of the time

4 all the time

$01-05$

3 often

2 several times

Inone of the time

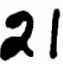

4 all the time

$01-06$

soften

Iseveral times

Inone of the time

tall the time

soften

2several times

Inone of the time

4 all the time

3 often

zseveral times

none of the time

4 all the time

3 often

Iseveral times

Inone of the time

sall the time

sobten

2several times

Inone of the time 
$\mathrm{n}$ the past week, how of ten have you elt angry?
4 all the time

01-11

3 often

zseveral times

Inone of the time

yall the time

$01-12$

in the past week, how of ten have you

:elt that life was going just about right

ior you?

zoften

2several times

Lnone of the time

4 all the time

$\frac{1}{3}$ often

2several times

Inone of the time

4 all the time

3 often

2 several times

Inone of the time

sall the time

3 often

Iseveral times

Inone of the time

4 all the time

In the past week, how often have you

In the past week, how of ten have you

felt good about decisions you've made?

In the past week, how of ten have you

had trouble sleeping?

3 often

Iseveral times

Inone of the time

In the past week, how often have you

felt like you've spent a worthwhile day?

4 all the time

3 often

2 several times

Inone of the time

In the past week, how often have you

had trouble with poor appetite, or inability

to eat?

4 all the time

3 obten

Iseveral times

Inone of the time

In the past week, how of ten have you

felt serene and calm?

4 all the time

30 ften

2several times

Lnone of the time

4 all the time

$01-20$

30 ften

2 several times

Inone of the time

tall the time

$01-21$

3 often

2several times

37

Inone of the time

4 all the time

$01-22$

In the past week, how of
had trouble with fatigue?

3 often

several times

inone of the time

38

Did make any difference to the way

5greatcy improved it

4 improved it

$3^{\text {no }}$ effect

2 made it worse

$\perp$ made it much worse 
ybody has unpleasant feelings sometimes: we wake up depressed, get upset or frustrated piahtened. These questions ask how much difficulty you have had recently in handling ie unpleasant feelings.

\begin{tabular}{|c|c|c|}
\hline $\begin{array}{l}\text { Jw much difficulty have you had handling } \\
\text { selings of depression? }\end{array}$ & $\begin{array}{l}3 \text { great difficulty } \\
2 \text { some difficulty } \\
\text { Ino difficulty }\end{array}$ & $\begin{array}{c}02-01 \\
40\end{array}$ \\
\hline $\begin{array}{l}\text { ow much difficulty have you had handling } \\
\text { eing upset? }\end{array}$ & $\begin{array}{l}\text { 3areat difficulty } \\
\text { 2some difficulty } \\
\text { Ino difficulty }\end{array}$ & $\begin{array}{c}02-02 \\
41\end{array}$ \\
\hline $\begin{array}{l}\text { ow much difficulty have you had handling } \\
\text { rustration? }\end{array}$ & $\begin{array}{l}\text { 3areat difficulty } \\
2 \text { some difficulty } \\
\text { 1 no difficulty }\end{array}$ & $\begin{array}{c}02-03 \\
42\end{array}$ \\
\hline $\begin{array}{l}\text { ow much difficulty have you had handling } \\
\text { eing frightened or shaken up? }\end{array}$ & $\begin{array}{l}3 \text { great difficulty } \\
2 \text { some difficulty } \\
\text { Ino difficulty }\end{array}$ & $\begin{array}{c}02-04 \\
43\end{array}$ \\
\hline $\begin{array}{l}\text { as } \\
\text { andle unpleasant feelings? }\end{array}$ & $\begin{array}{l}5 \text { greatly improved it } \\
4 \text { improved it } \\
3^{\text {no effect }} \\
2^{\text {made it worse }} \\
1 \text { made it much worse }\end{array}$ & $\begin{array}{c}2002 \\
44\end{array}$ \\
\hline
\end{tabular}

se auestions ask about your living situation, eating, income, transportation, and

Iica? care. The purpose is to see if these needs are met to at least a minimum el of satisfaction.

low satisfied are you with your home--its state ,f repair, amount of room, furnishing, warmth, lighting, etc.?

4 very satisfied

03-01

Isatisficd

Idissatisfied

Ivery dissatisfied

low satisfied are you with your home, considering

queru satisfied

$\frac{1}{3}$ satisfied

2 dissatisfied

Lvery dissatisfied

the amount of privacy, your neighbors, security, etc.?

sgreatly improved it

4 improved it

sno effect

zade it worse

1 made it much worse

This question asks about how well your income

\&very adequate

3 adequate

2 inadequate

Ivery inadequate

crothing, etc. How adequate is your present income for your present needs?

Are you worried about your future income covering the things you must have?

4 terribly worried

3 quite worried

2slightly worried

Inot at all worried

5 greatly improved it

simproved it

sno effect

2 made it worse

2 made it much worse

Can you get around town as you need for work,

4 can't get around at all

20-03

income?

affect the aderuacy of your

zwith much difficulty

48

shopping, medical appointments, visiting, etc. ?

2 with little difficulty

I with no difficulty 
lid :he community? affect your ability to get around 5areatly improved it

y improved it

3 no effect

2 made it worse

1 made it much worse

2yes

$\perp^{\text {no }}$

$03-06$

54

2 yes

03-07

Do you have a regular or family doctor?

$\perp^{\text {no }}$

55

2yes

$\perp$ no

$03-c 3$

Do you have medical insurance?

2yes

.56

Do you know where to get emergency medical

1 no

03-09

help?

Did affect your medical care? sgreatly improved it

\& improved it

zno effect

2 made it worse

1 made it much worse

ese questions ask how you handle making dicisions, dealing with conflict, asserting urself, etc.

In the last week, how did you find shopping, paying bills, preparing meals, and generally

looking after your basic necessities?

4 very easy

04-01

3bairly easy

zrather difficult

Lvery difoicult

... and how enjoyable was it?

4 very enjoyable

3 fairly enjoyable

2 fairly unpleasant

Lvery unpleasant

In the last week, how of ten did you go out?

4 more than 3 times

$\frac{4}{32}$ or 3 times

2 once

Inever

When you receive broken merchandise, poor service,

4 can't do it at all

or are overcharged, how hard is it for you to

complain to the store, dealer or company?

Ivery hard

2 a little hard

Inot hard at all

When you want to join a conversation (e.g., at a

4 can't do it all

party) how hesitant do you feel about doing so?

Ivery hesitant

2 slightly hesitant

not at all hesitant

When you are treated unfairly by someone you know

4 can't do it at all

well (family, close friend) how difficult is it

Ivery difficult

for you to tell them so?

2slightly difficult

1 not difficult

How confident are you in the decisions you make

4 quite confident

3 some confidence.

little confidence

to do, etc.)?

ino confidence

How often do you put off making important decisions

unt1l it is too late? 


\section{jid} affect your ability to make lecisions, deal with conflict, and assert yourself?

5greatly improved it

fimproved it

z no effect
$20-08$

67

$$
\begin{aligned}
& 2^{\text {made it worse }} \\
& 1^{\text {made it much wrise }}
\end{aligned}
$$

ese questions ask how you have been getting along with people in the last week.

In the past week, how many times have you spoken with neighbors?

4 more than 3 times

2 once

Lnever

In the last week, how of ten have you spoken with people you saw at work or school or other daily activity?

4 more than 3 times

$\frac{1}{2}$ or 3 times

2 once

Inever

Do you feel that people avoid you?

I all the time

sobten

2 occasionally

Inever

Do you feel that people are not nice to you?

4all the time

3 often

2 occasionally

Inever.

How comfortable do you feel being around people?

4 very uncomfortable

3 uncomfortable

2 conifortable

Ivery comfortable

Last week, how often did you get to places

fevery day

where you could meet new people?

Iseveral times

zonce

Inot at all

sgreatly improved it

Did affect how you get along with

4 improved it

sno effect

made it worse

1 made it much worse

people?

These questions ask how you have been getting along with your close friends recently.

How easily do you make close friendships?

4 can't do it at all

06-01

swith much difficulty

2with a little difficulty

Lquite easily

Do you have any close friends?

2yes

06-02

1 no

-(If "yes")

In the last week, how much of your free time did you spend with close friends talking or doing things together?

4 almost all

06-03

sabout half

zvery little

none

In the last month, how many times have you had

4 quite of ten

$06-06$

contact by visit, phone, or mail with friends who

live outside ?

several times 
ow much trouble have you had in your close

Fa great deal

Inone

iid make a difference in your close

riendships?

greatly improved them

3no effect

made them worse

1 made them much worse

ise questions ask how you have been getting along with your farily recently.

That is your marital situation now?

Gliving together as married

07-01

smarried and living

together

81482

4 separated

3 divarced

zwidowed

Inever married

How many people live in the household with you? (give numbers)

ages $0-5 \quad 83$

$-6-17$

$-18-64$

$-65+$

83

84

2 yes

Are there any children living with you for whom

1 no

you are responsible (by birth or otherwise)?

I almost all

$07-04$

In the last week, how much of your free time

did you spend with the people with whom you

live, talking or doing things together?

3 about half

zvery little

Inone

In the last month, how many times have you had

4 more than 3 times

Inot at all

- (If married or Living as married)

In the last week, how of ten have you gotten.

very angry with your spouse?

Levery day

zobten

zonce or twice

Inever

In the last week, how often did you go out of

your way to be nice to your spouse?

4all the time

soften

2several times

Inever

I a great deal

In the last month, how much have you enjoyed

your spouse's company?

squite a bit

za little

Inot at all

How well are you getting along with your spouse? 4 very well 


\begin{tabular}{|c|c|c|}
\hline $\begin{array}{l}\text { low much have you been involved with your } \\
\text { hildren's activities recently? }\end{array}$ & $\begin{array}{l}\frac{4}{3} \text { areat deal } \\
\frac{3}{2} \text { a little } \\
\text { Inot at all }\end{array}$ & $\begin{array}{c}09-01 \\
95\end{array}$ \\
\hline $\begin{array}{l}\text { How much difficulty have you lad meeting your } \\
\text { shildren's demands for your attention recently? }\end{array}$ & $\begin{array}{l}\frac{4 a}{3} \text { great deal } \\
3^{a} \text { lot } \\
2^{a} \text { little } \\
\text { Inone at all }\end{array}$ & $\begin{array}{c}09-02 \\
96\end{array}$ \\
\hline $\begin{array}{l}\text { In the last week, how many conversations did } \\
\text { you have with your children? }\end{array}$ & $\begin{array}{l}\frac{4 \text { mone than } 3}{3^{2} \text { or } 3} \\
2^{\text {one }} \\
1 \text { none }\end{array}$ & $\begin{array}{c}09-03 \\
97\end{array}$ \\
\hline How much have your children annoyed you recently? & $\begin{array}{l}4 a \text { great deal } \\
3 a \text { lot } \\
2 a \text { little } \\
1 \text { not at all }\end{array}$ & $\begin{array}{c}09-04 \\
98\end{array}$ \\
\hline $\begin{array}{l}\text { How much have you enjoyed your children's } \\
\text { company recently? }\end{array}$ & $\begin{array}{l}4 \text { great deal } \\
3^{a} \text { lot } \\
2^{a} \text { little } \\
\text { Inot at all }\end{array}$ & $\begin{array}{c}09-05 \\
99\end{array}$ \\
\hline 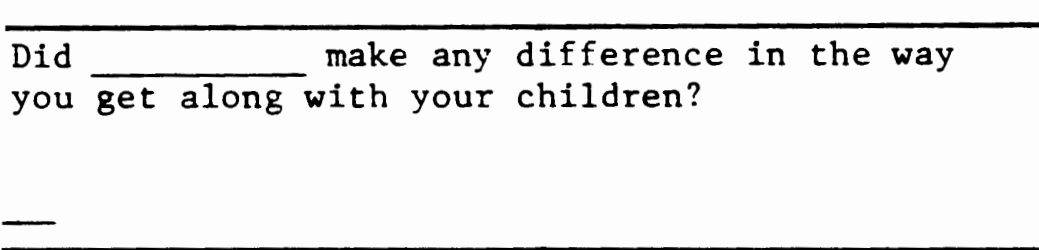 & $\begin{array}{l}5 \text { greatly improved it } \\
\text { Limproved it } \\
3_{\text {no efject }} \\
2 \text { made it worse } \\
1 \text { made it much worse }\end{array}$ & $\begin{array}{r}20-12 \\
100\end{array}$ \\
\hline
\end{tabular}

zere are some things we share with family and friends; some things we can count on iem for. These questions ask about your family and friends, as you see them now.

When something nice happens to you, do you want to share the experience with your family?

When something nice happens to you, do you want to share the experience with your friends?
4 always

3 often

2 sometimes

Inever

4 always

3 often

2 sometimes

Inever

How much would your family be of help and support if you were sick, or moving, or having any other kind of problem?

$3 a$ lot

2 a little

inone

How much would your friends be of help and support to you if you were sick, or moving, or having any other kind of problem?

\section{4 a great deal} thone

How much would anyone in the community, other than family and friends, be of help and support to you if you were sick, or moving. or having any other kind of problem?

4 a great deal

Ia lot

2a little

Did affect the help and support you Inone

feel you can count on from family, friends, and others? 
se questions are about your experience with work at home, on the iob, and in 2002 .

[n the last week, how well have you kept up with jour share of the housework (cleaning, laundry, shopping, errands)?

4 completely done

$3 q u i t e$ well

How much of the household money management (paying the bills, budgeting) do you do?

2 fairly well

Iall

2a little

Inone

How much of the shopping for the household do you do (groceries, furnishings, supplies)?

4 all

In the last month, how much time did you spend fixing or changing things connected with your home (roof, redecorating, yard work, plumbing) or car?

About how many hours per day do you usually spend preparing meals for the household?

3 most

Inone

4 several days

$I^{a}$ day or so

2 an hour or so

Inone

4 more than 3

$\frac{1}{3} 1$ to 3 hours

$\frac{3}{2}$ an hour on less

Inone

Did affect your work in the home?

5 greatly improved it

$20-14$

simproved it

3 no effect

112

2 made ii worse

tmade it much worse

Even if you are not looking for a job,

hese questions concerm looking for a job.
he questions ask about how you would feel.

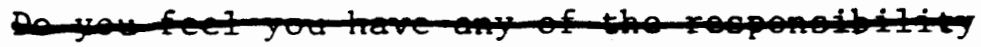

far gatting an inaomn far your howecivit?

-(If "yes")

How good an impression do you feel you would make in a job interview?

4 very good

3 good

2 poor

Ivery poor

How serious are any emotional problems you may have which would make it hard for you to find work?

4 very serious

How comfortable do you feel going out to look

for a job?

4 completely

3 quite

2 fairly

Inot at all

How hard is it for you to stick to a job when

it becomes unpleasant or boring or stressful?

4 can't do it at all

Ivery hard

2 a little hard Inot at all hard

If you had a chance to get more job training, Inot interested 


\begin{tabular}{|c|c|c|}
\hline $\begin{array}{l}\text { How comfortable do you feel working with other } \\
\text { people? }\end{array}$ & $\begin{array}{l}4 \text { not at all comfortable } \\
3 \text { fairly } \\
2 \text { quite } \\
1 \text { completely }\end{array}$ & $\begin{array}{l}12-07 \\
1 / 9\end{array}$ \\
\hline $\begin{array}{l}\text { Tinis question is about activities that you } \\
\text { especially enjoy. Please name some of your } \\
\text { hobbles and special interests. }\end{array}$ & $\begin{array}{l}4 \text { more than } 3 \\
32 \text { or } 3 \\
2 \text { one } \\
\text { Inone }\end{array}$ & $\begin{array}{l}12-08 \\
120\end{array}$ \\
\hline $\begin{array}{l}\text { Please name some of the ways you would look } \\
\text { for a job. }\end{array}$ & $\begin{array}{l}4 \text { more than } 3 \\
3^{2} \text { or } 3 \\
2^{\text {one }} \\
\text { Inone }\end{array}$ & $\begin{array}{l}12-09 \\
121\end{array}$ \\
\hline $\begin{array}{l}\text { Did make a difference in how easy it } \\
\text { would be for you to get a job? }\end{array}$ & 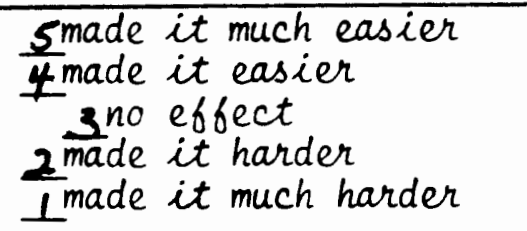 & $\begin{array}{l}20-15 \\
122\end{array}$ \\
\hline
\end{tabular}

hese questions ask about your work on the job.

Are you employed?

4 full-time

13-01

3 part-time

2 irregularly

123

-(If empioyed)

inot employed

In the last month, how much time did you miss from work?

I several days

$13-02$

Ia day or two

2 an hour on so

124

Inone

In the last month, how much difficulty did you

4 a great deal

have in doing your work?

squite a bit

$2 a$ little

Inone

How did you feel about the quality of the work you did?

4 very good

Igood

2 bad

Lvery bad

How much conflict have you had with people

while you were working?

4a great deal

13-03

Iquite a bit

2 a little

Inone

How interesting is your work?

4 very interesting

3 moderately

sslightly

Lit's boring

In general, how much do you like your job?

4really like it

Ilike it

Idon't like it

Lhate it

4 more than 3 times

In the last month, how many times did people

complain about your work?

32 or 3 times

once

Inot at all

13-05 
In the past month, how many times; did people say good thingis about your work?
4 more than 3 times

32 or 3 times

2 once

Inot at all

Did

last month? affect the way your job went
5 greatly improved it

4 improved it

3 no effect

made it worse

made it much worse

hese questions are about how things are going at school.

Are you enrolled in school, night classes, job training, etc.?
Ifull-time

3 half-time

2 less than $\frac{1}{2}$ time

ino

How many hours did you spend in any other informal $420+$ hours

inone

\section{-(If enrolled in school)}

In the last week, how many classes have you missed from school?

4 all week

Ia day or so

2 one or two classes

none

\section{ucompletely}

squite well

2 fairly well

Inot at all

In the last week, how
with your school work?

How satisfied are you with the work you did for your classes last week?

4 very satisfied

3 quite

2 a little

Inot at all

\section{4 more than 3 times}

In the last week, how many times have you had problems with people at school?

$\frac{1}{32}$ or 3 times
In the last week, how interesting was your school work?
Lvery interesting

3 moderately

slightly

Inot at all

In general, how much do you like being in school?

4 really like it

3 like it

2 don't like it

thate it

4 more than 3 times

$3^{2}$ or 3 times

once

Lnot at all

4 more than 3 times

32 or 3 times

2 once

not at all 
Did affect the way school has gone

for you?

4 improved it

zno effect

2 made it worse

Imade it much worse

ese questions ask about some of the ways you spend your time when you are not working the job, at home, or at school.

In the last week, how much time did you spend actively participating in recreation and sports?

$420+$ hours

$38-20$ hours

$21-7$ hours

Inone

In the last week, how much time did you spend on your hobbies (or creative pursuits, e.g., music)?

$420+$ hours

$38-20$ hours

$21-7$ hours

Lnone

of the TV watching you did last week, how much

time did you spend on really interesting programs?

$420+$ hours

15-03

$\frac{7}{3} 8-20$ hours

$21-7$ hours

Inone

ONA

In the last week, how much time did you spend

window shopping?

$420+$ hours

38-20 hours

$21-7$ hours

$15-04$

Inone

Volurteer work is anything you do for someone eise, on a fairly regular basis, that you don't get paid for. In the last week, how much time did you spend on volunteer work?

$420+$ hours

38-20 hours

$2^{1}-7$ hours

Inone

Not counting any time for which you were paid, how much time did you pass which you felt was boring and useless?

$420+$ hours

$\frac{1}{3} 8-20$ hours

$21-7$ hours

Inone

Regarding the activities we've just talked about, did your time? affect how you spend

5 made it much more satisfactory 20-19

4 made it more satisfactory sno effect

1 made it much less satisfactory

hese questions are about any contact you, personally, may have had with police, ourts, etc., in the last month. We are not interested in any wrong-doing--only $n$ contact with legal agencies.

Have you had any contact with legal agencies?

- If "yes", what kind of contact did you have in each

Traffic-related

of the folzowing areas...) 


\begin{tabular}{|c|c|c|}
\hline \multirow{2}{*}{ Ilcohol-related } & 2yes & $16-04$ \\
\hline & Lno & 155 \\
\hline \multirow{2}{*}{ Jiolence-related } & zyes & $16-05$ \\
\hline & $\perp^{\text {no }}$ & 156 \\
\hline \multirow[t]{2}{*}{ Thell-related } & zyes & $16-06$ \\
\hline & $\perp^{n \prime}$ & 157 \\
\hline \multirow[t]{2}{*}{ Civil action (being sued) } & zyes & $16-07$ \\
\hline & $\perp^{\text {no }}$ & 158 \\
\hline \multirow{2}{*}{$\begin{array}{l}\text { Commitment hearing (regarding } \\
\text { your mental health) }\end{array}$} & 2yes & $16-08$ \\
\hline & Ino & 159 \\
\hline $\begin{array}{l}\text { Did } \\
\text { difficulties? }\end{array}$ & $\begin{array}{l}\text { Sgreatly reduced them } \\
\text { Ireduced them } \\
\text { 3no effect } \\
\text { zincreased them } \\
1 \text { greatly increased them }\end{array}$ & $\begin{array}{l}20-20 \\
160\end{array}$ \\
\hline
\end{tabular}

lese questions are about drinking alcoholic beverages.

Have you had anything alcoholic to drink in the last month?

2yes

$17-01$

Ino

-(If "yes")

Peonlie sometimes have problems with using alcohol. The following questions ask

about problems you may have had with alcohol in the last month.

Have you had problems with

controlling your drinking?

Lveru severc

2a few

17-02

Problems with controlling your

3a lot

Inone

hehavior because of drinking?

svery severe

$2 a$ few

162

Problems with your feelings (guilt,

anger, depression) because of drink-

ing?

$\frac{1}{3}$ lot

enone

$17-03$

$\begin{array}{ll}4 \text { very severe } & 2 a \text { bew } \\ 2^{a} \text { lot } & \text { Inone }\end{array}$

163

Problems with your health because of drinking?

17-04

Problems with your parents because

of drinking?

Problems with your friends because

"If drinking?

4 very severe

sa lot

$2 a$ bew

17-05

Prcblems with your spouse because of drinking?

Problems with your children because of drinking?

\&very severe

Inone

Problems with your job or school because of drinking?

Ia lot

suery severe

sa lot

$2 a$ few

svery severe

sa lot

Ivery severe

Ia lot

Inone

Problems with your other activities

because of drinking?

Ivery severe

sa lot

$2 a$ bew

inone

yvery severe

sa lot

$2 a$ few

Inone

$\Omega^{N A}$

QNA

$\frac{115}{17-06}$

Did

affect any problems

you may have had with alcohol?

sgreatly reduced them

2a few

Lnone

ONA

ONA

$17-07$

2a bew

Inone

$2 a$ few

inone

167

17-08

168

$17-09$

169

$17-10$

Ireduced them

sno effect 
se questions are about druas.

ave you used any drugs or medication of any kind, $\frac{2 u e s}{I^{n o}}$
ncluding prescription, over-the-counter, and

treet drugs in the last month?

If "yes")

'eople sometimes have problems with the use of dmugs or medications. The following luestions ask about problems you may have had with dmugs in the last month.

\section{lave you had problems with}

controlling your use of drugs?

?roblems with controlling your

sehavior because of drug use?

Problems with your feelings (guilt,

anger, depression) because of drugs?

Problems with your health because of

drug use?

Problems with your parents because of

drug use?

Problems with your friends because of 4 very severe

drug use?

Problems with your spouse because of

drug use?

Problems with your children because of drug use?

Problems with your job or school

because of drug use?

Problems with your other activities

because of drug use?

Did affect any problems you

you may have had with drug use?
4 very severe

$3^{a}$ lot

Ivery severe

Ia lot

4 very severe

sa lat

4 very severe

sa lot

svery severe

Ia lot

Ia lot

4 very severe

sa lot

query severe

$3^{a}$ lot

4 very severe

sa lot

fuery severe

Ia lot

2a few

Inone

za bew

Inone

18-03

2a bew

Inone

2a hew

Inone

2a bew

Inone

$0^{N / A}$

2a bew

Inone

$Q^{N A}$

2 a bew

Inone

$e^{N A}$

2 a bew

Inone

$e^{N A}$

$2 a$ bew

Inone

$2 a$ bew

Inone

5 greatly reduced them

Ireduced them

$3^{\text {no }}$ effect

2 increased them
175

18-04

176

18-05

179

18-06

178

18-07

179

18-08

180

18-09

181

18-10

182

$18-11$

183

20-22

184

\section{1 greatly increased them}

Some $\because+$ the Silowing opportunities exist where you live. These questions ask which you have usea in the zast month.

(YMCA, city pools, etc.)?

2 yes 1 no

$19-01$

185

$19-02$

Movie theatres, bowling alleys, and other

entertainment?

2 yes $1^{\text {no }}$

186

Churches?................... 2yes Ino

19-0:

Social clubs?................. 2yes 1 no

Community parks? .............. 2yes 1 no

Libraries?

2 yes

$I^{\text {no }}$

Museums?

$\perp^{\text {no }}$

19-06

Welfare?

2 yes

1 no

19-0. 
jod stamps?................. 2yes $1^{n 0}$

ocial security?.............. 2!es $L^{n !}$

ublic transportation (buses, etc.)?

2ues 1 no

196

$19-10$

$19-11$

alvation Army or other hostel and meal

ervices?

zyes 1 no

196

$19-12$

:ounty health department?

2yes 1 no

amily planning?

2 yes

1 no

197

11 cohol and drug abuse programs?

2 yes 1 no

198

hildren's services?

2 yes

Lno

199

itate hospital?

2 yes

1 no

200

201

Jounseling/guidance services (doctor,

church, etc.)?

zyes Ino

202

$19-18$

University health service (speech, hearing, etc.)?

Single Parents' Club?

2 yes

1 no

205

$19-19$

Weight Watchers?.

2 yes

(no

$19-20$

Alcoholics Anonymous?

2 yes

Ino

2yes

Ino

Big Brother or other "buddy" programs?

2yes

lno

Legal Aid?

2 yes

lno

County Juvenile Department?

2 yes

lno

$19-21$

$19-22$

Advocate groups (tenants' association,

Consumers' Protection, Civil Liberties,

Women's Rights, etc.)?

.......

Vocational Rehabilitation?

Oregon State Employment Service?

Manpower Development and Training?

Sheltered Workshop?

Private employment counseling/placement

services?

Community college?

Night school?

2yes Ino

2 ues 1 no

2 yes 1 no

205

206

207

$19-23$

208

209

19-24

$19-25$

University classes?

2 yes

lno

2 yes 1 no

$2 / 2$

210

$19-26$

211

19-27

$2 / 2$

$19-28$

Continuing educaton?

2 yes 1 no

$2 / 5$

$19-29$

Business or vocational school?

2ues

1 no

$2 / 6$

$19-30$

Public school?

2yes

$\perp^{\text {no }}$

217

218

1 no

$19-31$

Experimental college?

2 yes

1 no

219

$19-32$

Special interest groups (e.g., science

fiction society)?

2yes $\operatorname{Ino}^{n y}$
2 yes $\perp^{n o}$
2 yes $\perp^{n o}$
2 yes $\perp^{n o}$

223 
ir counselor may have done some of the things listed below. These questions ask how ipful you feel these things were.

1 your counselor listen to you? [No = 0]

)id listening have an effect? [No = 3]

Jas 1istening helpful or harmful?

lelpful $=4$ or Very Helpful $=5$

larmful $=2$ or Very Harmful $=4$

5 very helpful 21-01

4 helpful

3 no effect

Q NA

228

2 Tharmful

I very harmful

1 your counselor care about you? [No = 0]

Jid caring have an effect? [No = 3]

Nas caring about you helpful or harmful?

Helpful $=4$ or Very Helpful $=5$

Harmful $=2$ or Very Harmful $=1$

5 very helpfice 21-02

I helpful

3 no effect

2 harmful

I very harmful

$d$ your counselor encourage you? [No = 0]

Did encouraging you have an effect?[No $=3$ ]

$\frac{5}{4}$ hery helpfol

Was encouraging you helpful or harmful?

3 no effect

2 harmbul

Helpful $=4$ or Very Helpful $=5$

Harmful $=2$ or Very Harmful $=1$

I very harmful

d your counselor tell you about things (jobs, community

rvices, relating to people, how one's mind works)?

$0=0]$

$\sigma$ very helpful

\& helpful

Did telling you about things have an effect? [No $=3$ ]

Was telling you helpful or harmful? Helpful $=4$ or Very

Helpful $=5$ Harmful $=2$ or Very Harmf $1=1$

.d your counselor attempt to calm your worries? [No $=0$ ]

Did calming your worries have an effect? [No $=3$ ]

Was attempting to calm your worries helpful or harmful?

Helpful $=4$ or Very Helpful $=5$

Harmful $=2$ or Very Harmful $=1$

id your couselor set limits for you? [No =0]

Did setting limits have an effect? [No = 3]

Was setting limits helpful or harmful?

Helpful $=4$ or Very Helpful $=5$

Harmful $=2$ or Very Harmful $=1$

ino effect oNA

2 harmful

1 very harmful

5 very helpful

4 helpful

3 no effect

2 harmful

I very harmful

5 very helpful

4 helpful

3 no effect o NA 235

2 harmful

I very harmful

If no counselor, mark $\mathrm{NA}=0$ ]

id your counselor have an effect on your problem? [No=3]

as the counselor helpful or harmful?

Helpful $=4$ or Very Helpful $=5$

Harmful $=2$ or Very Harmful $=1$

5 very helpful

$22-01$

s helpful

3 no effect 0 NA

234

2 harmful

L very harmful

If no friends, mark $\mathrm{NA}=0$ ]

lid friends have an effect on problem? [No = 3]

5 very helpful

I helpful

Was it helpful or harmful?

Helpful $=4$ or Very Helpful $=5$

s no effect ONA

22-02

Harmful $=2$ or Very Harmful $=1$

2 harmful

I very harmful

Jid you receive medications supplied by

5 very helpful

it helpful

Did medications have an effect on the problem? [No $=3$ ]

3 no effect

21-05

- Were the medications helpful or harmful?

Helpful $=4$ or Very Helpful $=5$

Harmful $=2$ or Very Harmful $=1$

2 harmful

$\perp$ very harmful

Do you have any religious associations? [No $=0$ ]

- Did religious associations effect your problem? [No $=3$ ]

- Were religious associations helpful or harmful?

Helpful $=4$ or Very Helpful $=5$

Harmful $=2$ or Very Harmful $=1$

5 very helpful

$\$$ helpful

3 no effect 으 NA

22-03 
id you have a counselor in other programs or a private counselor? [No $=0$ ]

- Did other counselor(s) have an effect?

- Were other counselor(s) helpful or harmful? Helpful or Very Helpful? Harmful or Very Harmful?

5 very helpful

4 helpful

id the passing of time have an effect on the problem?

[No $=3$ ]

- Was the passing of time helful or harmful?

Helpful $=4$ or Very Helpful $=5$

so effect

harmful

I very harmful

Harmful $=2$ or Very Harmful $=1$

5 very helpóul

$22-06$

4 helpful

Did you "drop in" to ? [No $=0$ ]

- Did "dropping in" have an effect on the probleq? [No=3]

- Was "dropping in" helpful or harmful?

Helpful $=4$ or Very Helpful $=5$

Harmful $=2$ or Very Harmful $=1$

I no effect

1 very harmful

5 very helpful

22-07

I helpful

3 no effect

2 harmful

L very harmful

Did keeping busy have an effect on the problem?

[No $=3$ ]

- Was keeping busy helpful or harmful?

Helpful $=4$ or Very Helpful $=5$

Harmful $=2$ or Very Harmful $=1$

Did being with people have an effect on the problem?

[No $=3$ ]

- Was being with people helpful or harmful?

Helpful $=4$ or Very Helpful $=5$

Harmful $=2$ or Very Harmful $=1$

5 very helpful

4 helpful

3 no effect

2 harmful

I very harmful

5 very helpful

4 helpful

3 no effect

22-09

e harmful

I very harmful

Did you do physical activity? [No = 0]

- Did the activity have any effect on the problem? [No=3]

- Was the activity helpful or harmful?

5 very helpful

$22-10$

Helpful $=4$ or Very Helpful $=5$

Harmful $=2$ or Very Harmful $=1$

4 helpful

3 no effect

2 harmful

L very harmful

5 very helpful

포 helpful

[If no family, mark $\mathrm{NA}=0$ ]

Did your family have an effect on the problem? [No = 3]

3 no effect

- Was the effect helpful or harmful Helpful $=4$ or Very Helpful $=5$

Harmful $=2$ or Very Harmful $=1$

a harmful

L very harmful

Did you attend group meetings at ? [No $=0$ ]

- Did the group meetings have an effect? [No $=3$ ]

- Was the effect helpful or harmful?

Helpful $=4$ or Very Helpful $=5$

Harmful $=2$ or Very Harmful $=1$

5 very helpful

22-08

241

4 helpful

[If no family doctor, mark $\mathrm{NA}=0$ ]

Did the family doctor have an effect on the problem? [No=3]

- Was the effect helpful or harmful?

Helpful $=4$ or Very Helpful $=5$

Harmful $=2$ or Very Harmful $=1$

Was there anything else that had an effect?

[No $=0$. If yes, write it down.]

3 no effect

2 harmful

I very harmful

o NA

5 very helpful

22-13

4 helpful

3 no effect o NA

2 Tarmful

I very harmful

5 very helpful

5 very help

- Was it helpful or harmful?

Helpful $=4$ or Very Helpful $=5$

Harmful $=2$ or Very Harmful $=1$

2 harmful

I very harmful 
se questions ask about the service you received at

id you have any difficulty finding out about

2 yes Ino

Jid you have any difficulty getting into

2 yes Ino

When you came to the program, did the receptionist make you

2 yes Ino

feel comfortable?

Was the waiting room satisfactory--its comfort, privateness, 2 yes Ino

Was your first contact with a counselor satisfactory (when

you discussed why you had come, etc.)?

2 yes Ino

$23-05$

Was your counselor's attitude toward you satisfactory? 2yes Ino

[If no medications, mark NA $=0$. If yes, then ask:]

2 yes Ino

Was the process of getting medications satisfactory?

Was your counselor accessible to you--could you get to

vour counselor when you needed to?

[If there was no individual counseling, mark $N A=0$.

2 yes 1 no

If yes, ask:]

Were the individual counseling sessions with your counselor satisfactory?

[If there were no group sessions, mark $\mathrm{NA}=0$. If yes, ask:] Were the group sessions you had with counselors and other clients satisfactory? 
Did you have any trouble with appointments because of

Was the attitude of staff toward you, as a client, satisfactory?

2 yes 1 no

\section{satisfactory?}

[If interviewee is still participating in program, mark $N A=0$. If not participating ask:]

Was the decision to end your participation in the program

2yes $\ln ^{\text {no }}$

at made in a satisfactory way?

$\begin{array}{lll}\text { Are you satisfied with the way you are (were) charged? } & 2 \text { yes } \perp^{\text {no }} & 23-14 \\ 26 /\end{array}$

Did you get the kind of service you wanted?

2 yes 1 no

23-15

262

\begin{tabular}{rrr}
\hline If you were to seek help again, would you go back to & 2 yes 1 no \\
\hline
\end{tabular}

Do you have any comments, criticisms, or suggestions about ? 
APPENDIX E

ASAP - (X)ICQ

DEMOGRAPHIC DATA

FOLLOW-UP

$\overline{\text { Interview Date }}$

Case Number

Clinic Number

Admit Date

Follow-up Interval (number of days since admission)

Research Group 1 = Intake

$$
\begin{aligned}
& 2=90 \text { Day Follow-up } \\
& 3=180 \text { Day Follow-up } \\
& 4=365 \text { Day Follow-up }
\end{aligned}
$$

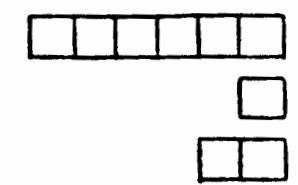

Date of Birth (month, day, year)

Sex $(0=$ male, 1 = female)

Ethnic Group 1 = White, non-Hispanic

2 = Black, non-Hispanic

3 = American Indian

4 = Alaskan Native

5 = Asian or Pacific Islander

6 = Hispanic (Mexican)

7 = Hispanic (Puerto Rican)

8 = Hispanic (Cuban)

$9=$ Other Hispanic

$10=$ Not Specified

$\square$ Living Situation--Social 0 = Solitary Head of Household

( 1 adult and 1 or more dependents)

$I=$ Lives Alone

2 = Lives with Parent(s)

3 = Lives with Spouse (and children)

4 = Lives with Friend(s)/Roomate(s)

$7=$ Lives with Relatives

$8=$ other

9 = Mandated Living Situation

Living Situation--Physical 1 = Single Family Dwelling

(house/mobile home)

2 = Apartment

3 = Group Home/Boarding Home

4 = Dormitory

$5=$ Hotel

$6=$ Hospital

$7=$ Jail

$8=$ Transient

$9=$ Other

$\square$ Histury of Long-term Hospitalization (more than 6 of the last 12 months spent in mental hospital or more than a total of 24 months out of the last 5 years in a mental hospital; $0=$ no, 1 = yes)

Mandated Treatment--this episode $(0=$ no, 1 = yes $)$ 
$\square$ Treatment Status 1 = Case Open and Active

2 - Case Open and Inactive

$3=$ Case Closed

4 = Untreated or

$\square$ Presenting Problem (at admission)

$1=$ Mental/Emotional Disturbance--M-ED

$2=$ Mentally Retarded/Developmentally Disabled--MR-DD

$3=$ Chronic

4 = Marital Problems

$5=$ Family Problems

$6=$ Drug Problems

$7=$ Alcohol Problems

$8=$ Drug \& Alcohol Problems

$9=$ Problems With the Law

$10=$ Family Member of Client

$11=$ Other

Services Received:

$A=$ Individual Counseling

$B=$ Group Counseling

$C=$ Couple Counseling

$D=$ Family Counseling

$E$ = Sucialization Program

$F=$ Day Treatment Program

$G=$ Residential Program

$\mathrm{H}=$ Detox (voluntary)

$I=$ Detox (emergency)

$\mathrm{J}=$ Crisis Intervention

$K=$ Training

$L=$ Medication

$M=$ Brokerage

$N=$ Vocational Training

$0=$ Informational

$P=$ Evaluation/Assessment Only

$Q=$ Unknown

Amount of Services Received (number of days client has come for and received services)

$\square \square$ Income (annual fur client's household)

$0=\$ 0-999$

$1=\$ 1,000-1,999$

$2=\$ 2,000-2,999$

$3=\$ 3,000-3,999$

$4=\$ 4,000-4,999$

$5=\$ 5,000-5,999$

$6=\$ 6,000-6,999$

$7=\$ 7,000-7,999$

$8=\$ 8,000-8,999$

$9=\$ 9,000-9,999$

$10=\$ 10,000-10,999$

$\ldots$ and so on using same rules

$99=99,000$ and above 


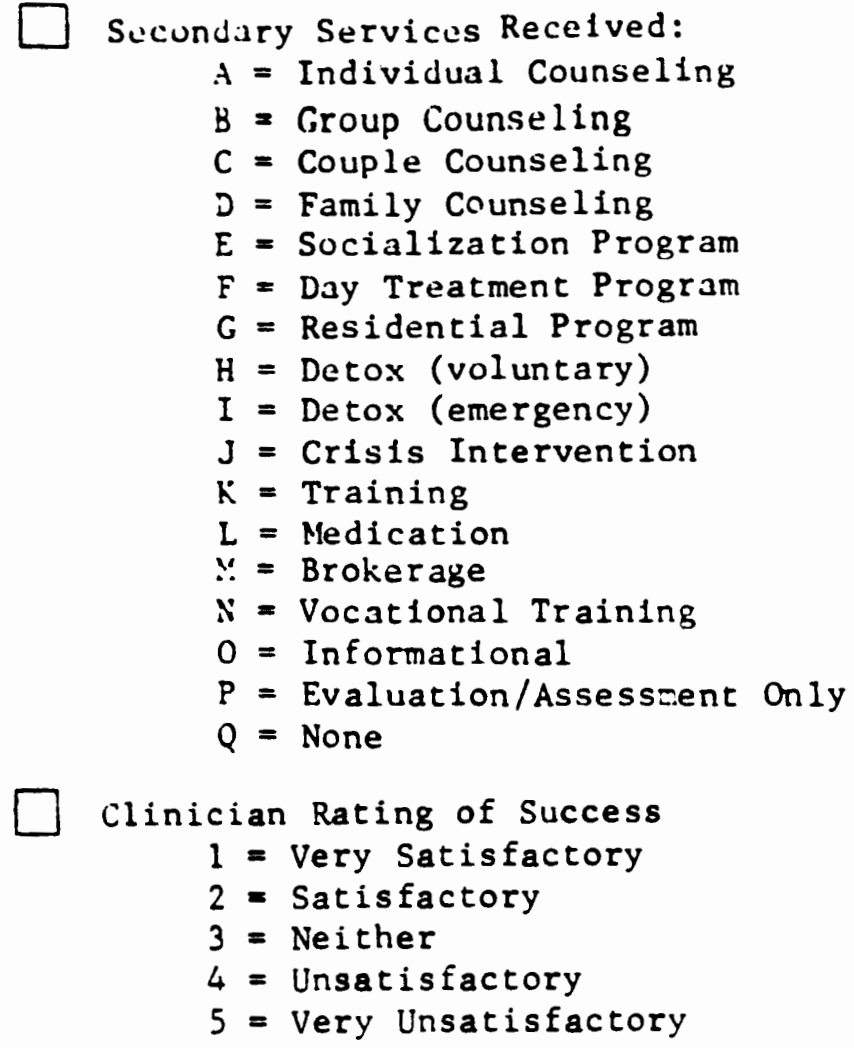

$\square$ Clinician Rating of Success

1 = Very Satisfactory

2 - Satisfactory

$3=$ Neither

4 = Unsatisfactory

5 = Very Unsatisfactory 


\section{APPENDIX F}

REFERRAL TO P.I.M.S. STUDY

NAME :

SEX :

DATE OF BIRTH:

ADDRESS :

HOME PHONE :

WORK PHONE:

Is it all right to call client at home phone?

Is it all right to call client at work phone?

ADMIT DATE :

CLIENT \# :

CLINICIAN :

NOTES FROM CLINICIAN OR SCREENING PERSON: 
You may remember Ruth Green having asked you a series of questions the first day you were at ASAP, before you saw your counselor. She explained that this agency wanted to study the helpfulness of the services we provide to you, and that we would need to see you again in a few months. That time has arrived -. a time to share your opinions of the services you have received at ASAP.

I work with Ruth, and would like to see you on at I need to have you call me to confirm this appointment. If you cannot make this appointment time, let me know another time when I can see you. If I'm not in the office when you call, leave a message for me and I will get back to you.

Your participation in our study is very important. There is no charge to you for this appointment.

Remember, please call me and confirm the appointment time and day.

Thank you.

Sincerely,

Interviewer

224-0075 


\section{APPENDIX H}

INTERVIEWER PROGRESS REPORT

Interviewer

Window to Client Name No.

Dates, Times, and Results of Attempted Contacts:

Scheduled Interview Date(s): 


\section{APPENDIX I}

\section{ASAP}

CONSENT FOR OQLQ FOLLOW-UP INTERVIEW

\section{TO THE CLIENT:}

IN ORDER TO LEARN MORE ABOUT THE HELPFULNESS OF THE SERVICES OFFERED BY ASAP, WE WOULD LIKE TO ASK YOU SOME QUESTIONS :

WE WOULD LIKE YOUR PERMISSION TO ASK ABOUT:

- HOW YOU ARE FEELING.

- WHETHER, AND HOW, THE SERVICES HELPED YOU.

- HOW YOU ARE GETTING ALONG WITH FAMILY AND FRIENDS.

- IF YOU ARE WORKING, HOW WORK IS GOING.

- WHETHER YOU ARE HAVING ANY DIFFICULTIES WITH ALCOHOL OR DRUGS.

- WHETHER YOU HAVE HAD ANY RECENT CONTACT WITH THE IAW.

- WHETHER YOU ARE MAKING USE OF OPPORTUNITIES AVAILABLE IN YOUR COMMUNITY.

ALSO :

- YOU DO NOT HAVE TO ANSWER ANY QUESTION THAT YOU DO NOT WANT TO ANSWER.

- YOU CAN STOP THE INTERVIEW IF YOU WISH.

- THE INFORMATION YOU GIVE WILL BE USED FOR EVALUATION OF THE SERVICES OFFERED BY THE CIINIC.

- THE INFORMATION WILI BE CONFIDENTIAL WITHIN THE PROGRAM AND WILL NOT BECOME PART OF YOUR CLIENT RECORD AND WILL NOT BE RELEASED TO ANYONE FOR ANY OTHER PURPOSE.

I HAVE READ OR LISTENED TO THE ABOVE INFORMATION REGARDING THE INTERVIEW AND I AM WILLING TO PROCEED WITH THE INTERVIEW.

I GIVE MY PERMISSION TO ALIOW THE INFORMATION COLLECTED IN THIS INTERVIEW TO BE USED FOR EVALUATION PURPOSES.

DATE :

SIGNATURE : 


\section{APPENDIX J}

CLINICIAN RATING OF SUCCESS

\section{CLIENT}

1 = Very Satisfactory

Regular attendance

Is working hard toward treatment goals

shows high degree of commitment/investment

2 = Satisfactory

Regular attendance

Is working toward most treatment goals

Is invested or involved

$3=$ So-so

Acceptable attendance

Is working toward some treatment goals

Shows some degree of commitment/investment

4 = Unsatisfactory

Erratic performance

Is not working toward most treatment goals Shows minimal commitment/investment

5 = Very Unsatisfactory

Erratic performance Uncooperative 


\section{APPENDIX $K$}

OQLQ SCALES

Scale\#

SI

S5

s6

S7

S 9

S13

S1 4

S15

S17

S23

524

$\mathrm{S} 25$

529

S 31

S32

$\mathrm{S} 40$

S50
S34 Employability

Name

Personal Adjustment

Program Impact on

Personal Adjustment

Program Impact on

Interpersonal

Adjustment

Program Impact on

Adjustment to

Productivity

Total Program Impact on Quality of Life

Client Satisfaction

Psychological

Distress

Psychological Well-Being

Affective Status

Tolerance of Anxiety and Depression

Total Basic Need Satisfaction

Independence

Interpersonal Interactions

Spouse Role

Social support

Adjustment to Workat-Home

other Constructive Activity

Negative Consequences of Alcohol Use

S52 Negative Consequences of Drug Use
Items

$17-38,40-43,46,47,49$,

$50,52,54-57,59-66$

$39,44,48,51,53,68,67$

$74,80,94,100,106$

$112,122,132,143,144$, 151

$S 5 U, S 6 U, S 7 U, S 8 U$

248-263

$17,19,21,23,25,27,29$, $30,32,34,36,38$

$18,20,22,24,26,28,31$, $33,35,37$

$17-38$

$40-43$

$46,47,49,50,52,54-57$

$59-66$

68-73

90-93

$101-105$

107-111

$114-121$

$145-150$

$162-171$

$174-183$ 
APPENDIX I 


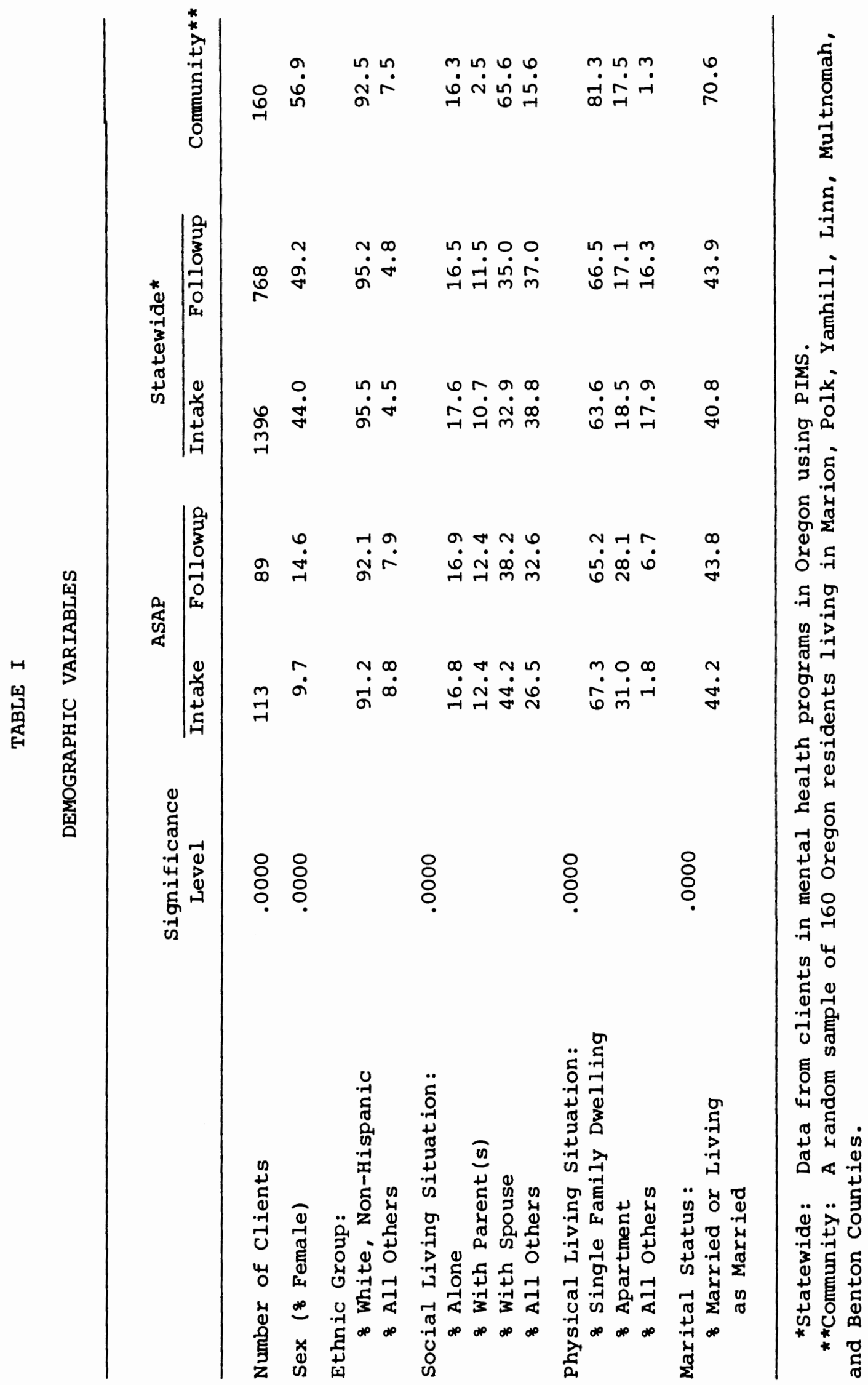




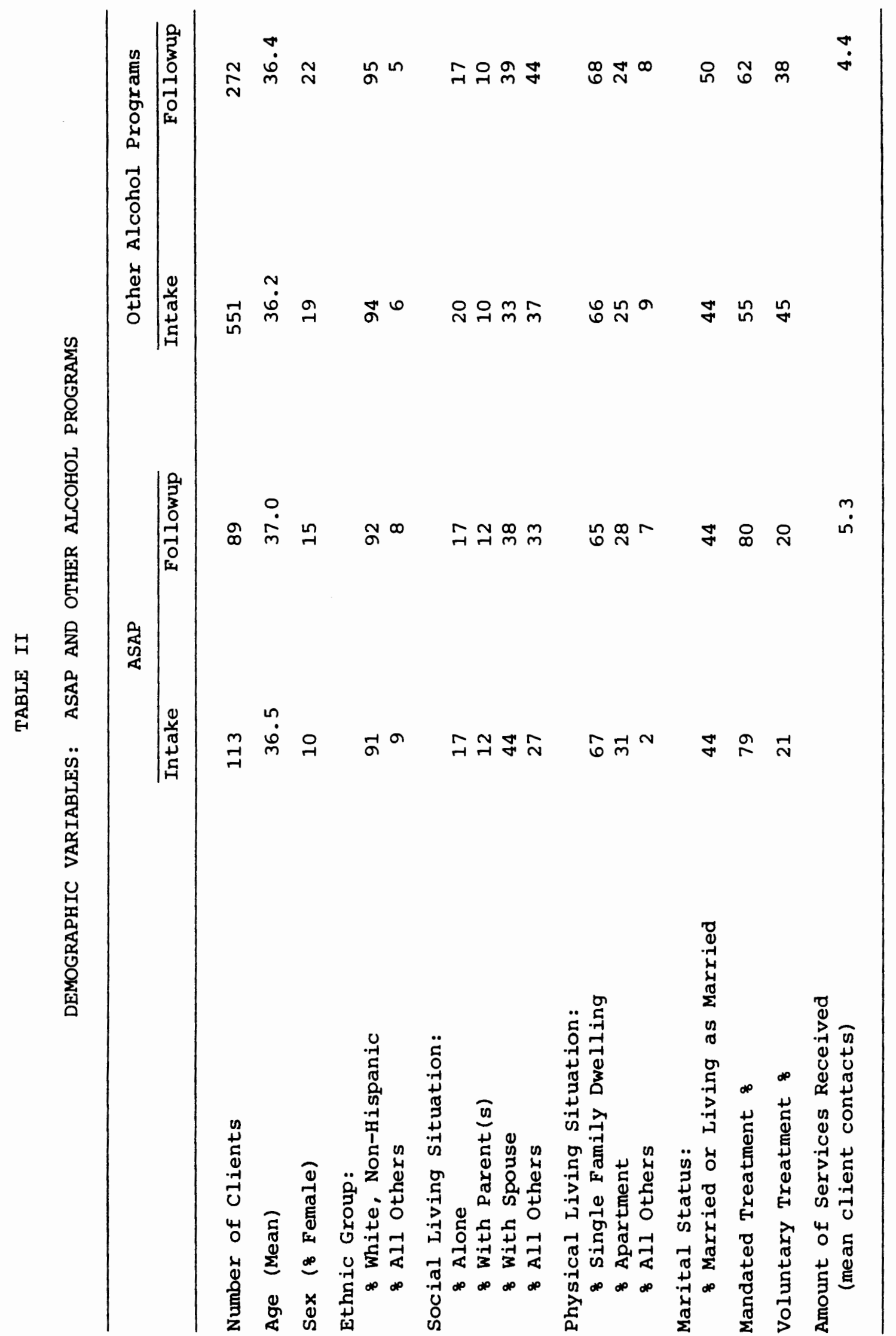




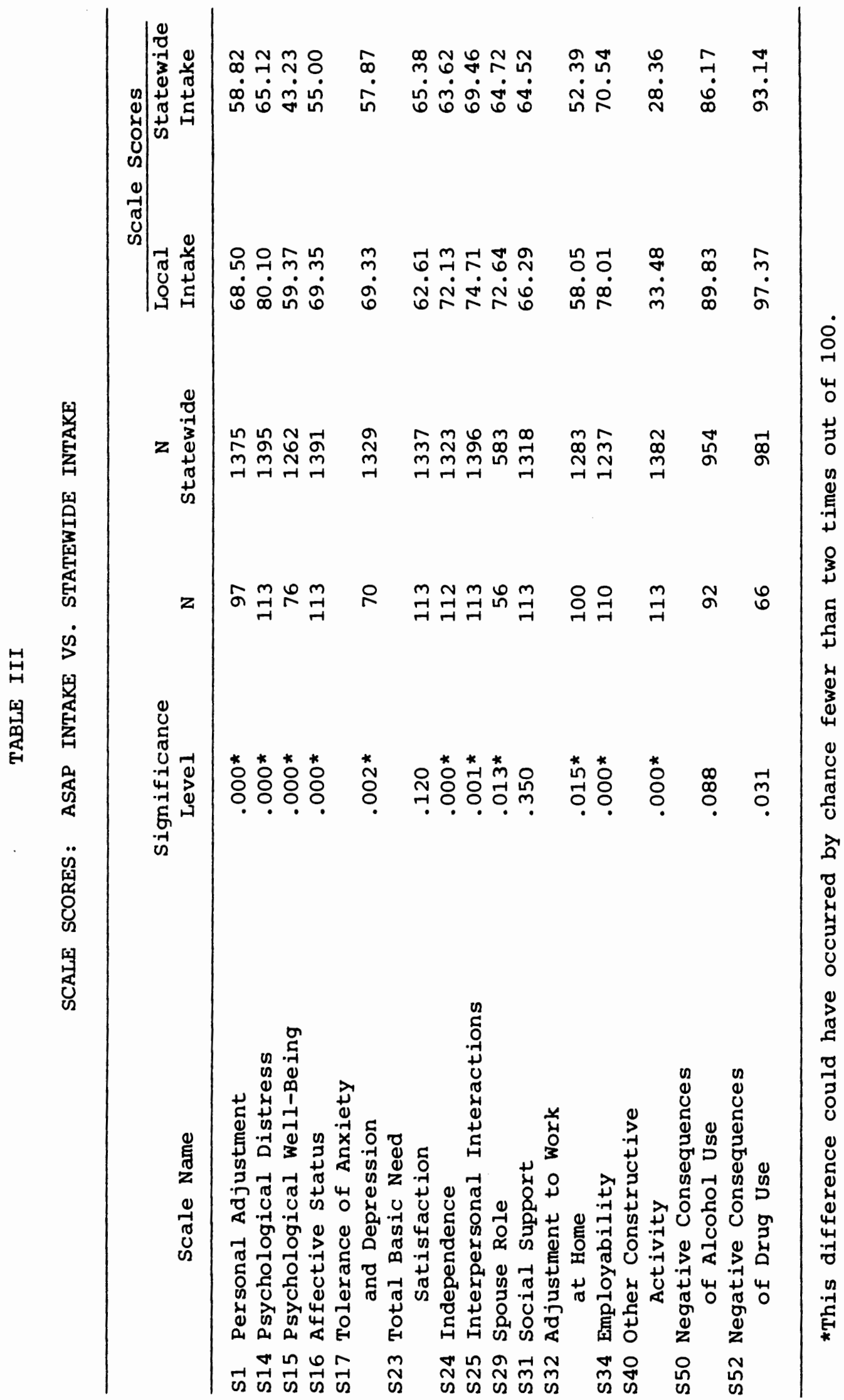




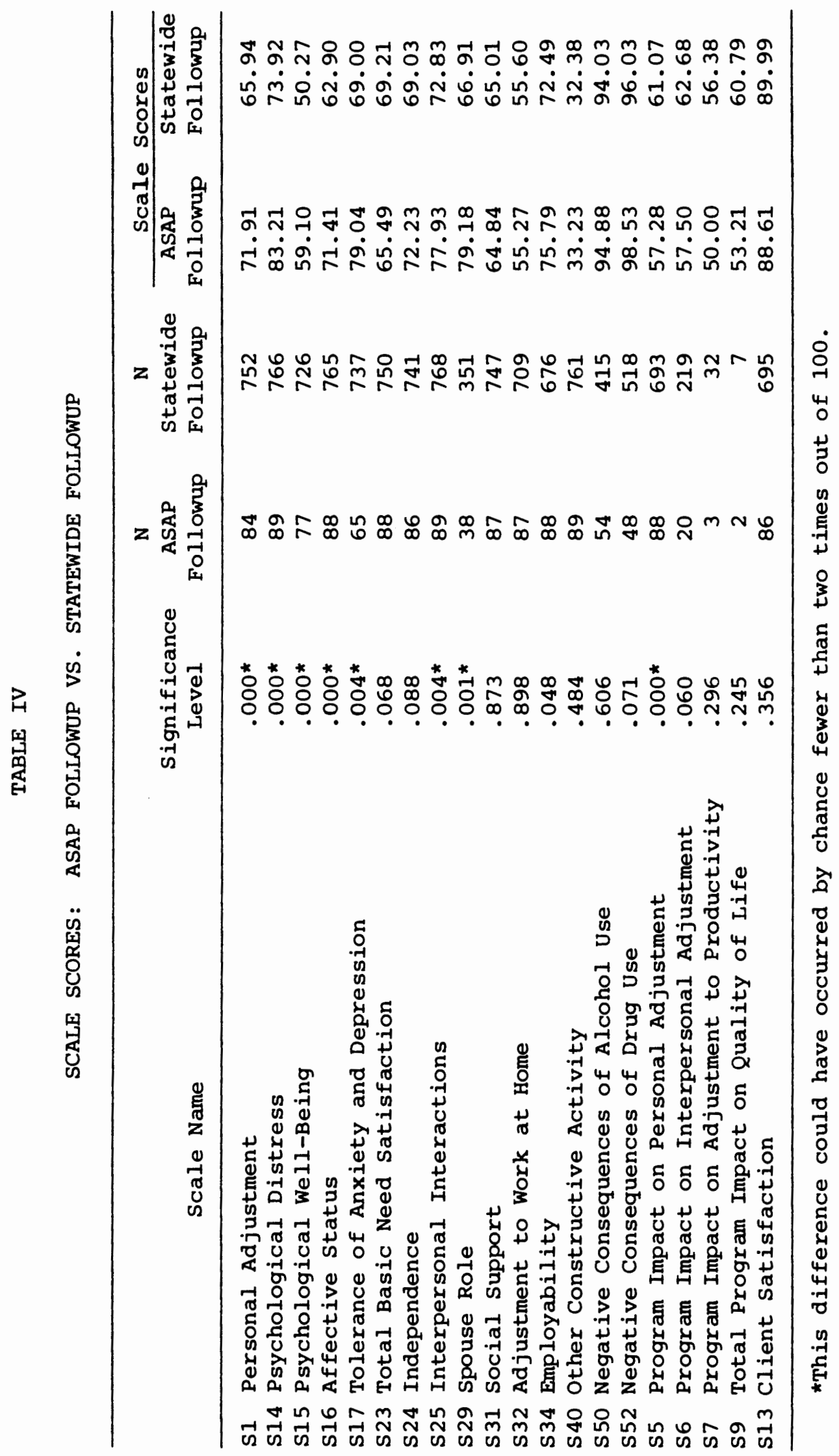




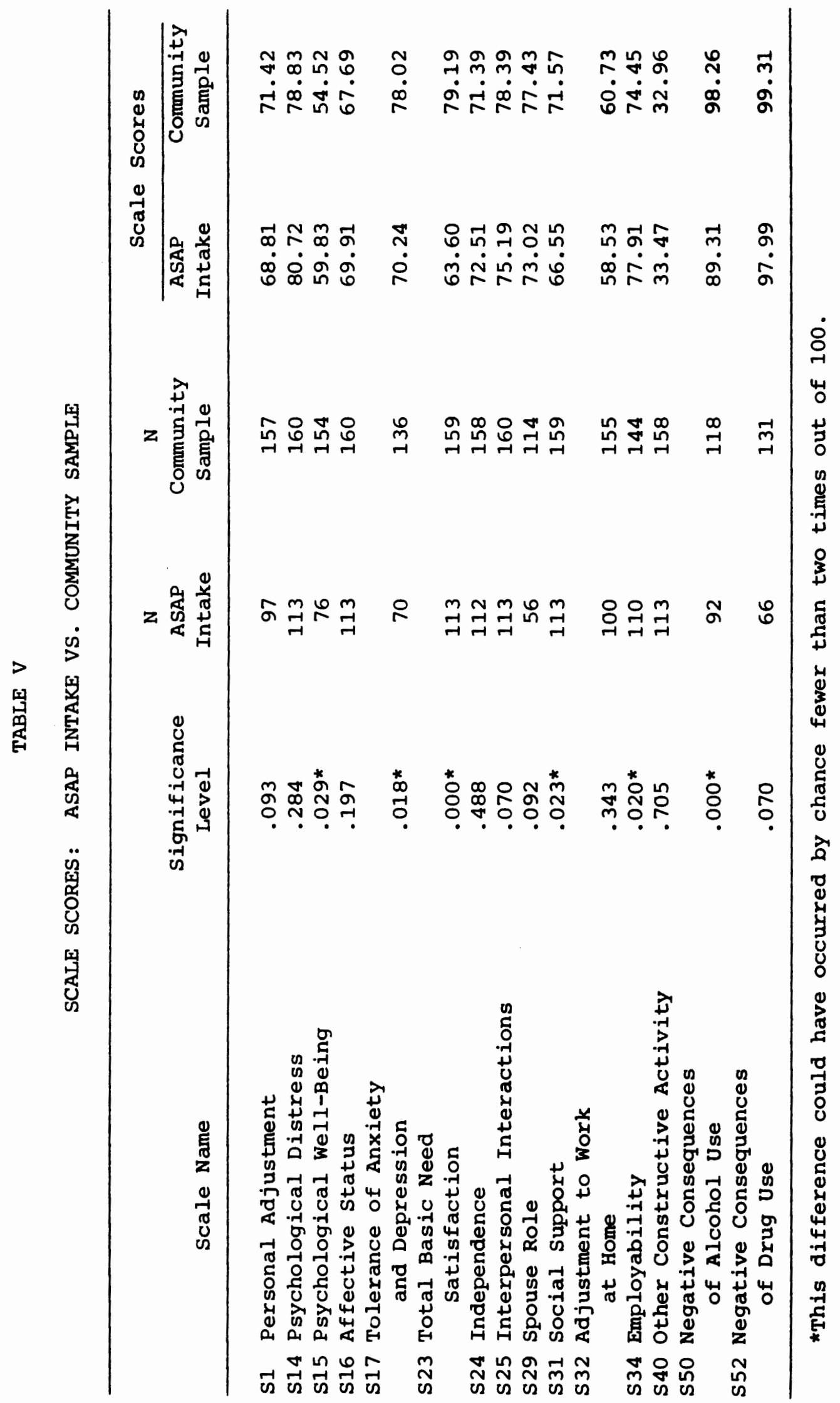




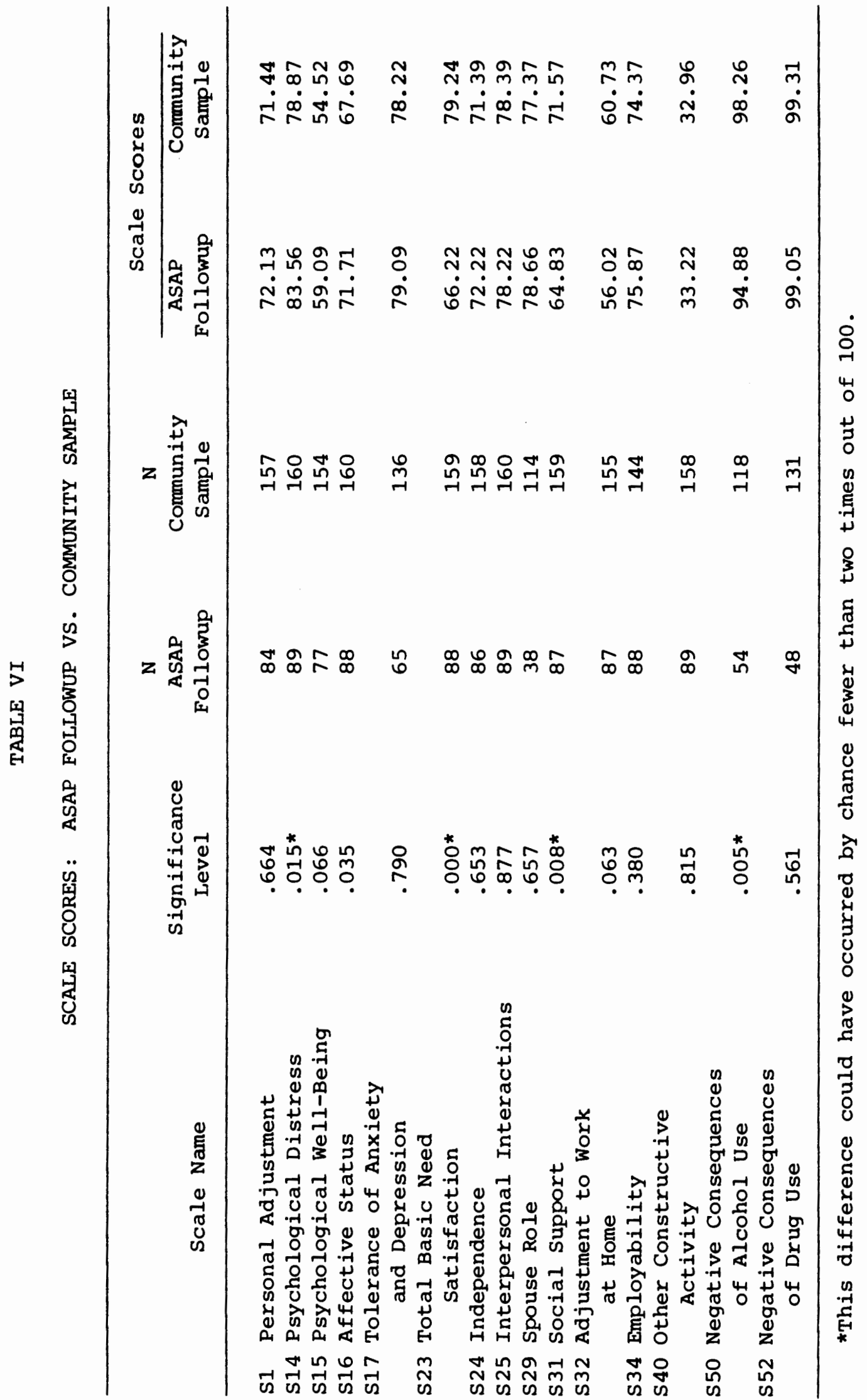




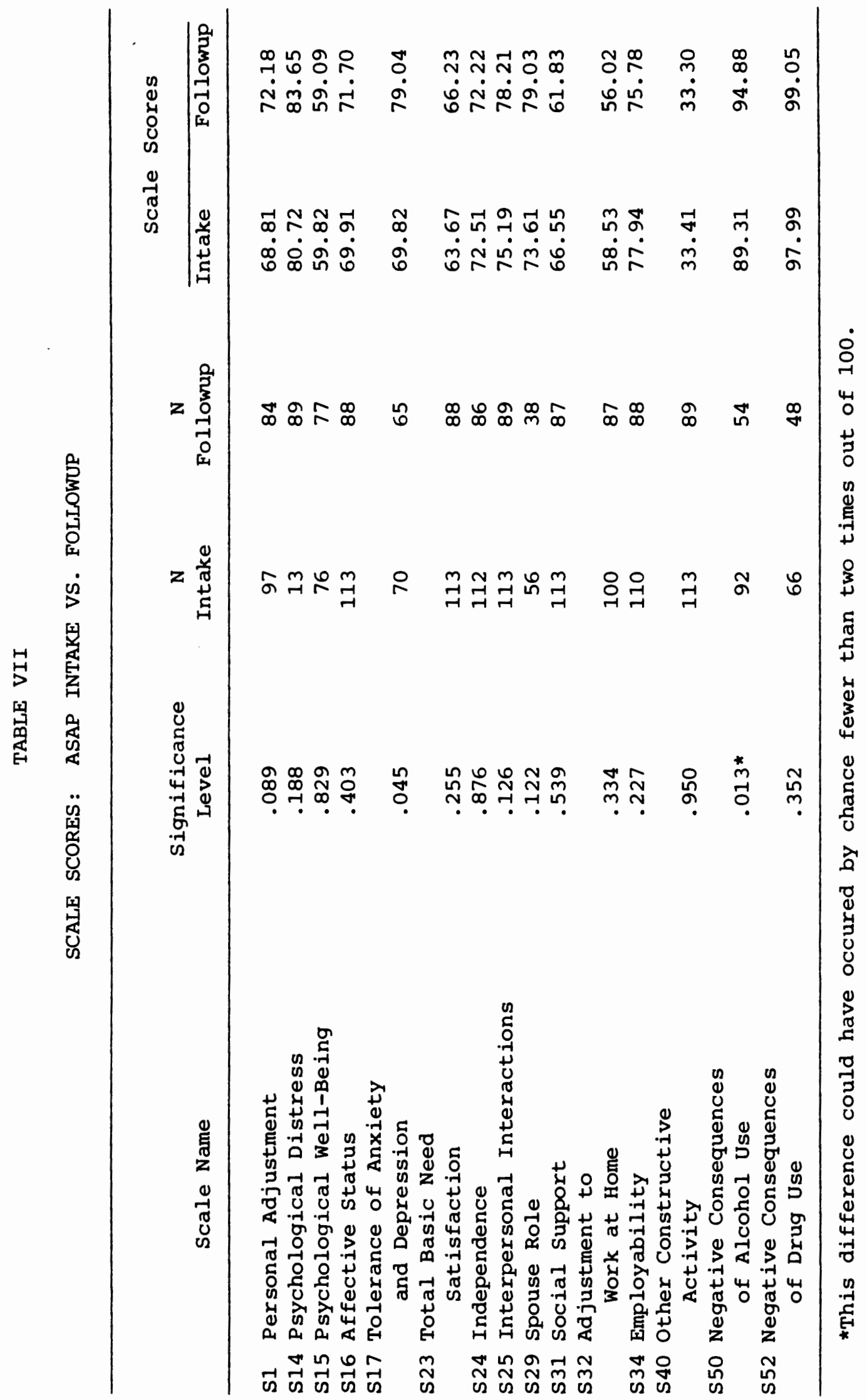




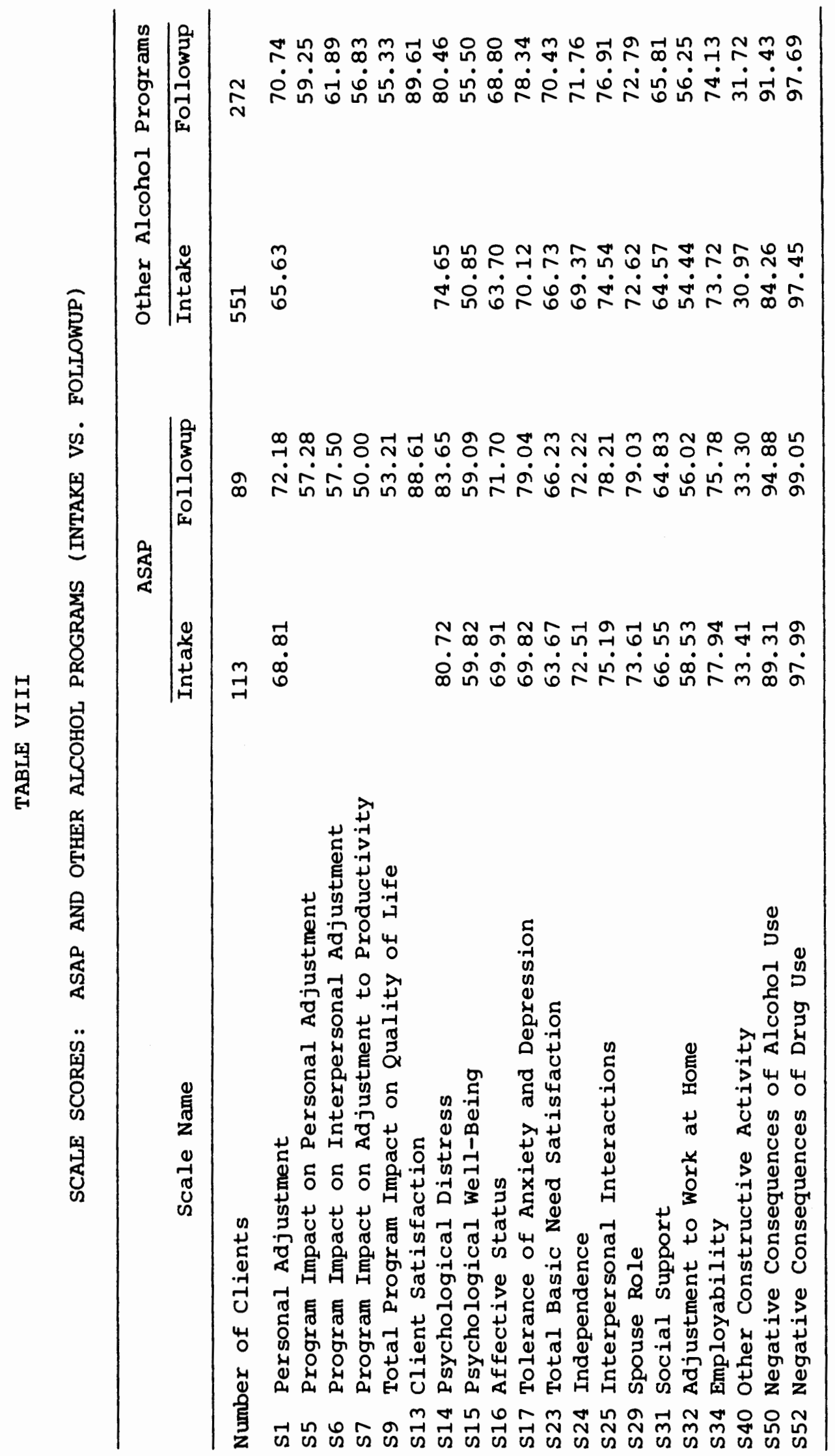




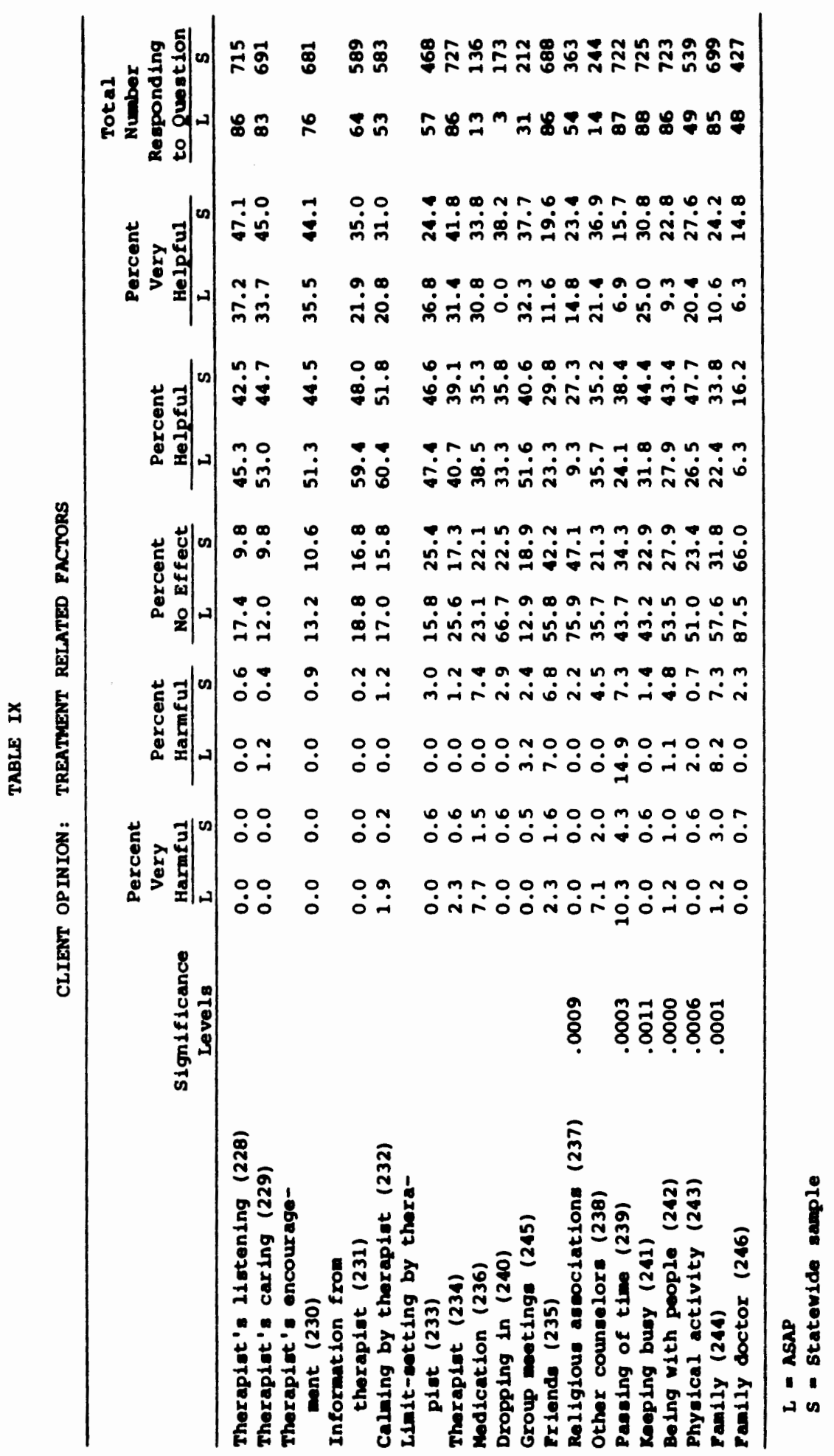




\section{ASAP SAMPLE}
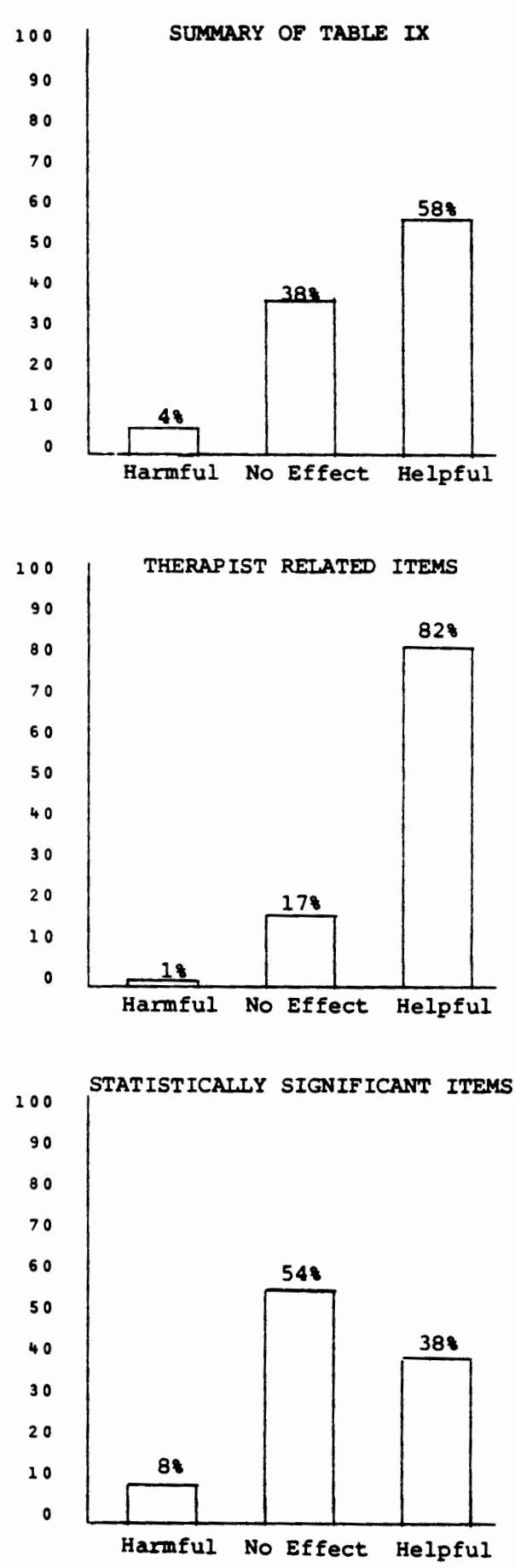

\section{STATEWIDE SAMPLE}
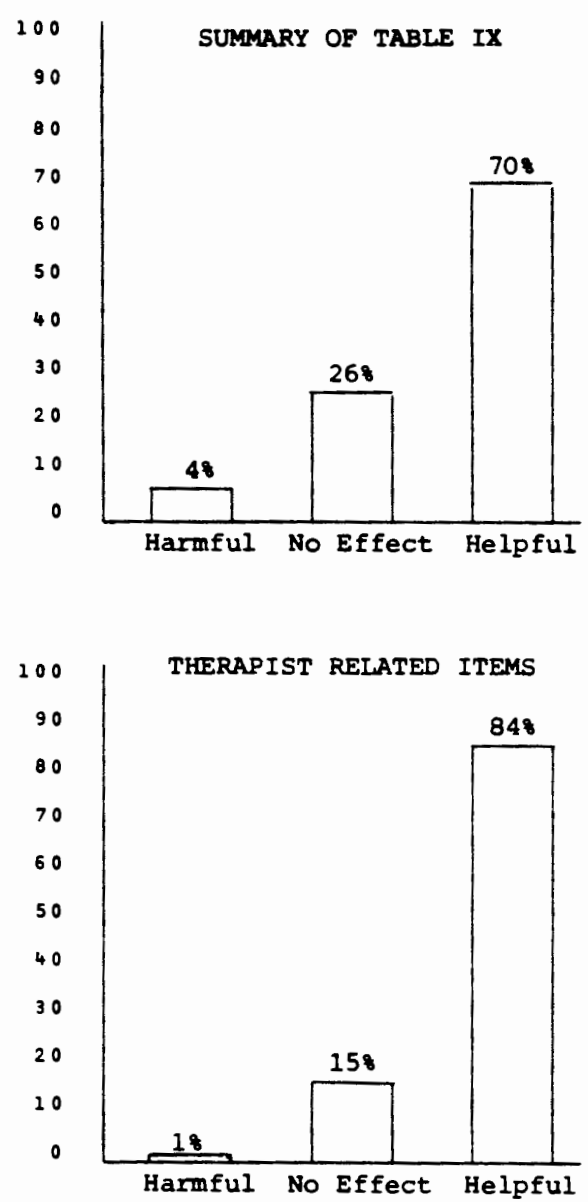

STATISTICALLY SIGNIFICANT ITEMS

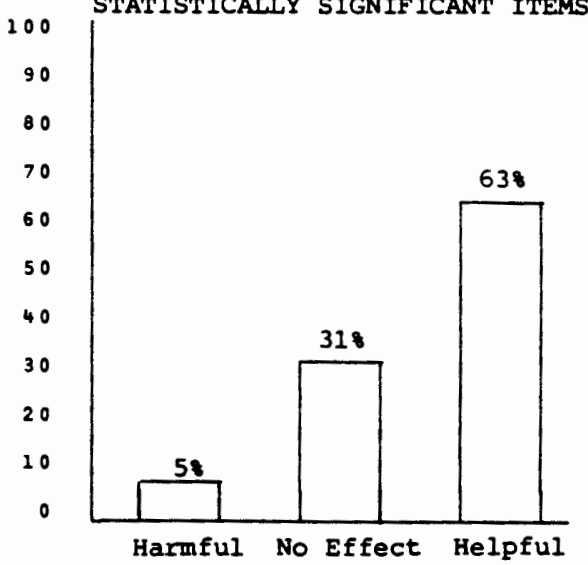


TABLE XI

ITEM RESPONSES: PERCENT CLIENT SATISFACTION

WITH ASAP (CMHP)

\begin{tabular}{lll}
\hline \multicolumn{1}{c}{ Item (Number) } & Number \\
\hline Ease of Finding CMHP (248) & Percent & $\begin{array}{c}\text { Responding } \\
\text { to Question }\end{array}$ \\
Ease of Getting into CMHP (249) & 95.5 & 88 \\
Receptionist (250) & 97.7 & 88 \\
Waiting Room (251) & 84.9 & 86 \\
First Contact with Therapist (252) & 95.5 & 88 \\
Therapist's Attitude (253) & 89.8 & 88 \\
Medications (254) & 97.7 & 88 \\
Access to Therapist (255) & 78.6 & 14 \\
Individual Sessions (256) & 86.2 & 87 \\
Group Sessions (257) & 96.6 & 31 \\
Access to CMHP--Time and Distance (258) & 63.6 & 88 \\
Staff Attitudes (259) & 98.9 & 88 \\
Termination of Treatment (260) & 81.8 & 11 \\
Fee Assessment (261) & 78.4 & 88 \\
Kind of Service (262) & 83.9 & 87 \\
Would You Return (263) & 84.1 & 87 \\
\hline
\end{tabular}

NOTE: Percentage is calculated on the basis of the $\underline{N}$ of clients to which the question applied. 
TABLE XII

ASAP CLIENT OPINION OF PROGRAM IMPACT VS. ASAP

COUNSELORS: CLINICIAN RATING OF SUCCESS

ASAP CLIENT OPINION OF PROGRAM IMPACT

(Scales 5, 6, 7 \& Items 27, 172, \& 184)
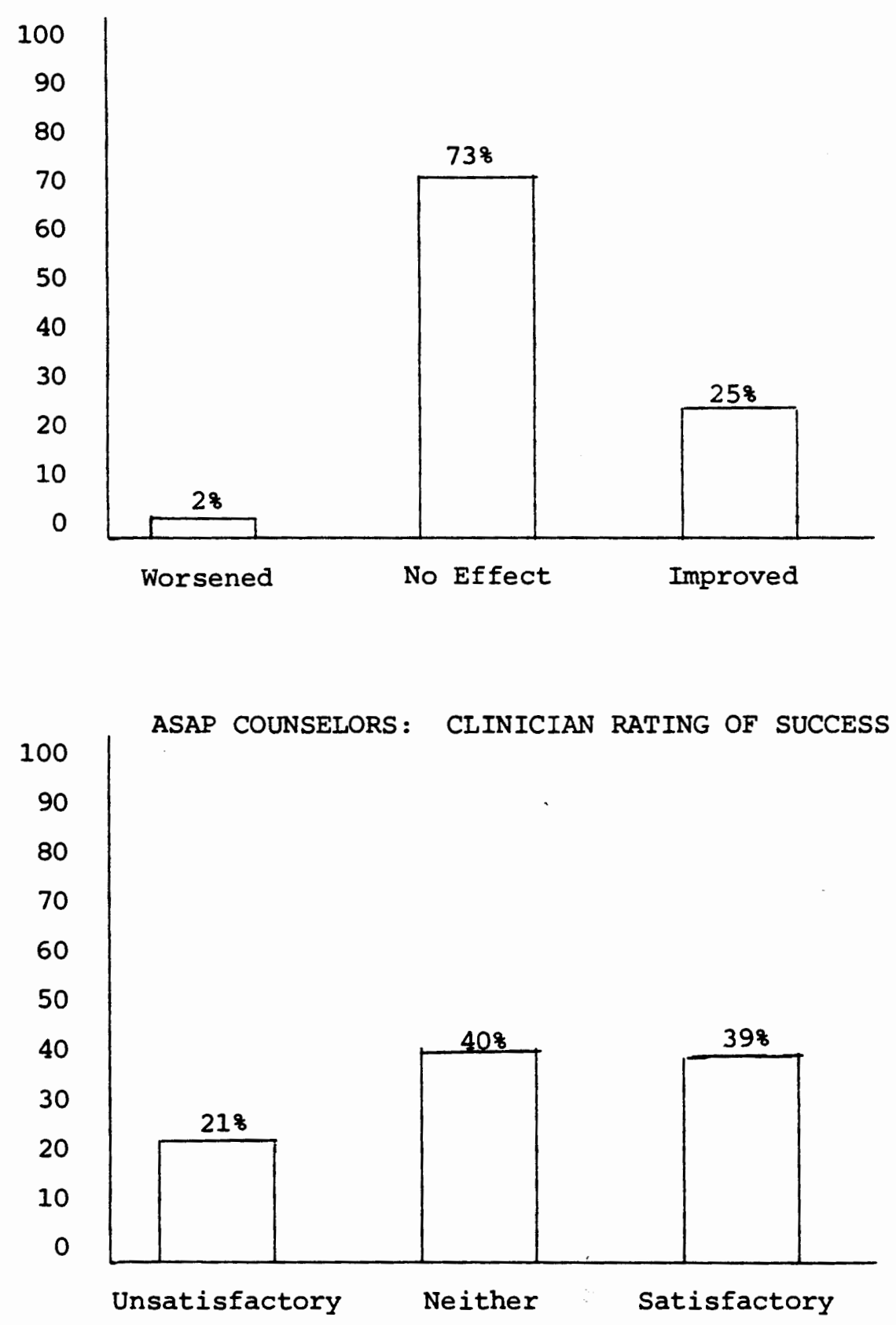